\title{
The Influence of Naturally-Occurring Organic Acids on Model Eatimates of Lakewater Acidification Using the Model of Acidification of Groundwater in Catchments (MAGIC)
}

\author{
Summary of Research Conducted During Year 1
}

By

\author{
T.J. Sullivan, B.J. Cosby, C.T. Driscoll, H.F. Hemond, \\ D.F. Charies, S.A. Norton, and J.M. Eilers
}

E\&S Environmental Chemistry, Inc.

Corvallis, OR

March 5, 1993

Prepared for

THE U.S. DEPARTMENT OF ENERGY

AGREEMENT NO. DE-FG02-92ER30196

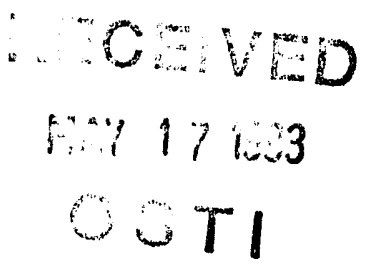

\section{DISCLAIMER}

This report was prepared as an account of work sponsored by an agency of the United States Government. Neither the United States Government nor any agency thereof, nor any of their employees, makes any warranty, express or implied, or assumes any legal liability or responsibility for the accuracy, completeness, or usefulness of any information, apparatus, product, or process disclosed, or represents that its use would not infringe privately owned rights. Reference herein to any specific commercial product, process, or service by trade name, trademark, manufacturer, or otherwise does not necessarily constitute or imply its endorsement, recommendation, or favoring by the United States Government or any agency thereof. The views and opinions of authors expressed herein do not necessarily state or reflect those of the United States Government or any agency thereof. 


\section{The Influence of Naturally-Occurring Organic Acids on Model Estimates of Lakewater Acidification Using the Model of Acidification of Groundwater in Catchments (MAGIC)}

By

T.J. Sullivan', B.J. Cosby ${ }^{2}$, C.T. Driscoll ${ }^{3}$, H.F. Hemond", D.F. Charles', S.A. Norton', and J.M. Eilers'

March 1993

'E\&S Environmental Chemistry, Inc., P.O. Box 609, Corvallis, OR 97339

2 Department of Environmental Sciences, University of Virginia, Charlottesville, VA 22903

${ }^{3}$ Department of Civil Engineering, Syracuse University, Syracuse, NY 13244

+ Department of Civil Engineering, Massachusetts Institute of Technology, Cambridge, MA 02139

${ }^{5}$ Patrick Center for Environmental Research, Academy of Natural Sciences, 1900 Benjamin Franklin, Parkway, Philadelphia, PA 19103

${ }^{6}$ Department of Geological Sciences, University of Maine, Orono, ME 04469 


\section{NOTICE}

This report was prepared as an account of work sponsored by the United States Government. Neither the United States nor the Department of Energy, nor any of their employees, nor any of their contractors, subcontractors, or their employees, makes any warranty, express or implied, or assumes any legal liability or responsibility for the accuracy, completeness, or usefulness of any information, apparatus, product or process disclosed or represents that its use would not infringe privately-owned rights.

\section{ACKNOWLEDGEMENTS}

The research described in this report was supported by a grant (DE-FG02-92ER30196) from the U.S. Department of Energy to E\&S Environmental Chemistry, Inc. This document has not yet been subjected to agency review and no official endorsement is implied.

We are grateful to J.P. Baker, M.R. Church, T. Fitzsimmons, E.C. Krug, L. Liang, H.M. Seip, G. Taugb $\phi l$, and $W$. Warnick for providing valuable critical comments and suggestions on an earlier draft of this report. 
LIST OF TABLES $\ldots \ldots \ldots \ldots \ldots \ldots \ldots \ldots \ldots \ldots \ldots \ldots \ldots \ldots \ldots$

LIST OF FIGURES $\ldots \ldots \ldots \ldots \ldots \ldots \ldots \ldots \ldots \ldots \ldots \ldots \ldots \ldots \ldots$

EXECUTIVE SUMMARY $\ldots \ldots \ldots \ldots \ldots \ldots \ldots \ldots \ldots \ldots \ldots \ldots \ldots \ldots$

1.0 BACKGROUND AND OBJECTIVES $\ldots \ldots \ldots \ldots \ldots \ldots \ldots \ldots \ldots \ldots \ldots$

2.0 INFLUENCE OF ORGANIC ACIDS ON SURFACE WATER ACID/BASE STATUS $\ldots \ldots \ldots$

2.1 Empirical Evidence $\ldots \ldots \ldots \ldots \ldots \ldots \ldots \ldots \ldots \ldots \ldots \ldots \ldots \ldots \ldots$

2.2 Modeling the Acidity of Organic Acids $\ldots \ldots \ldots \ldots \ldots \ldots \ldots \ldots \ldots \ldots$

2.3 Substitution of Mineral for Organic Acidity . . . . . . . . . . . . . . 10

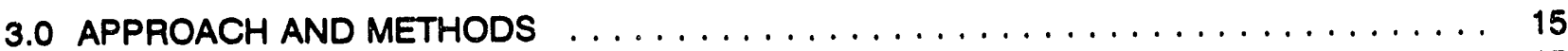

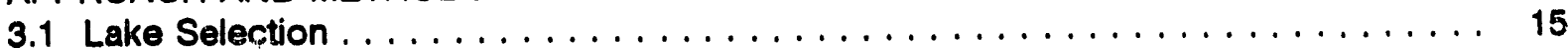

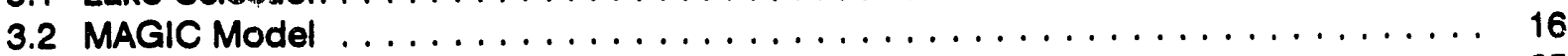

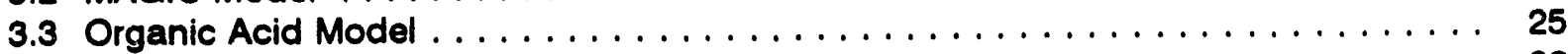

3.4 Paleolimnological Model $\ldots \ldots \ldots \ldots \ldots \ldots \ldots \ldots \ldots \ldots \ldots \ldots \ldots \ldots$

4.0 SUMMARY OF PREVIOUS MODEL COMPARISON $\ldots \ldots \ldots \ldots \ldots \ldots \ldots$

5.0 RESULTS OF MODEL COMPARISONS CONDUCTED IN THE CURRENT PROJECT $\ldots . .41$

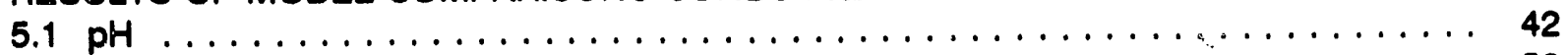

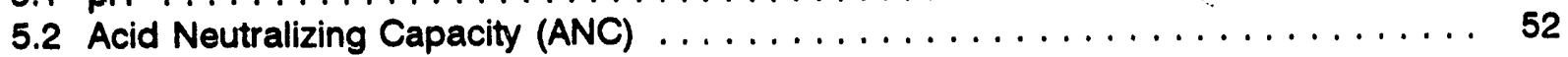

6.0 DISCUSSION ............................... 60

6.1 Comparisons Between MAGIC and Diatom Estimates of Acid-Base Status . . . . 60

6.2 Relative Magnitude of the Discrepancies Between Models . . . . . . . . . . . 65

6.3 Importance of Findings $\ldots \ldots \ldots \ldots \ldots \ldots \ldots \ldots \ldots$

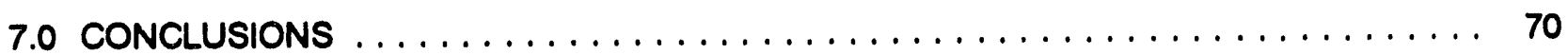

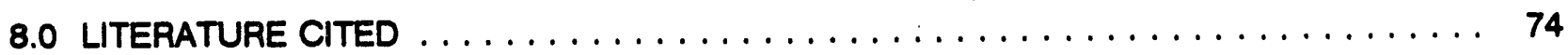

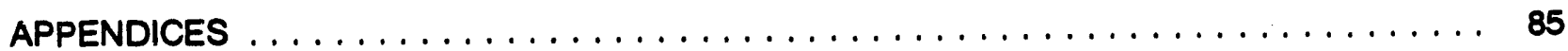

A. Manuscripts Prepared for Peer-Reviewed Literature

B. Sensitivity Analyses

C. Rocalibration 
LIST OF TABLES

1. List of workshop participants $\ldots \ldots \ldots \ldots \ldots \ldots \ldots \ldots \ldots \ldots \ldots \ldots \ldots \ldots$

2. Description of sample and target populations for the Eastern Lake Survey for the northeastern United States $\ldots \ldots \ldots \ldots \ldots \ldots \ldots \ldots \ldots \ldots \ldots$

3. Sample structure for the Direct/Delayed Response Project - Northeastern sample $\ldots \ldots$. 17

4. Chemical constituents included in soil solutions and surface water for the

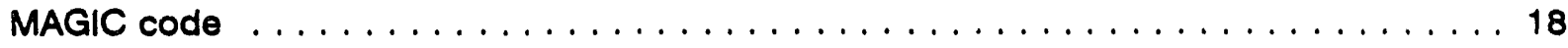

5. Major processes incorporated in the codes of MAGIC/TOPMODEL $\ldots \ldots \ldots \ldots \ldots$

6. Meteorological data required by the MAGIC/TOPMODEL codes $\ldots \ldots \ldots \ldots \ldots$

7. Chemical constituents in wet and dry deposition considered by the MAGIC codes $\ldots \ldots 21$

8. Operational assumptions for DDRP modeling efforts $\ldots \ldots \ldots \ldots \ldots \ldots \ldots \ldots \ldots$

9. Dissociation reactions and equilibrium expressions for the four analog organic

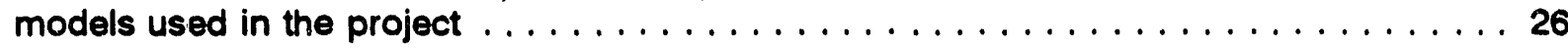

10. Complexation reactions between aluminum and organic anions and the equilibrium expressions for the diprotic and triprotic acids $\ldots \ldots \ldots \ldots \ldots \ldots$

11. Values of the parameters in the four organic acid analog models and constants for the aluminum organic complexes used for the project $\ldots \ldots \ldots \ldots \ldots \ldots$

12. Differences between MAGIC and diatom model estimates of pre-industrial (1844) and current (1984) $\mathrm{pH}$ estimates for the 33 lake Adirondack data set, based on five different MAGIC model applications . . . . . . . . . . . . . . . . . 47

13. Comparisons between the various MAGIC model estimates of current (1984) $\mathrm{pH}$ and $\mathrm{pH}$ values measured by the ELS-1.

14. Differences between MAGIC and diatom model estimates of pre-industrial (1844) and current (1984) ANC estimates for the 33 lake Adirondack data set, based on five different MAGIC model applications 
1. Calibration relationship developed in PIRLA-II between measured and inferred values of $\mathrm{pH}$. A.) based on diatoms, B) based on chrysophytes . . . . . . . . . . . . 34

2. MAGIC model hindcast estimates and diatom inferences of $A$ ) current and B) pre-industrial $\mathrm{pH}$ for 33 statistically selected Adirondack lakes $\ldots \ldots \ldots \ldots \ldots \ldots$

3. MAGIC model hindcast estimates of pre-industrial $\mathrm{pH}$ versus diatom-inferred $\mathrm{pH}$ for $\mathbf{3 3}$ statistically selected Adirondack lakes $\ldots \ldots \ldots \ldots \ldots \ldots \ldots \ldots$

4. MAGIC model hindcast estimates of pre-industrial pH versus diatom-inferred $\mathrm{pH}$ for 33 statistically selected Adirondack lakes

5. Model estimates of current (1984) lakewater $\mathrm{pH}$ versus $\mathrm{pH}$ values measured by the ELS: A) MAGIC estimates without including organic acids, B) MAGIC estimates with a triprotic organic acid representation, C) diatom estimates

6. MAGIC model hindcast estimates of pre-industrial pH versus diatom-inferred pH for 33 statistically-selected Adirondack lakes, using A) monoprotic,

B) diprotic, and c) Oliver et al. (1983) organic acid analog models . . . . . . . . . . . . 48

7. Cumulative frequency distributions of current measured $\mathrm{pH}$ from ELS-I and estimates of pre-industrial pH using three different approaches (diatoms, MAGIC with the triprotic organic acid, and MAGIC without an organic acid representation)

8. Comparison of calculated $\left(C_{8}-C_{N}\right)$ versus Gran titrated ANC for the study

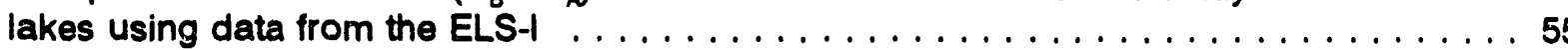

9. MAGIC model estimates of ANC versus diatom-inferred ANC (calculated as described in text from diatom-inferred $\mathrm{pH}$ ) for 33 statistically selected Adirondack lakes: A) pre-industrial estimates; B) current estimates $\ldots \ldots \ldots \ldots \ldots \ldots \ldots \ldots$

10. ANC estimated from diatom-inferred $\mathrm{pH}$, using the MAGIC algorithm that includes $D O C, K_{N}, P_{C O}$, and the site density and $p K_{a}$ values of organic acids, versus direct diatom inferences of ANC

11. Measured pH (non-equilibrated) values obtained in 1984 by the ELS-I versus measured values obtained in 1986 by the ELS-II for the 33 study lakes 


\section{EXECUTIVE SUMMARY}

Sullivan et al. $(1990,1991,1992)$ recently compared MAGIC model hindcasts and paleolimnological inferences of historical acidification (based on diatom-inferred $\mathrm{pH}$ ) for a set of 33 statistically-representative Adirondack lakes. This study represented the only regional and statistical model verification exercise conducted for a process-based acid-base chemistry model. Both assessment methods suggested that acidification of low-ANC Adirondack lakes had occurred since pre-industrial times. They differed primarily in that MAGIC inferred greater acidification and also that acidification had occurred in all lakes in the comparison. The diatom approach inferred that acidification had been restricted to low-ANC lakes (currently < about 50 $\mu \in q\left(L^{-1}\right)$.

The lack of organic acid representation in the MAGIC simulations conducted by Sullivan et al. (1990, 1991, 1992), and similarly by the U.S. EPA's Direct Delayed Response Project (Cosby et al. 1989, Church et al. 1989) and the NAPAP Integrated Assessment analyses (NAPAP 1991), may have been an important factor contributing to the observed discrepancy. Organic acids commonly exert a large influence on surface water acid-base chemistry, particularly in dilute waters having moderate to high dissolved organic carbon (DOC) concentrations.

Recently, Driscoll et al. (1990, in review) modeled the organic acidity of lakewater sampled by the Adirondack Lakes SLrvey Corporation (ALSC). The ALSC data base was fitted to mono-, di-, and triprotic organic acid models, and also to the model of Oliver et al. (1983). The work of Driscoll et al. is important because of the large ALSC data base (> 1400 lakes) and wide range of organic acid contributions to the lakewater chemistries. An objective of this ongoing research project has been to couple Driscoll et al.'s ( 9990 , in review) or a similar approach with MAGIC to produce a more rigorous evaluation of organic acid influence on the comparison results. This improved version of MAGIC might be superior for NAPAP projections than the version without organic acid representation used thus far within NAPAP. The ongoing research described in this 
report involves development of an organic acid representation to be incorporated into the MAGIC model and testing of the improved model using independent data.

The 33 study lakes included in this project were sampled as part of the U.S. EPA's Eastern Lake Survey (ELS-I, Linthurst et al. 1986). They were also included in EPA's Direct Delayed Response Project (DDRP) and the Paleoecological Investigation of Recent Lake AcidificationPhase II study (PIRLA-II).

A number of organic acid analog models were examined, using data from the Adirondack, NY lakes. The models ranged from simple monoprotic acids to the variable pK model of Oliver et al. (1983). The possibility was also examined that complex formation between aluminum and the organic anion might be important in Adirondack lakes, and it was determined that for at least the diprotic and triprotic analog models, inclusion of these complexes improved the fit to observed data. The organic acid analog models and the aluminum complexation reactions were evaluated to determine if they could improve the agreement between $\mathrm{pH}$ values simulated by MAGIC and those inferred from paleolimnological reconstructions.

The calibration procedure consisted of numerical fitting of the pK values and site densities of each model to observed $\mathrm{pH}$, aluminum, dissolved organic carbon, and calculated charge imbalance (i.e. assumed to be organic anion charge) for all of the lakes in the ALSC data base. The object of the fitting routine was to minimize the differences (across all lakes) between the organic charge simulated by the pertinent organic acid model and the observed organic charge for the lakes. This error minimization procedure resulted in the calibrated values for the parameters of each organic model that are used in this work. Driscoll et al. (in review) concluded that the triprotic acid medel gave the best fit to the ALSC data.

Paleolimnological reconstructions of past lakewater chemistry used in this study were based on transfer functions derived from relationships between measured current chemistry and assemblages of recently-deposited diatom or chrysophyte remains collected from surface sediment of 71 lakes within the Adirondack region. Predictive equations were developed from 
these relationships to infer water chemistry, especially $\mathrm{pH}$. The correlation coefficient for the relationship between maasured and inferred $\mathrm{pH}$ for the Adirondack Mountain lakes used for the calibration was high $\left(r^{2}=0.91\right)$; the apparent root mean square error (RMSE) $(0.31)$ and the RMSE using a bootstrap technique (0.35) indicate that $\mathrm{pH}$ can be inferred with an error of about one-third of a pH unit (Cumming et al. 1992, Dixit et al. in press).

The principal objectives of the on-going project described in this report are to test further the MAGIC model and to assess the degree to which the discrepancy between the diatom and MAGIC inferences can be improved by including a rigorous organic acid model in the MAGIC applications.

Three independent data sets (DDRP, PIRLA-II, and ALSC) and three independent interpretive models (MAGIC, diatom, and Driscoll's triprotic organic acid analog) were combined to test the consistency of the results between the diatom approach and the improved MAGIC model, incorporating organic acid, for estimating pre-industrial lakewater $\mathrm{pH}$. Driscoll's triprotic organic acid model was incorporated into MAGIC and simulated $\mathrm{pH}$ values were then compared with diatom-inferred $\mathrm{pH}$. This comparison yialded considerably closer agreement for pre-industrial pH than did the comparison that excluded the effects of organic acids. The mean difference in MAGIC versus diatom estimates of pre-industrial $\mathrm{pH}$ was $0.6 \mathrm{pH}$ units when organic acids were omitted from the modeling scenarios, with the greatest discrepancies occurring in the lakes with diatom-inferred $\mathrm{pH}<6.0$. This mean difference was only $0.2 \mathrm{pH}$ units when the triprotic organic acid analog model was inclt: jed, and the agreement for individual low-pH lakes improved by as much as a full pH unit.

Comparisons of MAGIC based on alternative formulations for the organic acid analog model and diatom estimates yieided similar results. Although the triprotic acid was judged to provide the best empirical fit to the ALSC data, use of the ALSC-fitted monoprotic, diprotic, and Oliver models produced similar regional patterns when compared to diatom reconstructed historical pH's. 
The three basic models that we evaluated for estimating pre-industrial pH (diatoms, MAGIC without organics, and MAGIC with triprotic organic acid) all resulted in cumulative frequency distributions of pre-industrial pH that were higher than current measured (ELS-1) pH. The diatom estimates suggested the least amount of acidification, and MAGIC without organic acids suggested the greatest amount of acidification. MAGIC estimates with the triprotic organic acid were intermediate, but were closer to diatom estimates than to the MAGIC estimates without organics.

Results of the hindcast comparisons between paleolimnological inferences of pre-industrial lakewater $\mathrm{pH}$ and MAGIC simulations, with and without the inclusion of organic acids, illustrate three important points:

1. There is a systematic departure with decreasing pH between diatom and MAGIC model hindcasts of pre-industrial $\mathrm{pH}$ when organic acids are not included in the MAGIC simulations.

2. Inclusion of a reasonable formulation for organic acidity in the MAGIC simulations of preindustrial pH greatly improves their agreement with diatom reconstructions, particularly for lakes having $\mathrm{pH}<6.0$.

3. The choice among organic acid analog models (e.g., mono-, di-, triprotic, or Oliver model) does not alter the degree of agreement with diatom reconstructions to an appreciable degree for a regional analysis.

The inclusion of organic acids in the MAGIC model simulations of pre-industrial pH did not alter the agreement between diatom and MAGIC model hindcasts for lakes with pH values greater than about 6.5. Provious hindcast comparisons (Sullivan et al. 1991) that did not include an organic acid representation had obtained good agreement for these high-pH lakes. For low-pH lakes, however, the lack of organic acid representation had resulted in an incieasing level of divergence between diatom and MAGIC modei hindcasts of pre-industrial $\mathrm{pH}$ for the lower-pH lakes. Thus, the lakes of most relevance with respect to potential biological effects of acidification, especially those having $\mathrm{pH}$ less than 5.5 , exhibited increasingly larger discrepancies with decreasing $\mathrm{pH}$ between diatom and MAGIC model estimates of pre-industrial $\mathrm{pH}$ when organic acids were omitted from the analysis. The inclusion of an organic acid representation in 
the MAGIC simulations conducted in this study resulted in a great improvement in the agreement between these two modeling approaches. Coupling of Driscoll's triprotic organic acid analog model to MAGIC resulted in pre-industrial $\mathrm{pH}$ estimates that were, on average, $0.4 \mathrm{pH}$ units closer to diatom estimates than were the MAGIC hindcasts that excluded organics. For lakes having $\mathrm{pH}$ less than 6.0, the improvement was even more pronounced; inclusion of the triprotic organic acid analog model reduced the discrepancy between diatom and MAGIC pH hindcasts for there lakes by 0.6 of a pH unit, from a mean difference of 0.8 to a mean difference of 0.2 . For some individual lakes, the improvement was a full $\mathrm{pH}$ unit.

An analysis of predicted $1984 \mathrm{pH}$, using MAGIC with the triprotic organic acid representation, versus the measured $\mathrm{pH}$ values obtained in 1984 by the ELS-I yielded a mean difference of 0.22 $\mathrm{pH}$ units and root mean squared difference of $0.33 \mathrm{pH}$ units. These differences were generally similar to the differences obtained between the diatom and triprotic model estimates for both 1984 and 1844 simulations ( 0.29 and $0.21 \mathrm{pH}$ units, respectively). In other words, the MAGIC triprotic model matched diatom estimates nearly as well as it matched measured values. Thus, the diatom estimates and MAGIC triprotic estimates of pre-industrial pH agreed nearly as closely as one could expect, given the uncertainties inherent in the model formulations and the fundamental differences in approach.

Comparisons of lakewater chemistry between pre-industrial and modern times also may be sensitive to a number of factors that are not represented in process models of acidification. Changes in acid base chemistry may have occurred in response to climatic differences, anthropogenic activities (e.g., logging, road building), forest growth, or beaver abundance, for example. These changes are expected to be reflected in diatom reconstructions, but not process model simulations. The influence of such factors on historic changes in lakewater chemistry is poorly known. The differences between MAGIC and diatom estimates of pre industrial pH based on the MAGIC/triprotic model were well within the range of expected differences due to annual and seasonal variability, uncertainties in the algorithm used to calculate $\mathrm{pH}$ from measured ion 
chemistry, and the influence of dissolved $\mathrm{CO}_{2}$ on the measured air-equilibrated $\mathrm{pH}$ values that were used to calibrate the diatom model. Although further model testing is needed, the inclusion of organic acids in MAGIC is a necessary and important component of modeling the effects of acid deposition on surface water chemistry using this model.

These results demonstrate that 1) organic acids must be considered in modeling the respense of lakewaters in the Adirondack Mountains to acidic deposition, and 2) once organic acids are included in the modeling effort, reasonable agreement is obtained in hindcast comparisons with diatom-inferred pH. It should be emphasized, however, that the test presented here included only two points in time, and essentially only pH. MAGIC, and other process models, require further testing and validation. Many important geochemical processes are not well represented in the model or often in the input data, and it is not clear how this might affect model results. In particular, there remain problems in simulating hydrological flow paths, aluminum dynamics, and nitrogen processing.

The results of this intercomparison are important for acidic deposition assessment activities in two respects. First, this study is the first to show quantitative agreement between changes in pH of natural aquatic systems subjected to acidic deposition, as estimated by two independent and conceptually different approaches over a large geographic region and over a long temporal span. Previous model verification and validation studies have been of relatively short duration (e.g. Norton et al. 1992), site specific (e.g. P.anherg and Hultberg 1992), or comparisons among two or more models that share many fundiamental assumptions (e.g., Cook et al. 1992). Second, and perhaps more importantly, this demonstrated agreement between MAGIC and paleolimnological model hindcast estimates of lakewater $\mathrm{pH}$ is dependent upon inclusion of organic acids in the process model. The latter result was obtained despite the relatively low levels of DOC in the study lakes (mean value $=313 \mu \mathrm{M})$.

Thus, we have shown here that long-term projections of the effects of acidic deposition on surface water $\mathrm{pH}$ are sensitive to the dynamics of organic acids for lakes having only moderate concentrations of DOC. Future assessment activities, such as those conducted previously by 
NAPAP (1991) and those on-going in Europe in conjunction with the critical loads debates and mapping activities (e.g., Bull 1992, Forsius et al. 1992), should consider organic acid effects in the process models used in conducting assessments. Failure to include consideration of organic acids may introduce substantial bias into the assessment results regarding $\mathrm{pH}$ and associated biological effects. 


\subsection{BACKGROUND AND OBJECTIVES}

A project for the U.S. Department of Energy, entitled "Incorporation of an organic acid representation into MAGIC (Model of Acidification of Groundwater in Catchments) and Testing of the Revised Model Using Independent Data Sources" (DOE Grant DE-FG02-92ER30196.A000) was initiated by E\&S Environmental Chemistry, Inc. in March, 1992. Major components of the project include:

1. improving the MAGIC model by incorporating a rigorous organic acid representation, based on empirical data and geochemical considerations, and

2. testing the revised model using data from paleolimnological hindcasts of pre-industrial chemistry for 33 Adirondack Mountain lakes, and the results of whole-catchment artificial acidification projects in Maine and Norway.

MAGIC (Cosby 1985a,b,c) has been the principal model used thus far by the National Acid Precipitation Assessment Program (NAPAP) for making projections of probable future changes in surface water chemistry throughout the United States in response to various levels of acidic deposition. The current version of the model has been described in the NAPAP State of Science/Technology Report on modeling methods (Thornton et al. 1990). MAGIC has also been described by Jenne et al. (1989) and Church et al. $(1989,1992)$. Numerous model projections of future scenarios were presented in the Integrated Assessment (NAPAP 1991).

MAGIC, like other processed-based models, is a simplified representation of catchment processes. Although rooted in hydrochemical principles, the model includes major temporal and spatial process aggregation, and some catchment processes are only poorly or not at all represented in the model. Few data sets are available that contain a sufficiently long period of record for validating the approach. In the absence of such validation, however, past or future scenario projections are subject to potentially large, and unquantifiable, uncertainties (Sullivan et al. 1992).

The most extensive model verification exercise conducted for MAGIC, or any process-based acid-base chemical model, was the recent comparison between model hindcasts and 
paleolimnological inferences of historical acidification (based on diatom-inferred $\mathrm{pH}$ ) for a set of 33 statistically-representative Adirondack lakes (Sullivan et al. 1990, 1991, 1992). This research effort was sponsored by the U.S. Department of Energy. Although only model hindcasts (not forecasts) were evaluated, this represents the only regional and statistical model verification exercise conducted to date for a process-based acid-base chemistry model. Both assessment methods suggested that acidification of low-ANC Adirendack lakes has occurred since preindustrial times. They differed primarily in that MAGIC inferred greater acidification and also that acidification had occurred in all lakes in the comparison. The diatom approach inferred that acidification had been restricted to low-ANC lakes ( $<$ about $50 \mu e q L^{-1}$ ).

The lack of organic acid representation in the MAGIC simulations conducted by the U.S. EPA's Direct Delayed Response Project, Sullivan et al. (1991), and the NAPAP Integrated Assessment analyses may have been an important factor contributing to the observed discrepancy. Organic acids commonly exert a large influence on surface water acid-base chemistry, particularly in dilute waters having high dissolved organic carbon (DOC) concentrations. To investigate the potential role of organic acids in influencing the comparison results, a MAGIC model simulation was conducted by Sullivan et al. (1991) that included a "reasonable" first-approximation organic acid representation (uniform organic acid contribution assumed for all lakes, using $20 \mu \in q \mathrm{~L}^{-1}$ of organic anion charge at $\mathrm{pH}=5$, and a diprotic acid with $p K=4.0$ and 10.0). The results of this simulation suggested that inclusion of a reasonable representation of organic acids in MAGIC can substantially improve the agreement between MAGIC-simulated and diatom-inferred pre-industrial lakewater pH. Quantification of the degree of improvement was uncertain, however, because a rigorous treatment of organic acids, based on measurements from individual lakes, was not performed.

Recently, Driscoll et al. (1990, in review) modeled the organic acidity of lakewater sampled by the Adirondack Lakes Survey Corporation (ALSC). They obtained a good fit between measured ANC and modeled ANC, by including organic acids in the modeled ANC expression. Mono-, di-, 
and triprotic organic acid models, and also the model of Oliver et al. (1983), were fitted to the ALSC data base. The work of Driscoll et al. (1990, in review) is important because of the large ALSC data base (> 1400 lakes) and wide range of organic acid contributions to the lakewater chemistries. An objective of this ongoing project has been to couple Driscoll et al.'s (1990, in review) or a similar, approach to MAGIC to produce a more rigorous evaluation of organic acid influence on the comparison results. An improved version of MAGIC might be superior for NAPAP projections than the version without organic acid representation used thus far within NAPAP.

The ongoing research in this project involves development of an organic acid representation to be incorporated into the MAGIC model and testing of the improved model using three independent data sources. This work has been subdivided into four discrete tasks, as follows:

Task 1 - Develop an organic acid model subroutine, based upon empirical data and theoretical considerations, and incorporate it into the MAGIC model.

Task 2 - Conduct MAGIC model hindcasts, using the revised model, for 33 statisticallyselected Adirondack Mountain lakes for which diatom-inferred current and preindustrial lakewater $\mathrm{pH}$ and ANC estimates are available; test the revised MAGIC model by comparing hindcast results with the diatom $\mathrm{pH}$ and ANC inferences. Task 2 also includes site visits to the two project sites to be studied within Tasks 3 and 4.

Task 3 - Conduct MAGIC model forecasts, using the revised model and pre-acidification baseline chemistry, for the U.S. EPA's watershed manipulation project (WMP) site in Maine, and compare simulated streamwater chemistry with the measured chemistry resulting from chemical manipulation.

Task 4 - Conduct MAGIC model forecasts, using the revised model and pre-acidification baseline chemistry, for the Norwegian whole-catchment manipulation project (HUMEX), and compare simulated lakewater chemistry with the measured chemistry resulting from chemical manipulation.

The research during Year 1 has included conducting two workshops to agree on an approach for the oryanic acid modeling, developing the organic subroutine and incorporating it into MAGIC (Task 1), conducting MAGIC hindcasts for Adirondack lakes and comparing the results with paleolimnological reconstructions (Task 2), and conducting site visits to the manipulation project sites in Maine and Norway. The research to be completed in Year 2 will include conducting MAGIC forecasts (based on pre-treatment and dose application data) of 
catchment responses to experimental acidification at WMP and HUMEX and comparing those forecasts with post-treatment measured chemistry (Tasks 3 and 4). Results of a modeling exercise for the first year of results at WMP were reported by Norton et al. (1992). Lakewater responses at HUMEX have not yet been modeled.

Two workshops were conducted during Year 1, prior to and after development and refinement of the organic acid subroutine. An approach to the modeling was agreed upon by the workshop participants (Table 1). Detailed acid-base chemical data were examined at the workshops for brown-water systems from the northeastern United States and Scandinavia. These empirical data, and also theoretical geochemical considerations, formed the basis for the modeling approach.

The agreed-upon organic acid modeling approach has been incorporated as a subroutine into the MAGIC model. A series of sensitivity analyses has been conducted to evaluate parameter uncertainty and internal consistency of calibrated and calculated variables. The comparisons between model output results and independent measurements and paleolimnological inferences provide important information on: (1) the accuracy of the model projections, and (2) the importance of organic acid modeling to the accuracy of those results.

Table 1. List of workshop participants

\begin{tabular}{ll}
\hline T. Sullivan & F\&S Environmental Chemistry, Inc. \\
C. Driscoll & Syracuse University \\
B. Cosby & University of Virginia \\
H. Hemond & Massachusetts Institute of Technology \\
H. Seip & University of Oslo \\
F. Wigington & U.S. EPA \\
J. Eilers & E\&S Erivironmental Chemistry, Inc: \\
G. Taugbol & University of Oslo \\
D. Charles & Patrick Center for Environmental Research, \\
& Academy of Natural Sciences of Philadelphia
\end{tabular}


The purpose of this report is to provide a summary of the work that has been conducted on this project during Year 1. Tasks 1 and 2 have now been completed. Several project deliverables have been prepared as manuscripts for submission to peer-reviewed scientific journals (Appendix A).

\subsection{INFLUENCE OF ORGANIC ACIDS ON SURFACE WATER ACID/BASE STATUS}

Although organic substances have been well studied in recent years (e.g., Thurman 1985; Aiken et al. 1985), quantitative evaluation of organic acidity is difficult. A direct measurement technique is not available for organic acid anions, and the influence of organic matter on the pH and ANC of natural water is an area of considerable uncertainty. Dissolved organic carbon (DOC) is commonly measured as a surrogate for organic acidity. DOC includes a large variety of organic compounds that differ in molecular weight and degree of dissociation. DOC contains many types of functional groups, including carboxylic acids, phenols, thiols, and alcohols (Perdue 1985). It is difficult to characterize the complex and heterogeneous mixture of organic solutes present in natural waters. The contribution of $\mathrm{H}^{+}$from dissolved organic matter to surface waters depends on the number and type of functional groups present, and the degree to which those functional groups are dissociated. In addition, organic matter which is not in solution also may provide $\mathrm{H}^{+}$to surface waters, but the importance of this contribution is not known. Accounting for this latter type of organic acidity is beyond the scope of the current research.

This section of the report is divided into three subsections, that cover empirical evidence illustrating the important role of organic acidity in natural waters (Section 2.1), approaches for modeling the acid-base characteristics of dissolved organic substances (Section 2.2) and hypotheses concerning historic changes in organic acidity (Section 2.3). 


\subsection{Empirical Evidence}

Although the dominating role of organic acids in peatlands had been long hypothesized, and was later demonstrated by Hemond (1980) and by Gorham et al. (1985), organic acids were not widely thought to be important in the acidity of most streams and lakes until quite recently. Studies of watershed acidity during the past decade in Europe and North America have now revealed a significant role of organic acids in surface water acidity in many cases. The question of the importance of organic acids in connection with acidification was debated within the Norwegian SNSF (Acid Precipitation - Effects on Forests and Fish, 1972-1980) Project (e.g., Glover and Webb 1979, Henriksen and Seip 1980). SNSF concluded that organic acids may cause low pH values in softwater lakes, but that there was no evidence to support the hypothesis that recent regional acidification was due to organic acidity (Overrein et al. 1980).

In the U.S., NAPAP concluded that $22 \%$ of acidic lakes (all larger than 4 ha in area) and $27 \%$ of acidic streams surveyed had organic anions as the dominant anion (Baker et al. 1991). The organically-acidic waters were commonly associated with organic soils or wetlands in their watersheds, and had DOC $>800 \mu \mathrm{M}$. An even larger fraction of acidic lakes sampled in the Adirondacks region of New York State by the Adironciack Lakes Survey Corporation (ALSC) was found to be acidic as a consequence of organic acids; more than $38 \%$ of the lakes had a pH $<5$ due largely to organic acids, despite the fact that they would have $\mathrm{pH}>5$ if the organic acids were removed (ALSC 1990). The ALSC survey included lakes as small as 0.5 ha in surface area, a fact suspected to account in part for the larger average organic influence (Sulivan et al. 1990). ALSC reported an average charge density of about $5 \mu e q / \mathrm{mg}$ organic carbon, and an average $\mathrm{pH}$ depression due to organic acids of 0.5 to $2.5 \mathrm{pH}$ units. Again, a positive relationship between organic acid concentrations and wetlands within the watersheds was observed.

In Canada, Campbell et al. (1992) reported that episodic acidification of 3 Quebec North Shore rivers is due primarily to organic acids, with average "anion deficits" ( $\approx$ organic anion) rising from around $35 \mu \mathrm{eq} / \mathrm{L}$ to the range of $70-100 \mu \mathrm{eq} / \mathrm{L}$ during high flows at snowmelt (causing 


\subsection{APPROACH AND METHODS}

\subsection{Lake Selection}

The 33 study lakes included in this project were sampled as part of the U.S. EPA's Eastern Lake Survey (ELS-1, Linthurst et al. 1986). They were also included in EPA's Direct Delayed Response Project (DDRP) and the Paleoecological Investigation of Recent Lake AcidificationPhase II study (PIRLA-II).

The DDRP lakes in the northeastern United States (Church et al. 1989) represent a subsample of lakes sampled in Phase I of the ELS-I. ELS-I consisted of a probability-based survey of lakes in regions of the eastern United States containing lakes (identified on 1:250,000 scale maps), generally $>4$ ha in surface area, and expected to have alkalinity $\leq \mathbf{4 0 0}$ Heq $L^{-1}$, based on a regional compilation of published and unpublished surface water alkalinity data (Linthurst et al. 1986). Lakes were stratified on the basis of subregions and three alkalinity map classes $\left(<100 ; 100-200 ;>200 \mu \notin q L^{-1}\right)$. Within each strata approximately 50 lakes were systematically selected from an ordered list following a random start. Thus each lake was selected with a known inclusion probability; the inclusion probability varied among strata. The sample structure for ELS-I lakes in the Northeast is shown in Table 2.

DDRP included lakes greater than $1.5 \mathrm{~m}$ deep. Lakes with gross anthropogenic disturbances were excluded from the DDRP subsampling frame along with several other minor exclusion

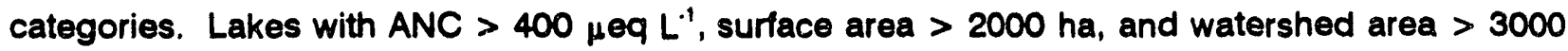
ha were excluded (Church ot al. 1989).

Lakes in the frame selected for the northeastern region of the DDRP were grouped into three clusters based on ANC measured in ELS-I: ANC (1) $\leq 25 \mu e q L^{-1} ;(2) 25-100 \mu e q L^{-1}$; and (3) 100-400 $\mu$ eq $L^{-1}$. Approximately 50 lakes were selected from each cluster using a variable probability systematic sampling design that resulted in the selected lakes having nearly equal inclusion probabilities within and among strata. This was accomplished by having DDRP selection probabilities inversely proportional to ELS-I inclusion probabilities. The resulting sample structure for the DDRP is presented in Table 3. 
Table 2. Description of sample and target populations for the Eastern Lake Survey for the northeastern United States (Linthurst et al. 1986). The Adirondack Mountains, New York are represented by Strata 1A1, 1A2, and $1 \mathrm{~A} 3$.

\begin{tabular}{lrrrrrr}
\hline STR & $N^{*}$ & $n^{*}$ & $n^{* * *}$ & $W$ & $N$ & SE(N) \\
\hline 1A1 & 711 & 75 & 57 & 9.633 & 549.08 & 33.08 \\
1A2 & 542 & 65 & 51 & 8.338 & 425.24 & 26.13 \\
1A3 & 431 & 68 & 47 & 6.719 & 315.79 & 22.14 \\
& & & & & & \\
1B1 & 208 & 70 & 49 & 3.192 & 156.41 & 9.29 \\
$1 B 2$ & 96 & 70 & 48 & 1.477 & 70.90 & 3.00 \\
1B3 & 1682 & 68 & 47 & 27.209 & 1278.82 & 90.37 \\
& & & & & & \\
$1 C 1$ & 631 & 88 & 63 & 7.822 & 492.79 & 27.31 \\
1C2 & 752 & 70 & 54 & 10.743 & 580.12 & 36.20 \\
1C3 & 650 & 74 & 47 & 8.953 & 420.79 & 34.59 \\
& & & & & & \\
1D1 & 443 & 70 & 47 & 6.572 & 308.88 & 23.00 \\
1D2 & 656 & 95 & 43 & 6.905 & 296.92 & 31.14 \\
1D3 & 1568 & 93 & 37 & 19.426 & 718.76 & 85.22 \\
& & & & & & \\
1E1 & 1038 & 130 & 89 & 8.070 & 718.23 & 39.71 \\
1E2 & 606 & 74 & 48 & 8.344 & 400.51 & 31.80 \\
1E3 & 744 & 72 & 41 & 10.333 & 423.65 & 41.55 \\
\hline
\end{tabular}

STR = Stratum

$\mathrm{N}^{*} \quad=$ Frame population of mapped lakes

$n^{*} \quad=$ Number of lakes in the probability sampling

$n^{* * *} \quad=$ Number of lakes sampled

$W \quad=$ Expansion factor

$\hat{N} \quad=$ Estimated target population size, after excluding certain nontarget lakes

$\operatorname{SE}(\hat{N})=$ Standard error of $\hat{N}$

\subsection{MAGIC Model}

\subsubsection{Model Formulation and Application}

The Model of Acidification of Groundwater in Catchments (MAGIC) is a lumped-parameter model of intermediate complexity, originally developed to predict the long-term effects (i.e. decades to centuries) of sulfur deposition on surface water chemistry (Cosby et al. 1985a,b,c). One of the model's principal assumptions is that a small number of critical processes in a watershed influence the long-term response to sulfur deposition. The MAGIC formulation was 
Table 3. Sample structure for tha Direct/Delayed Response Project - Northeastern sample (Church et al. 1989)

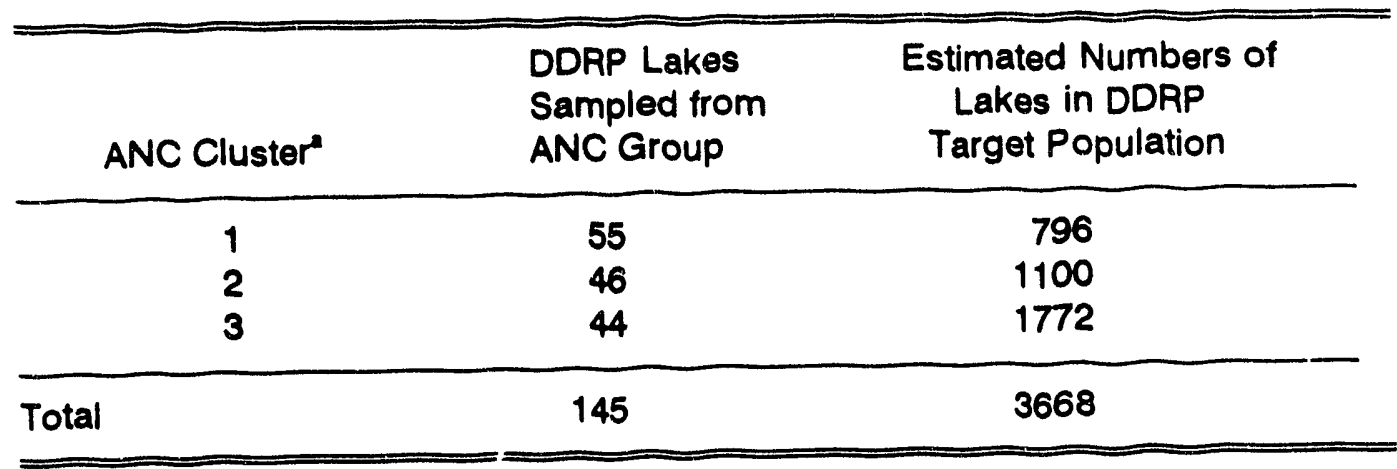

- Group $1=$ ANC $<25 \mu e q L^{-1}$

Group $2=25 \cdots ! 00 \mu e q L^{-1}$

Group $3=$ ANC $>100 \mu e q L^{\circ}$

based on recalculated ANC values

parsimonious in the processes selected for inclusion and was intended to be used as a heuristic tool for understanding the influences of the selected processes on surface water acidification.

The spatial/temporal scales in the model refle_ted the intended use for assessment and multiscenario evaluations. The model simulates soil solution chemistry and surface water chemistry to predict the monthly or annual average concentrations of the water chemistry constituents listed in Table 4. Both equilibrium and rate-controlled expressions are used to represent geochemical processes. Mass balances for the major cations and anions and the effects of aqueous aluminum on ANC are incorporated in the model. These processes are listed in Table 5.

Hydrologic flow of water through soil layers to the receiving system is simulated using the hydrologic model, TOPMODEL (Hornberger ot al. 1985). TOPMODEL is a topography-based, variable contributing area, catchment model adapted from the version of Beven and Kirkby (1979). The model considers overland flow, macropore flow, drainage from the upper zone to the lower zone and to the stream, and baseflow from the lower zone. Flow routing through the 
Table 4. Chemical constituents included in soil solutions and surface water for the MAGIC code.

\begin{tabular}{ll}
\multicolumn{2}{c}{ Chemical Constituent } \\
$\mathrm{ANC}$ & $\mathrm{SO}_{4}^{2 \cdot}$ \\
$\mathrm{Ca}^{2+}$ & $\mathrm{NO}_{3}{ }^{2+}$ \\
$\mathrm{Mg}^{2+}$ & $\mathrm{Cl}^{\cdot}$ \\
$\mathrm{K}^{+}$ & $\mathrm{F}$ \\
$\mathrm{Na}^{+}$ & $\mathrm{CO}_{2}(\mathrm{~g})$ \\
$\mathrm{NH}_{4}^{+}$ & $\mathrm{CO}_{2}(\mathrm{aq})$ \\
$\mathrm{H}^{+}$ & $\mathrm{H}_{2} \mathrm{CO}_{3}(\mathrm{aq})$ \\
$\mathrm{Al}(\mathrm{OH})_{n}{ }^{3-n}(n=0$ to 4$)$ & $\mathrm{HCO}_{3}{ }^{-}$ \\
$\mathrm{Al}(\mathrm{F})_{n}{ }^{3-n}(n=1$ to 6$)$ & $\mathrm{CO}_{3}{ }^{2 \cdot}$ \\
$\mathrm{Al}(\mathrm{SO})_{4}{ }^{3-n}(n=1$ to 2) & \\
\hline \hline
\end{tabular}

Table 5. Major Processes incorporated in the Codes of MAGIC/TOPMODEL (modified from Jenne et al., 1989)

\begin{tabular}{|c|c|}
\hline $\begin{array}{l}\text { Atmospheric Processes } \\
\text { - Dry deposition } \\
\text { - Wet deposition } \\
\text { Hydrological Processes } \\
\text { - Evapotranspiration } \\
\text { - Interception storage } \\
\text { - Snowmelt } \\
\text { - Overland flow } \\
\text { - Macropore flow } \\
\text { - Unsaturated subsurface flow } \\
\text { - Saturated subsurface flow } \\
\text { - Stream flow }\end{array}$ & $\begin{array}{l}\text { Geochemical Processes } \\
\text { - Carbonic acid chemistry } \\
\text { - Aluminum chemistry } \\
\text { - Weathering } \\
\text { - Anion Retention } \\
\text { - Cation exchange } \\
\text { Blogeochemical Processes } \\
\text { - } \text { SO }_{4}^{2} \text { reduction in lake } \\
\text { - Nitrification in soil } \\
\text { - Nutrient uptake } \\
\text { - Canopy interactions } \\
\text { - Litter decayc } \\
\text { - Root respiration } \\
\text { c }\end{array}$ \\
\hline $\begin{array}{l}\text { Limited treatment of process is } \\
\text { Sulfate reduction, nitrification, } \\
\text { specifying uptake rates of SO } \\
\text { Canopy interactions and root } \\
\text { by use of dry deposition facto } \\
\text { waters. }\end{array}$ & $\begin{array}{l}\text { an be simulated with the MAGIC code by } \\
\text { hydrologic compartments. } \\
\text { are implicitly included in the MAGIC code } \\
\text { of } \mathrm{CO}_{2} \text { partial pressure in soils and surface }\end{array}$ \\
\hline
\end{tabular}


watershed is provided from TOPMODEL to MAGIC. MAGIC modelling efforts for this study were based on model calibrations that had been perforned within the DDRP (NE Region). The original model calibrations were performert by Cosby et al. (1989b) The final DDRP NE report (Church et al. 1989) summarized the modeling process and results.

Measured runoff values were not available for the DDRP study sites, and runoff was estimated by a combination of interpolations of runoff contour maps developed with existing runoff data, and expert judgement of hydrologists. The runoff contour maps were developed for annual average runoff during the period 1951 to 1980 , from gauging stations having no diversions or regulations. A simple nearest-contour linear interpolation method was used to estimate runoff for each study site (Church et al. 1989). Comparisons between measured and interpolated runoff values at selected sites suggested that runoff could be estimated, on average, within $15 \%$ of measured values.

The hydrologic pathway followed by water as it moves through watershed soils to surface waters is one of the most important parameters influencing watershed neutralization of acidic inputs (Peters and Driscoll 1987). TOPMODEL was f'iosen to estimate an index of flowpath partitioning in the DDRP because the model uses input data that can be estimated from topographic and soils information, and it predicts internal hydrologic states that can be used to predict the partitioning of streamflow (Cosby et al. 1989b, Church et al. 1989). Flowpath partitioning is characterized by the spatial distribution of $\ln (a / K b \operatorname{Tan} B)$ where " $a$ " is the area drained per unit contour, "Tan $B$ " is the local slope, " $K$ " is the hydraulic conductivity, and "b" is the depth to bedrock. High values of $\ln (\mathrm{a} / \mathrm{Kb} \operatorname{Tan} \mathrm{B})$ suggest that surface runoff (quickflow) is important. Low values suggest well-drained soils draining little upslope area, where baseflow is more important.

Local slope (Tan B) and the area drained per unit contour (a) were computed for the study watersheds using U.S.G.S. digital elevation models interpolated from 1:250,000-scale topographic maps. Depth to bedrock (b) and hydraulic conductivity $(K)$ were estimated from data collected by 
the DDRP soil survey (Lammers et al. 1987, Lee et al. 1989), aggregated by soil map units and depth-to-bedrock classes. $K$ values were acsigned to soil texture classes based on data provided by Rawls et al. (1982).

The estimates of $\operatorname{In}(\mathrm{a} / \mathrm{Kb}$ Tan B) obtained by Cosby et al. (1989b) and used in this modeling effort, must be viewed with caution, however. A weakly-significant $\left(r^{2}=0.08\right)$ positive relationship was found between $\ln (\mathrm{a} / \mathrm{Kb} \operatorname{Tan} \mathrm{B})$ and lakewater $\mathrm{ANC}$ for the Northeast region (Church et al. 1989). This result was only weakly significant, and was actually contrary to theory. High values of $\ln (\mathrm{a} / \mathrm{Kb}$ Tan B) should be correlated with quickflow hydrology and low surface water ANC within similar soils/geologic settings (Church et al. 1989). The treatment of hydrology in the modeling results presented in this report should be considered as perhaps the most important uncertainty among the various model inputs and formulations.

MAGIC represents the watershed as a homogeneous unit with two soil-layer compartments. These soil layers can be arranged vertically or horizontally to represent the vertical or horizontal movement, respectively, of water through the soil. A vertical configuration was used in the DDRP, and the soil compartments were assumed to be areally homogeneous.

The meteorological and deposition input requirements for MAGIC are shown in Tables 6 and 7. The output soil solution and water chemistry constituents are shown in Table 4. Note that

Table 6. Meteorological data required by the MAGIC/TOPMODEL codes (from Jenne et al., 1989)

Interval for data measurement

Precipitation

Min. air temperature

Max. air temperature

Mean daylight hours

\section{Monthly" or yearly}

m

${ }^{\circ} \mathrm{C}$

${ }^{\circ} \mathrm{C}$

$\%$

- TOPMODEL runs with a daily time step. 
Table 7. Chemical constituents in wet and dry deposition considered by the MAGIC codes (modified from Jenne et al. 1989).

\begin{tabular}{|c|c|c|}
\hline Constituent & $\frac{\text { Dep }}{\text { Wet }}$ & $\frac{\text { sition }}{D y^{*}}$ \\
\hline $\begin{array}{l}\mathrm{SO}_{\mathrm{x}}(\mathrm{g}) \\
\mathrm{NO}_{\mathrm{x}}(\mathrm{g}) \\
\mathrm{Ca}^{+2} \\
\mathrm{Mg}^{2+} \\
\mathrm{K}^{+} \\
\mathrm{Na}^{+} \\
\mathrm{NH}_{4}^{+} \\
\mathrm{SO}_{4}^{2+} \\
\mathrm{NO}_{3}^{+} \\
\mathrm{Cl}^{-} \\
\mathrm{F}^{-} \\
\text {Units } \\
\text { Interval }\end{array}$ & $\begin{array}{l}x \\
x \\
x \\
x \\
x \\
x \\
x \\
x \\
x \\
\text { con } \\
\text { mo }\end{array}$ & $\begin{array}{l}X^{b} \\
X^{b} \\
X \\
X \\
X \\
X \\
X \\
X \\
X \\
X \\
X \\
c=\mu e q L^{-1} \text { or flux }=\mu e q / m^{2} / \text { interval } \\
\text { thly or yearly averaye }\end{array}$ \\
\hline
\end{tabular}

- The MAGIC code requires that dry deposition be expressed as a dry deposition factor

- $\mathrm{SO}_{\mathrm{x}}(\mathrm{g})$ and $\mathrm{NO}_{\mathrm{x}}(\mathrm{g})$ are implicitly included by the dry deposition factor.

DDRP analyses were constrained by a set of assumptions that guided the modeling efforts (Table 8).

MAGIC did not use a Gran ANC in simulating watershed response. Rather, it used two definitions of ANC as follows:

$$
\begin{aligned}
& \mathrm{ALK}= {\left[\mathrm{HCO}_{3}\right]+2\left[\mathrm{CO}_{3}{ }^{2 \cdot}\right]+[\mathrm{OH}]+\left[\mathrm{Al}(\mathrm{OH})_{4}\right]-} \\
& {\left[\mathrm{H}^{+}\right]-3\left[\mathrm{Al}^{3+}\right]-2\left[\mathrm{Al}(\mathrm{OH})_{2}^{+}\right]-\left[\mathrm{AlOH}^{2+}\right] } \\
& \mathrm{CALK}=\mathrm{SBC}+\mathrm{NH}_{4}^{+}-\mathrm{SAA}
\end{aligned}
$$

where: $\quad \mathrm{SBC}=\mathrm{Ca}^{2+}+\mathrm{Mg}^{2+}+\mathrm{Na}^{+}+\mathrm{K}^{+}\left(\mu \oplus \mathrm{q} \mathrm{L}^{-1}\right)$

$$
\mathrm{SAA}=\mathrm{Cl}+\mathrm{NO}_{3}^{+}+\mathrm{SO}_{4}^{2 \cdot}\left(\mu e q L^{-1}\right)
$$


Table 8. Operational assumptions for DDRP modeling efforts (modified from Church et al. 1989).

1. Index sample water chemistry from the NSWS provides an index of chronically acidic systems and systems with low ANC that are susceptible to acidic deposition.

2. Index soil data from the DDRP Soil Survey adequately characterize watershed attributes influencing surface water chemistry.

3. Forecasts of future acidification consider primarily chronic acidification. Episodic acidification is considered in the EPA Episodic Response Project.

4. Surface water acidification is a sulfur-driven process. Sulfur is assumed to be the primary acidifying agent in acidic cieposition. Eastern deciduous forests generally are nitrogen-limited (Likens et al., 1977; Swank and Crossley, 1988) so there is low export of nitrate. In addition, annual nitrate deposition exceeds annual ammonium deposition in the eastern U.S. (NAPAP, 1988) and nitrate has a slight alkalizing effect in the watershed if systems are not nitrogensaturated (Lee and Schnoor, 1988).

5. The watershed processes controlling the effects of sulfur deposition on surface waters are sulfate adsorption and desoiption and base cation depletion and resupply through mineral weathering and cation .xxciange.

6. The effects of organic acids on acid-base chemistry are constant through time and independent of the concen'ration of sulfate.

7. These major processes are known well enough to be incorporated into the forecasting models used in the DDRP.

8. Current watershed attributes and conoitions (e.g., climate, land use, basin characteristics) will remain relatively constant over the next 20 years and not influence the results of the forecasts.

9. Long-term forecasts using models are plausible and are the only feasible approach for evaluating the long-term effects of sulfur deposition scenarios on surface water chemistry.

10. "Typical" year projections (based on long-term-average runoff estimates) are not intended to represent future predictions of water chemistry but rather to provide a common basis for comparisons among deposition scenarios to assess potential changes in surface water chemistry.

11. Acidification is reversible and the processes in the models are adequate to describe both chemical acidification and deacidification.

12. Only chemical processes are considered in the Level III models.

13. Uncertainty calculations provide estimates of relative error for long-term comparisons among models and deposition scenarios but are not absolute error estimates. 
Equation 2 (referred to as charge balance alkalinity) is identical to calculated alkalinity $\left(C_{B}-C_{A}\right.$ ) used in this analysis. This report employs definition (2) of calculated alkalinity unless stated otherwise.

Watershed data for MAGIC were lumped or aggregated to provide avrerage or weighted average values for each of the soil layers. The top soil compartment represented the massweighted average conditions of the $A$ and $B$ horizons. The lower soil compartment represented the mass-weighted average conditions in the $C$ horizon.

\subsubsection{Calibration Methodology}

The MAGIC and TOPMODEL models were calibrated using an optimization procedure that selected parameter values so that the differences between the observed and predicted measurements was minimized (Cosby et al. 1985 a,b,c). Calibration of MAGIC involves selecting initial parameter values that, in conjunction with estimated precipitation and deposition, yield a trajectory from 1844 through a "window" about the 1984 measured lake chemistry values (Cosby et al. 1989b). The hindcast pre-industrial lakewater chemistry for each lake used here is the mean of those initial conditions that resulted in a trajectory that passed through the specified window for 1984 chemistry.

The calibration exercise was a three-step process. The first step specified the model inputs: precipitation, deposition (both wet and dry), an estimate of historical inputs for the long-term model, and fixed parameters or parameters whose values correspond directly to (or can be computed directly from) field measurements, e.g. topographic variables such as slope, aspect, area. This approach, in effect, assigns all of the uncertainty associated with sampling, aggregation, and intrinsic spatial variability to the "adjustable" parameters. The adjustable parameters are those that are calibrated or scaled to match observed field measurements.

The second step selected optimal values for the adjustable parameters using the method of Rosenbrock (1960). Optimized values were determined by minimizing a loss function defined as 
the sum of squared errors between simulated and observed values of system state variables.

Different loss functions were used for the hydrologic and chemical models. The hydrologic model used monthly stream flow volumes while the MAGIC model used ELS-I fall lake chemistry or observed soil chemistry.

The final step was to assess the structural adequacy of the model in reproducing the observed behavior of the criterion variables and identifiability (or the uniqueness) of the set of optimized parameters. Structural adequacy was assessed by examining the mean error in simulated values of observed state variables for those variables used in the calibration procedure as well as for an additional state variable which was not used during calibration. Parameter identifiability was assessed using approximate estimation error variances for the optimized parameters (Bard 1974). Additional information on the MAGIC calibration process was presented by Cosby et al. (1989b).

MAGIC simulations were performed for the project described here as done earlier by Cosby et al. (1989b) and NAPAP (1991), with two notable exceptions. To remove known biases, MAGIC was recalibrated using soils data specific to the Adirondack, NY subregion and assuming a more realistic pre-industrial sulfur deposition, equal to $13 \%$ of $198^{\circ}$ values (Husar et al. 1991). The earlier (DDRP) model projections had been calibrated to the entire northeastern region of the United States and had assumed zero pre-industrial sulfur dep nsition. The recalibration to the Adirondack subregion was intended to provide model results as comparable as possible to the diatom inferences. The latter were calibrated to the Adirondack subregion rather than the entire northeastern region. Additional information on the MAGIC model calibration procedure used in this project and the generation of uncertainty estimates for the model outputs is provided by Sullivan et al. (1991) and Church et al. (1989). 


\subsection{Organic Acid Model}

\subsubsection{Introduction}

Organic acids have been included in some applications of watershed acidification models. For example, Rustad et al. (1986) applied a modification of the Birkenes model (Christophersen et al. 1982) that included an organic subroutine based on the Oliver et al. (1983) model. The Birkenes model has also been applied to the Svartberget catchment in Sweden, where organic acids are important in influencing episodic pH depressions (Taugb $\phi$ l et al. in press). The ILWAS model (Goldstein et al. 1984) is generally applied using either a monoprotic or triprotic organic acid formulation.

Driscoll et al. (1990, in review) examined a number of organic acid analog models using data from the Adirondack, NY lakes. The models ranged (Table 9) from simple monoprotic acids to variable pK models like that of Oliver et al. (1983). They also examined the possibility that complex formation between aluminum and the organic anion might be important in Adirondack lakes and determined that for at least the diprotic and triprotic analog models (Table 10), inclusion of these complexes improved the fit to observed data.

The organic acid analog models in Table 9 and the aluminum complexation reactions in Table 10 were used for this study to determine if inclusion of these mode, could improve the comparisons between $\mathrm{pH}$ values simulated by MAGIC and those inferred from paleolimnologiral reconstructions.

\subsubsection{Calibration to ALSC Data}

These analog organic acids must be calibrated to observed data in order to arrive at estimated values of the pK's and site densities. Driscoll et al. (in review) calibrated the four analog acids given in Table 9 to data from the Adirondack Lakes Survey Corporation (ALSC) survey of approximately 1400 lakes in the Adirondack Mountains, NY. The calibration procedure consisted of numerical fitting of the pK values and site densities of each model to observed $\mathrm{pH}$, 
Table 9. Dissociation reactions and equilibrium expressions for the four analog organic models used in the project. (Brackets denote activities)

Triprotic acid reactions:

$$
\begin{aligned}
& \mathrm{H}_{3} \mathrm{~A} \rightleftharpoons \mathrm{H}^{+}+\mathrm{H}_{2} \mathrm{~A}^{-} \\
& \mathrm{H}_{2} \mathrm{~A}^{-} \rightleftharpoons \mathrm{H}^{+}+\mathrm{HA}^{2-} \\
& \mathrm{HA}^{2-} \rightleftharpoons \mathrm{H}^{+}+\mathrm{A}^{3-}
\end{aligned}
$$$$
\frac{\left\{B_{2} A^{-}\right\}\left\{B^{+}\right\}}{\left\{B_{3}^{A}\right\}}=R_{1}
$$$$
\frac{\left\{\mathrm{HA}^{2-}\right\}\left\{\mathrm{H}^{+}\right\}}{\left\{\mathrm{H}_{2} \mathrm{~A}^{-}\right\}}=\mathrm{R}_{2}
$$

$$
\frac{\left\{\mathrm{A}^{3-}\right\}\left\{\mathrm{H}^{+}\right\}}{\left\{\mathrm{HA}^{2-}\right\}}=\mathrm{K}_{3}
$$

Diprotic acid ractions:

$$
\begin{aligned}
& \mathrm{H}_{2} \mathrm{~A} \rightleftharpoons \mathrm{H}^{+}+\mathrm{HA}^{-} \\
& \mathrm{HA}^{-} \neq \mathrm{H}^{+}+\mathrm{A}^{2-}
\end{aligned}
$$

$$
\frac{\left\{\mathrm{BA}^{-}\right\}\left\{\mathrm{B}^{+}\right\}}{\left\{\mathrm{H}_{2} \mathrm{~A}\right\}}=\mathrm{R}_{1}
$$$$
\frac{\left\{\mathrm{A}^{2-}\right\}\left\{\mathrm{H}^{+}\right\}}{\left\{\mathrm{HA}^{-}\right\}}=\mathrm{K}_{2}
$$

Monoprotic acid reactions:

$$
\mathrm{HA} F \mathrm{H}^{+}+\mathrm{A}^{-} \quad \frac{\left\{\mathrm{A}^{-}\right\}\left\{\mathrm{B}^{+}\right\}}{\{\mathrm{BA}\}}=\mathrm{R}_{1}
$$

oliver acid reactions:

$$
\begin{aligned}
\mathrm{HA} \mathrm{H}^{+}+\mathrm{A}^{-} & \frac{\left(\mathrm{A}^{-}\right\}\left\{\mathrm{H}^{+}\right\}}{\{\mathrm{HA}\}}=\mathrm{K} \\
\text { where } \mathrm{PR} & =a+b(\mathrm{PH})+c(\mathrm{PH})^{2}
\end{aligned}
$$


Table 10. Complexation reactions between aluminum and organic anions and the equilibrium expressions for the diprotic and triprotic acids. (Brackets denote activities)

Organic aluninum reactions (triprotic acid)
$\mathrm{Al}^{3+}+\mathrm{A}^{3-} \rightarrow \mathrm{A} \perp \mathrm{A}$
$\mathrm{Al}^{3+}+\mathrm{B}^{+}+\mathrm{A}^{3-} \Rightarrow \mathrm{A} \mathrm{HA}{ }^{+}$

Equilibrium expressions:

$\frac{\{A \perp A\}}{\left.\{A\}^{3+}\right\}\left\{A^{3-}\right\}}=R_{1} \quad \frac{\left\{A \perp A^{+}\right\}}{\left\{A 1^{3+}\right\}\left\{A^{3-}\right\}\left\{B^{+}\right\}}=X_{2}$

Organic aluminum reactions (diprotic acid)

$\mathrm{Al}^{3+}+\mathrm{A}^{2 \cdot}-\mathrm{AlA}^{+} \quad \mathrm{Al}^{3+}+\mathrm{H}_{2} \mathrm{O}+\mathrm{A}^{2 \cdot}-\mathrm{Al}(\mathrm{OH}) \mathrm{A}+\mathrm{H}^{+}$

Equilibrium expressions:

$$
\frac{\{A \mid A+\}}{\left\langle A^{3+}\right\}\left(A^{2-\}}\right.}=K_{1} \quad \frac{(A)(O H) A\}(H+\}}{\left\langle A^{3+}\right\}\left(A^{2}-\right\}}=K_{2}
$$

aluminum, dissolved organic carbon, and calculated charge imbalance (i.e. assumed to be organic anion charge) data for all of the lakes in the ALSC data base. The object of the fitting routine was to minimize the differences (across all lakes) between the organic charge simulated by the pertinent organic acid model and the observed organic charge for the lakes. This error minimization procedure (see Driscoll et al., in review, for details) resulted in the calibrated values 
for the parameters of each organic model that are used in this work (Table 11). Driscoll et al. (in review) concluded that the triprotic acid model gave the best fit to the ALSC data.

\subsection{Paleolimnological Model}

\subsubsection{Background on Paleolimnological Techniques}

In the absence of long-term chemical monitoring data, inference based upon diatom and chrysophyte fossil assemblages preserved in lake sediments has been viewed as the most reliable technique available to evaluate historical chemical changes (Charles and Norton 1986). Diatoms (Bacillariophyceae) and scaled chrysophytes (Chrysophyceae, Synurophyceae) are single-cell algae composed of siliceous valves and overlapping siliceous scales, respectively. The fossil remains of these organisms are good indicators of past lake water chemistry because (1) they are common in a wide variety of habitats, (2) many taxa have rather narrow ecological (water chemistry) tolerances, (3) remains are well preserved in sediment, typically in very large numbers, and (4) they can be identified to the species level or below (Smol et al. 1984; Charles 1985;

Charles and Norton 1986; Smol et al. 1986; Husar et al. 1991).

Table 11. Values of the parameters in the four organic acid analog models and constants for the aluminum organic complexes used for the project. These values were derived by a fitting procedure applied to ALSC data on Adirondack lakes (Driscoll et al. in review). (Units of site density are moles of charge per mol of carbon.)

\begin{tabular}{lcccc}
\hline \hline Analog Acid & Site Density & pK1 & pK2 & pK3 \\
\hline Monoprotic & 0.133 & 4.45 & & \\
Diprotic & 0.082 & 4.20 & 6.04 & \\
Triprotic & 0.055 & 2.62 & 5.66 & 5.94 \\
Oliver et al. & 0.181 & $\left(\mathrm{pK}=0.15+1.41^{\star}(\mathrm{pH})-0.078^{\star}(\mathrm{pH})^{\star}(\mathrm{pH})\right)$
\end{tabular}

Constants for the Aluminum Organic complexes

Diprotic acid $\quad$ pK1 $=6.48 \quad$ pK2 $=1.745$

Triprotic acid $\quad$ pK1 $=8.38 \quad$ pK2 $=13.1$ 
Paleolimnological reconstructions of past lakewater chemistry are based on transfer functions derived from relationships between measured current chemistry and assemblages of recentlydeposited diatom or chrysophyte remains collected from surface sediment of several lakes within a region. Predictive equations are developed from these relationships to infer water chemistry, especially $\mathrm{pH}$. Calibration equations have also recently been developed for inferring the concentration of DOC, ANC, total Al, and monomeric Al (Kingston and Birks 1990, Birks et al. $1990 a, b)$.

Temporal trends can be reconstructed from sediment cores that have been dated radiometrically, usually with ${ }^{210} \mathrm{~Pb}$. Water chemistry inferred from diatom or chrysophyte assemblages in individual strata can be compared with stratigraphies of other lake sediment markers such as pollen, charcoal, coal and oil carbonaceous particles, polycyclic aromatic hydrocarbons, $\mathrm{Pb}, \mathrm{Zn}, \mathrm{Cu}, \mathrm{V}, \mathrm{Ca}, \mathrm{Mg}, \mathrm{Ti}, \mathrm{Al}, \mathrm{Si}, \mathrm{S}$, and others that provide a record of atmospheric inputs of materials associated with the combustion of fossil fuels and watershed disturbance (Charles and Norton 1986). With these data, in addition to knowledge of watershed events and some historical information on regional atmospheric emissions of sulfur and nitrogen, it is often possible to assess with reasonable certainty whether lakes have been affected by acidic deposition, and to what extent (Husar et al. 1991; Charles et al., 1989).

Diatom studies have documented the rates and magnitude of acidification of selected lakes in the Adirondack Mountains, NY (Del Prete and Schofield 1981; Charles 1984, 1987; Charles et al. 1986, 1987, 1990), New England (Davis et al. 1983, 1990), the Upper Midwest (Kingston et al., 1990), Florida (Charles et al. 1986, Sweets et al. 1990), Ontario (Dixit 1983; Dixit et al. 1987, 1989a, 1992), Sweden (Renberg and Hultberg 1982; Renberg and Wallin 1985; Renberg and Hultberg 1992), Finland (Tolonen and Jaakkola 1983, Huttunen et al. 1990), Norway (Davis and Anderson 1985; Davis and Berge 1980), Scotland (Flower and Battarbee 1983; Flower et al. 1987). West Germany (Arzet et al. 1986) and the Netherlands (van Dam 1988). 
Davidson (1984) demonstrated at experimentally acidified Lake 223 in the Experimental Lakes Area in Ontario the rapid response of diatoms to changes in water chemistry. The sediment core stratigraphy showed close agreement with the striking change in planktonic diatoms measured in the water column. Similarly, paleolimnological inferences of recent changes in lakewater chemistry have been shown to correspond closely with measured $\mathrm{pH}$ values at three lakes near Sudbury, Ontario (Dixit et al. 1987, 1989a, 1989b). Dixit et al. (1987) reconstructed the pH of Hannah Lake, near Sudbury, using diatom remains. Between about 1880 and 1975 the inferred lakewater $\mathrm{pH}$ declined from about 6.0 to 4.6. After the lake was limed in 1975, its measured $\mathrm{pH}$ increased from 4.3 to 7.0. This increase was also reflected in the diatom-inferred values (Dixit et al. 1987). A recent paleolimnological investigation (Dixit et al. 1989a) of acidification and subsequent recovery of Swan Lake, near Sudbury, Ontario, indicated that paleolimnological reconstructions of recent chemical change corresponded well with measured values. Also of significance were the large observed declines in trace metal concentrations in sediments coincident with $\mathrm{pH}$ recovery. The changes in metal concentrations did not inhibit accurate $\mathrm{pH}$ reconstruction. Dixit et al. (1992) also used diatoms and chrysophytes to reconstruct the recovery of Baby Lake subsequent to the closure of the nearby (1 km distance) Conistan Smelter near Sudbury in 1972. Measured lakewater pH increased from 4.2 in 1972 to 6.5 in 1987 . This recovery was closely mirrored by shifts in the diatom and chrysophyte species composition and inferred $\mathrm{pH}$.

Diatoms and chrysophytes differ somewhat in their ecological characteristics and both can provide useful qualitative and quantitative information regarding temporal trends in acid-base status of lakewater. Chrysophytes are euplanktonic; diatoms are both planktonic and benthic, but the diatom flora of low pH $(<5.5)$ lakes is dominated by benthic forms (Battarbee 1984; Charles 1985; Charles and Smol 1988). Chrysophytes usually bloom in spring. Although planktonic diatoms are also most abundant in spring, most littoral species are common throughout spring and summer (DeNicola 1986; Jones and Flower 1986; Charles and Smol 1988). Thus, 
chrysophyte assemblages may provide a better reflection of spring snowmelt pH depressions. Chrysophyte assemblage composition seems to change more rapidly than diatom assemblages along the $\mathrm{pH}$ gradient for $\mathrm{pH}$ values $\leq 5.5$, and are, therefore, particularly useful indicators in this range. Chrysophyte scales are not always present in sufficient quantity and variety to be useful, however. Lake sediments can be dominated by diatom valves or by chrysophyte scales, and the relative abundance and diversity of these groups will determine which will provide the most accurate information on past lake chemistry (Charles and Smol 1988). In general, assemblages with the greatest diversity of algal remains will provide the most ecological information and the best predictive equations. Results must be interpreted with caution where equations are applied to assemblages containing only a few dominant taxa. In such cases, the inferred $\mathrm{pH}$ will be determined largely by the $\mathrm{pH}$ category or the abundance weighted mean of the few dominant taxa. This problem can be especially important if the distribution of one or more of the dominant taxa is not well characterized in the calibration set (Charles and Smol 1988).

The diatom model as it has been applied to the study of anthropogenic acidification implicitly assumed that the acid-base chemistry of lakewaters during pre-industrial times was identical to the current acid-base chemistry, with the exception of changes that have occurred in response to acidic deposition. This assumption may not be entirely valid because:

1. other pollutants besides oxides of sulfur and nitrogen may have influenced lakewater chemistry;

2. watersheds have been altered as a result of anthropogenic activities such as logging and road building; and

3. natural processes, including climatic effects, forest growth, beaver abundance, and fire, may have altered the flux of ions from the watershed to the receiving waters and/or altered the watershed processing of atmospheric inputs.

\subsubsection{Paleoecological Investigation of Recent Lake Acidification (PIRLA)}

Considerable paleolimnological data for lake acidification studies in the United States were obtained as part of two large regional studies, PIRLA-I (Paleoecological Investigation of Recent 
Lake Acidification; Charles and Whitehead 1986a,b) and PIRLA-II (Charles and Smol 1990). PIRLA-I included stratigraphic analysis for about 35 lakes in four regions of the United States (Adirondack Mountains and northern New England, Upper Midwest, and Florida.) In addition to obtaining biological data (diatoms, chrysophytes) for inferring water chemistry, measurements also included analyses of metals, sulfur, nitrogen, carbon, polycyclic aromatic hydrocarbons, coal and oil carbonaceous particles, pollen, and ${ }^{210} \mathrm{~Pb}$ for dating strata. The PIRLA-I project developed standardized protocols for all aspects of paleolimnological research, including quality assurance/quality control (QAQC) guidelines (Charles and Whitehead 1986a).

Major objectives of the PIRLA-II study were to determine the proportion of low ANC Adirondack lakes that have become more acidic since about 1850, to quantify the ANC change that occurred, and to determine the percentage of lakes that were naturally acidic. Sediment cores from 33 of the 38 Adirondack lakes that were included in the DDRP (Church et al. 1989) were analyzed. The "tops" (0-1 cm depth) and "bottoms" (pre-1850, typically $>30 \mathrm{~cm}$ ) of the sediment cores were analyzed for diatoms and chrysophytes. The PIRLA-II research effort was designed to answer several of the key questions of the NAPAP State of Science and Assessment activities. The project was described by Charles and Smol (1990) and major results have been presented by Sullivan et al. (1990) and Cumming et al. (1992).

\subsubsection{Paleolimnological Methodology}

During the past several years, the standard paleolimnological procedure has been to develop equations for inferring water chemistry from diatom assemblages, using category-based, multiple regression techniques (based on the assignment of diatom taxa to $\mathrm{pH}$ categories). Recently, these have been replaced by theoretically superior "gradient analysis" techniques, particularly canonical correspondence analysis (CCA) and weighted averaging. The theory of CCA has been developed and summarized primarily by Cajo ter Braak (ter Braak 1985, 1986, 1987, 1988; ter Braak and Barendregt 1986; ter Braak and Looman 1986; ter Braak and Gremmen 1987; ter 
Braak and Prentice 1988). Gradlent analysis theory is based on a species-packing model, which assumes a normal distribution of each species' abundance in samples along the environmental gradient. Birks et al. (1990a,b) described a two-step technique for applying the new procedures to the inference of lake chemistry, using diatoms.

For the PIRLA-\|l Project, weighted averaging calibration (Birks et al. 1990b) was used for development of calibration equations (Dixit et al. in press). Seventy-one lakes were included in the drainage lake calibrations and 20 lakes in the seepage lake calibrations. Predicted versus observed diatom-inferred $\mathrm{pH}$ for calibration drainage and seepage lakes is presented in Figure 1a. Calibration equations were also developed for drainage lakes to infer $\mathrm{pH}$ from chrysophyte scales (Figure 1b). The calibration relationship was not as strong for chrysophytes as for diatoms, but the chrysophyte data provide additional corroborative evidence of chemical change.

Error estimates for diatom-inferred pH values in the PIRLA-II project have been obtained by using bootstrapping, a computationally-intensive resampling procedure (Efron 1983; Birks et al. $1990 a, b)$. First, a subset of training samples which is the same size as the original training (calibration) set is selected at random with replacement. This set is used to develop a predictive equation to infer $\mathrm{pH}$. Second, the remaining unselected samples are used as a test set, and the new predictive equation is used to infer $\mathrm{pH}$ values for this test set. This process (bootstrap cycle) is repeated a large number of times (for example 1000). The new inferred values are then correlated with the corresponding measured values for the test set lakes, and a root mean square error (RMSE) is calculated for the relationship. An advantage of the bootstrapping technique, essential for comparisons to acidification models, is that unique error estimates are obtained for the predicted pH from each fossil sample. For sediment core samples, the errors downcore are expected to exceed the errors for surface samples if the sampled assemblages diverge from the floristic composition of surface analogs. These errors are also greatly affected by data screening, and the removal of outlier samples from the calibration can greatly improve performance of the relationships (Birks et al. 1990 a). 

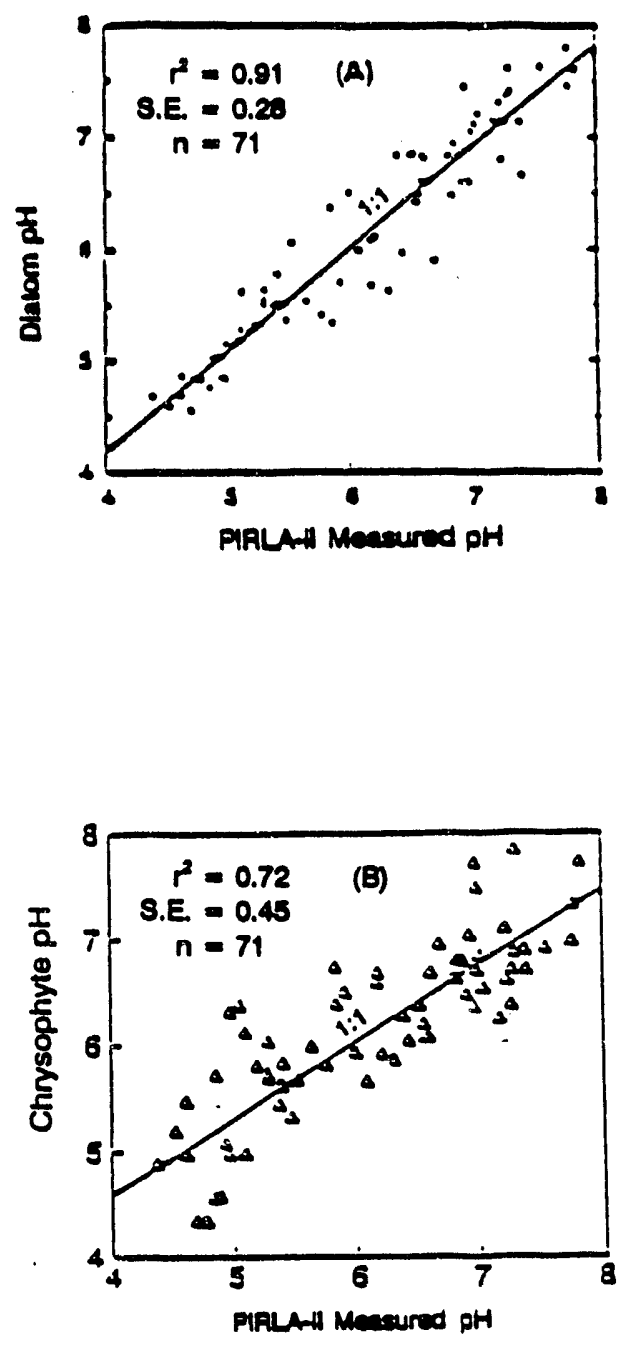

Figure 1. Calibration relationship developed in PIRLA-ll between measured and inferred values of $\mathrm{pH}$. A) based on diatoms, B) based on chrysophytes. (Source: Sullivan et al. 1991. Dixit et al. in press) 
The correlation coefficient for the relationship between measured and inferred $\mathrm{pH}$ for the 71 Adirondack lakes used for the calibration was high $\left(r^{2}=0.91\right)$; the apparent root mean square error (RMSE) (0.31) and the RMSE using a bootstrap technique $(0.35)$ indicate that past pH can be inferred with an error of about one-third of a pH unit (Cumming et al. 1992, Dixit et al. in press).

\subsection{SUMMARY OF PREVIOUS MODEL COMPARISON}

Sullivan et al. (1991) compared paleolimnological estimates of pre-industrial pH and ANC of Adirondack lakes with MAGIC model hindcast estimates of pre-industrial chemistry. Thirty-three lakes that had been statistically selected from the ELS-I and DDRP were included in the comparison. It was found that direct comparison of pre-industrial and current chemistry estimates, using DDRP protocols for MAGIC and PIRLA-II diatom-inferred chemistry, was inappropriate. A host of inconsistencies in methodologies and problematic assumptions obscured the reasons for differences between the paleolimnological and MAGIC model inferences. The major potential difficulties included (1) the influence of watershed disturbance and land use on acid-base chemistry, which influences paleolimnological results but is not considered in the MAGIC model, (2) seasonal differences between sampling times for the paleolimnological study and the EPA survey, (3) differences in the definition of ANC used as MAGIC model output versus that used in the diatom calibration, (4) uncertainties regarding preindustrial atmospheric deposition of sulfur and base cations, which must be estimated in order to conduct MAGIC hindcast simulations, and (5) uncertainties regarding the soils aggregation and calibration of MAGIC to the northeastern region, rather than the Adirondack subregion, within the DDRP. In order to evaluate the relative importance of these issues in confounding direct comparison between paleolimnological and MAGIC model recons.juctions, several different scenarios and calibrations were conducted for both approaches. Although all uncertainties 
cannot be quantified and all potentially confounding factors cannot be removed, an effort was made to make we diatom and MAGIC model hindcast estimates as comparable as possible.

The most reasonable comparison available between the paleolimnological and MAGIC hindcasts was between the MAGIC scenario that was based on the subregional reaggregation and recalibration of MAGIC to the Adirondack Mountains and the paleolimnological inferences of ANC defined as $\left(\mathrm{C}_{\mathrm{B}}-\mathrm{C}_{N}\right)$ (where $\mathrm{C}_{\mathrm{B}}$ is the base cation sum: $\mathrm{Ca}^{2+}+\mathrm{Mg}^{2+}+\mathrm{Na}^{+}+\mathrm{K}^{+}+\mathrm{NH}_{4}^{+}$. and $\mathrm{C}_{A}$ is the mineral acid anion sum: $\mathrm{SO}_{4}^{2-}+\mathrm{NO}_{3}^{-}+\mathrm{Cl}^{-}$, and all units are in $\mu$ eq $\mathrm{L}^{-1}$ ). This comparison removed the biases associated with different ANC definitions, and the regional (rather than subregional) nature of the rriginal MAGIC scenarios.

Results of this comparison showed good agreement for the estimates of current chemistry (Figure 2a), thus demonstrating that both approaches can be successfully calibrated to current conditions. Substantial differences were observed, however, between the MAGIC and paleolimnological estimates of pre-industrial chemistry (Figure 2b). The MAGIC model estimates of pre-industrial pH and ANC (not shown) were generally higher than the diatom-inferred estimates, and MAGIC implied that lakewater acid-base chemistry had changed more in response to historical increases in acid deposition than did paleolimnology. Both approaches suggested thiat acidification of low-ANC Adirondack lakes had occurred since pre-industrial times. They differed primarily in that MAGIC inferred greater acidification and also that acidification had occurred in all lakes in the comparison. In contrast, paleolimnology inferred that acidification had been restricted to low-ANC lakes (< about $50 \mu e q L^{-1}$ ). The discrepancy was greatest for those lakes at the most biologically-sensitive portion of the $\mathrm{pH}$ spectrum, e.g., $\mathrm{pH}$ less than 6.0. Furthermore, MAGIC hindcast pH estimates were greater than 6.0 for all lakes investigated, whereas diatom inferences of pre-industrial pH ranged from as low as 5.2 to above 7.0.

The comparison presented in Figure 2 requires further explanation. Part of the calibration of MAGIC, both by Sullivan et al. (1991) and in the current application, involved specification of a value for the partial pressure of $\mathrm{CO}_{2}\left(\mathrm{P}_{\mathrm{CO}_{2}}\right)$ in the lake. In the original calibration protocol for 
A)

1984 pH Comparison

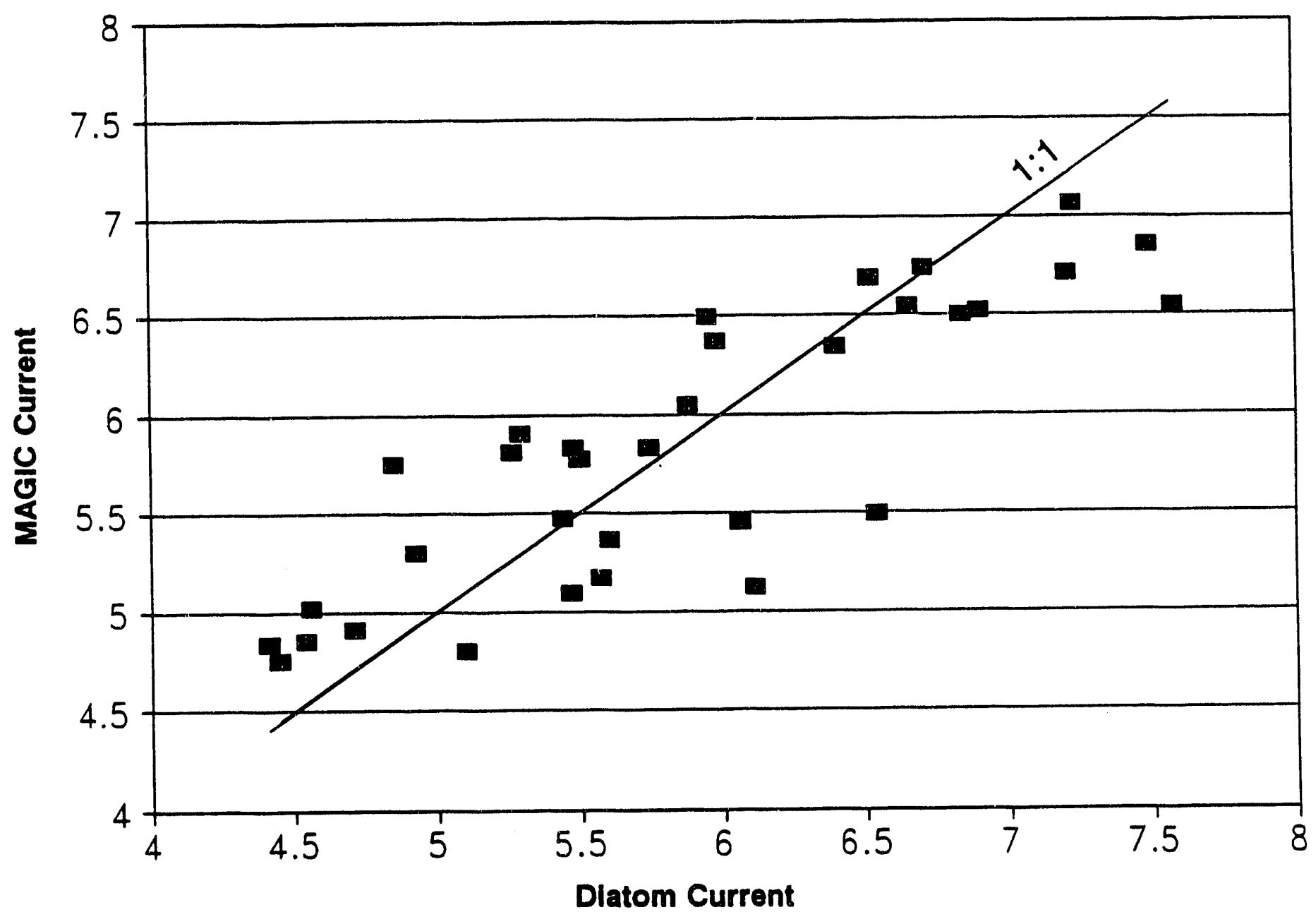

Figure 2. MAGIC model hindcast estimates and diatom inferences of $A$ ) current and B) preindustrial pH for 33 statistically selected Adirondack lakes. The MAGIC formulation/calibration for the simulations was from Sullivan et al. (1991). No organic acids were included in the MAGIC model and $p_{c 0}$ was "calibrated" to compensate partially for the missing organics (see discussion in text). 
B)

$1844 \mathrm{pH}$ Comparison

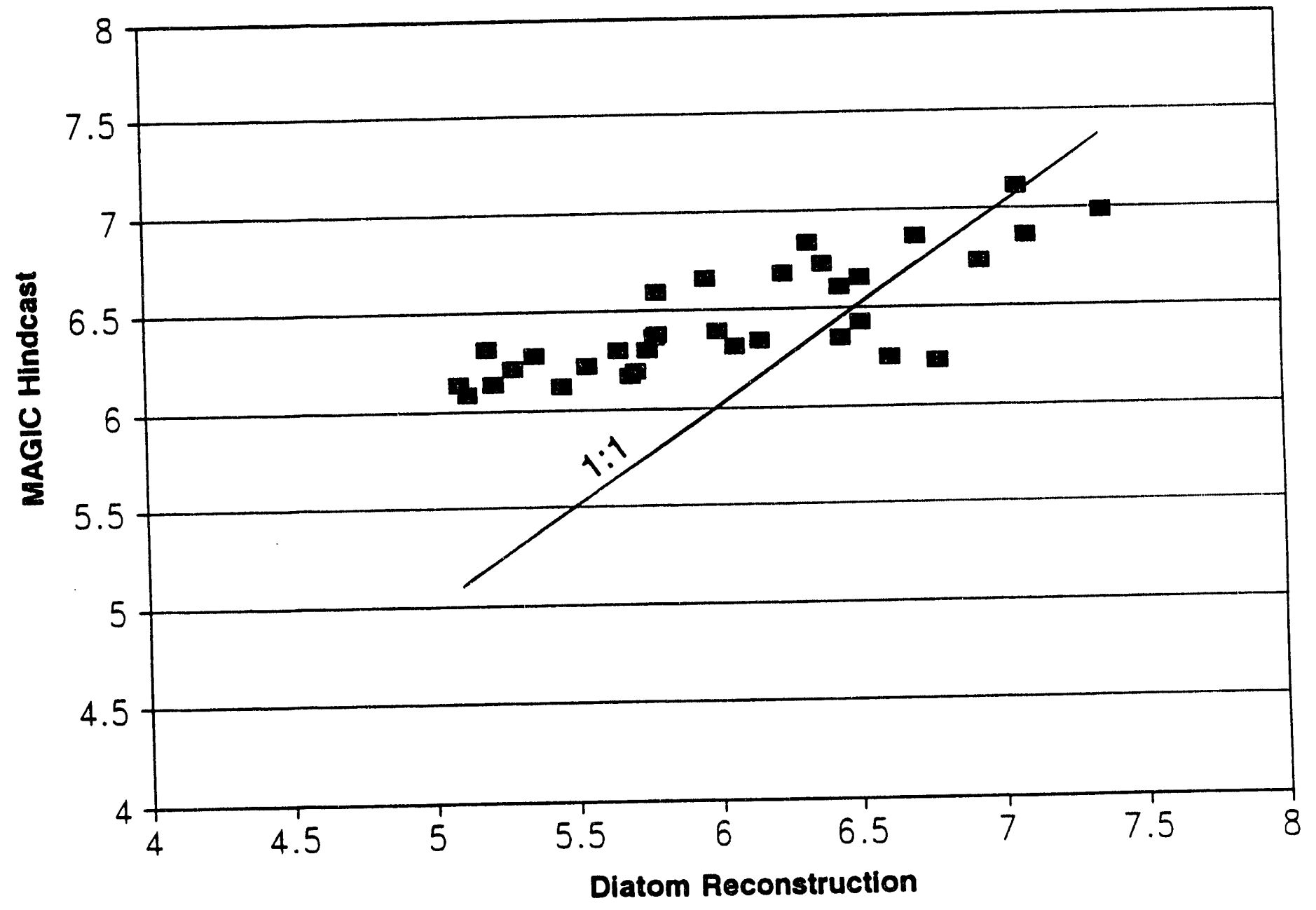

Figure 2. Continued 
MAGIC, the observed $\mathrm{pH}$ and ANC values for each lake having a pH greater than 4.5 were used along with aqueous inorganic carbon equilibrium equations to calculate a $\mathrm{P}_{\mathrm{CO}_{2}}$ value for each lake. These calculated values were averaged across all of the lakes, and the average value was used for all lakes in performing slibsequent simulations (including the comparisons to the diatoms). Because no organics were included in the original application of MAGIC, this "calibration" of $\mathrm{P}_{\mathrm{CO}_{2}}$ resulted in a partial compensation for the missing organics. That is, the calibration procedure resulted in high estimates of $\mathrm{P}_{\mathrm{CO}_{2}}$ that would in turn produce the lower values of simulated $\mathrm{pH}$ that were needed to match the measured $\mathrm{pH}$ values. The mean $\mathrm{P}_{\mathrm{CO}_{2}}$ for the 33 study lakes in the simulation of Sullivan et al. (1991) was $0.0013 \mathrm{~atm}\left(\mathrm{P}_{\mathrm{CO}_{2}}=10^{-2.89}\right)$.

In the work reported here, a different procedure was used to calculate $\mathrm{P}_{\mathrm{CO}_{2}}$ for inclusion in MAGIC. Measured values of $\mathrm{pH}$ and dissolved inorganic carbon (DIC) from the ELS data base were used for each lake to calculate a $P_{\mathrm{CO}_{2}}$ value for each lake. These calculated values were averaged across all of the lakes and the average value was then used for all lakes in performing subsequent simulations (including the comparisons to the diatoms). In this procedure (unlike the earlier one) the possibility of intended (or unintended) compensation for inadequate organic acid representation does not exist; the influence of $\mathrm{P}_{\mathrm{CO}_{2}}$ on simulated pH's is constrained entirely by the measured DIC in the lakes. The mean $\mathrm{P}_{\mathrm{CO}_{2}}$ for the 33 study lakes in this report was 0.00077 $\operatorname{atm}\left(P_{\mathrm{CO}_{2}}=10^{-3.11}\right)$.

Given these considerations, it would be expected that the comparison between simulated historical pH's from MAGIC and the diatoms would be even worse than those generated by Sullivan et al. (1991) and shown in Figure 2b. This is indeed the case. Using the old calibration method and allowing $P_{\mathrm{CO}_{2}}$ to partially compensate for missing organic acids produced a mean difference between MAGIC and diatom pre-industrial $\mathrm{pH}$ values of $0.4 \mathrm{pH}$ units (calculated as MAGIC value minus diatom value, see Figure $2 \mathrm{~b})$. Using the corrected procedure of calculating $\mathrm{P}_{\mathrm{CO}_{2}}$ based on measured DIC produced a mean difference between MAGIC and diatom preindustrial pH values of $0.6 \mathrm{pH}$ units. This larger discrepancy (Figure 3 ) is addressed in this 


\section{4 pH Comparison}

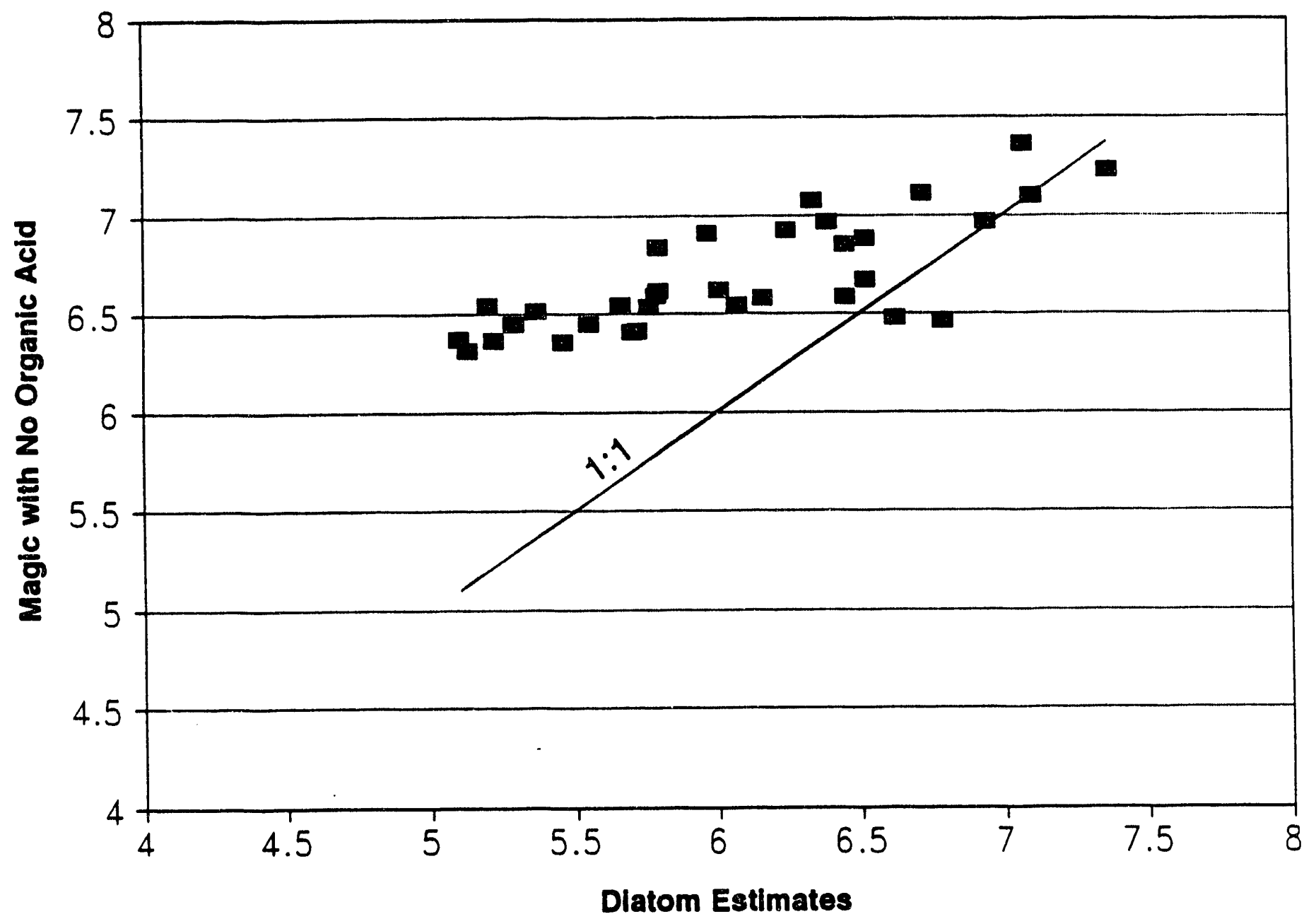

Figure 3. MAGIC model hindcast estimates of pre-industrial pH versus diatom-inferred $\mathrm{pH}$ for 33 statistically selected Adirondack lakes. No organic acids were included in the MAGIC model simulations. Partial pressure of $\mathrm{CO}_{2}$ in the lakes was calculated directly using observed dissolved inorganic carbon and $\mathrm{pH}$. This is the reference comparison between reconstructed historical pH from MAGIC and the diatoms against which subsequent formulations of the models must be assessed. 
project. All results presented later in this report which display comparisons of MAGIC and diatom simulated historical pH's should be compared to Figure 3 to assess the improvement achieved by the modification under consideration.

The principal objectives of the on-going project described in this report are to test further the MAGIC model and to assess the degree to which the discrepancy between the diatom and MAGIC inferences can be improved by including a rigorous organic acid model in the MAGIC applications. Results of this effort to date are described in the following section.

\subsection{RESULTS OF MODEL COMPARISONS CONDUCTED IN THE CURRENT PROJECT}

A number of different formulations for organic acids were considered in this project (see Section 3.3). In presenting and discussing the results when individual lakes are considered (as in scatterplots), we consider only the triprotic organic acid representation using regional average values of $\mathrm{P}_{\mathrm{CO}_{2}}$ and aluminum solubility, with the aluminum solubility constant based on extractable aluminum values from the ELS data base. As demonstrated in the sensitivity analysis section of the report (Appendix B), however, there was very little difference among the results of the various formulations.

There are a wide variety of comparisons that can be made among the measured (ELS-I) and simulated (diatom, MAGIC) results. To facilitate these comparisons we will use two statistics to summarize pairwise comparisons across the 33 lakes. The mean of the differences will be reported as a measure of the regional bias of the results. If the pairwise data are clustered evenly around a $1: 1$ line the expected value of the mean difference is 0.0 . The root mean square of the difference (RMS difference) will be used to give a combined measure of both the regional bias plus the scatter (noise) in the comparisons. Note, however, that the mean difference is dependent upon the range of $\mathrm{pH}$ values in the data set under consideration. In other words, lakes having $\mathrm{pH}$ above 6.5 generally showed good agreement, whereas low $\mathrm{pH}$ lakes differed by 
an amount considerably in excess of the mean difference. Thus, the slope of the relationship in Figure 3 deviated substantially from the 1:1 line.

\section{$5.1 \mathrm{pH}$}

Three independent data sets (DDRP, PIRLA-II, and ALSC) and three independent interpretive models (MAGIC, diatom, and Driscoll's triprotic organic acid analog) were combined to test the consistency of the results of the diatom approach and the combined MAGIC and organic acid modeling approach for estimating pre-industrial lakewater $\mathrm{pH}$. Driscoll's triprotic organic acid model was inserted as a subroutine into MAGIC and simulated $\mathrm{pH}$ values were then compared with diatom-inferred $\mathrm{pH}$. This revised comparison yielded considerably closer agreement for preindustrial pH (Figure 4) than did the comparisun that excluded the effects of organic acids (Figure 3). The mean difference in MAGIC versus diatom estimates of pre-industrial $\mathrm{pH}$ was $0.6 \mathrm{pH}$ units when organic acids were omitted from the modeling scenarios, with the discrepancy increasing for lakes with diatom-inferred $\mathrm{pH}<6.0$. This mean difference was only $0.2 \mathrm{pH}$ units when the triprotic organic acid analog model was included, and the agreement for individual low-pH lakes improved by as much as a full pH unit (Figures 3 and 4).

The inclusion of the organic acids also had an effect on simulated $1984 \mathrm{pH}$ (Figure 5a and b). As would be expected, the inclusion of organic acids depressed the simulated pH values. This effect was greatest for lakes with observed $\mathrm{pH}$ values between about 5.5 and 6.0 (Figure $5 \mathrm{a}$ and b). The mean of the differences between observed and simulated $\mathrm{pH}$ values shifted by $0.4 \mathrm{pH}$ units, from 0.2 to +0.2 when the organic acid was included in MAGIC.

Although no attempt was made to recalibrate the organic acid model when it was added to MAGIC, it would be possible to adjust the values of the organic acid model parameters until the simulated values of $\mathrm{pH}$ more closely matched the observed values in 1984 (this calibration procedure is addressed in Appendix C). The differences between the simulated and observed current $\mathrm{pH}$ values for the two MAGIC runs (with and without organic acids) are for most lakes 


\section{4 pH Comparison}

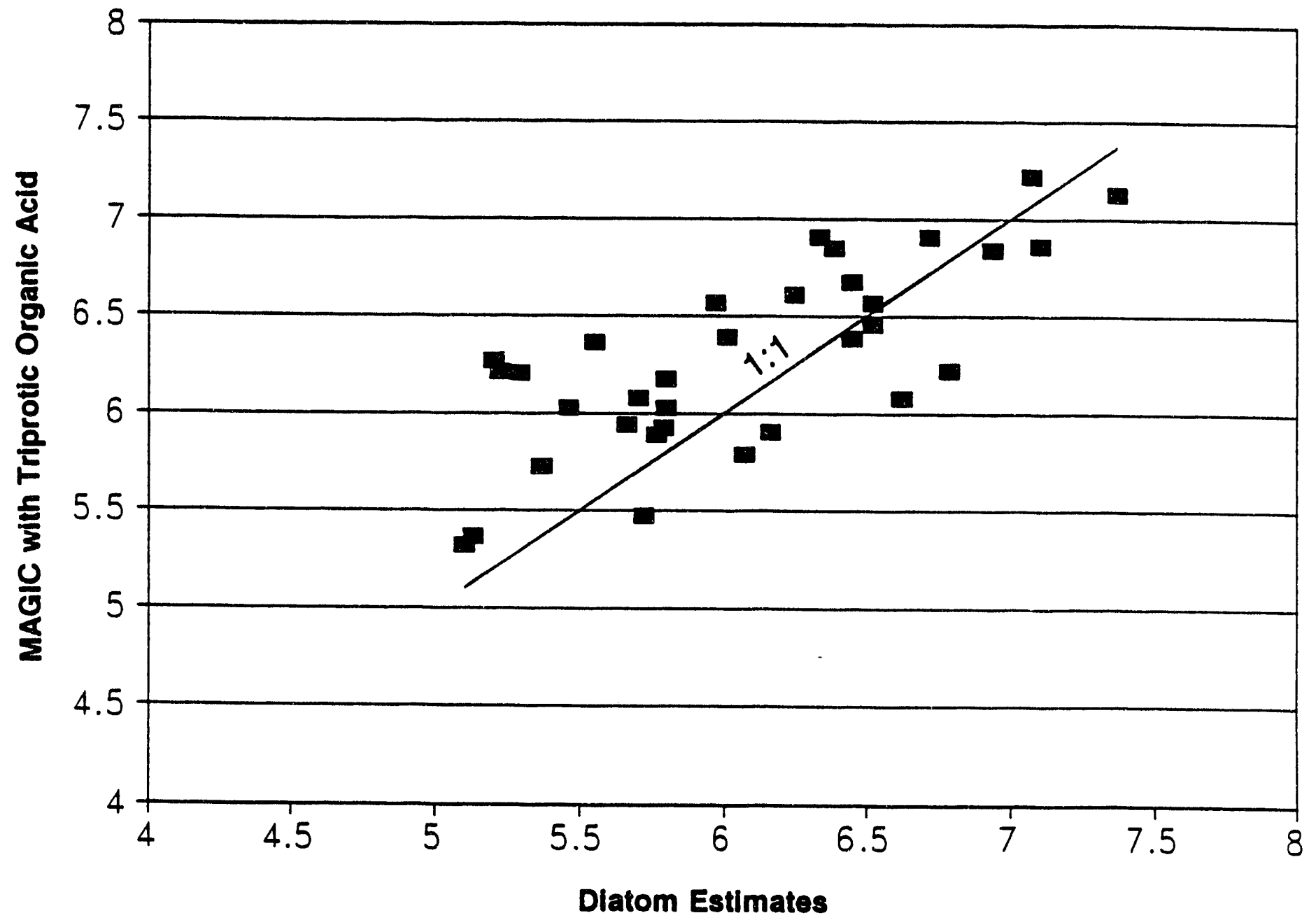

Figure 4. MAGIC model hindcast estimates of pre-industrial pH versius diatom-inferred $\mathrm{pH}$ for 33 statistically selected Adirondack lakes. A triprotic organic acid representation was included in the MAGIC simulations. The parameter values for the triprotic organic acid are those of Driscoll et al. (in review) derived from the ALSC data set. 
A)

1984 pH Comparison

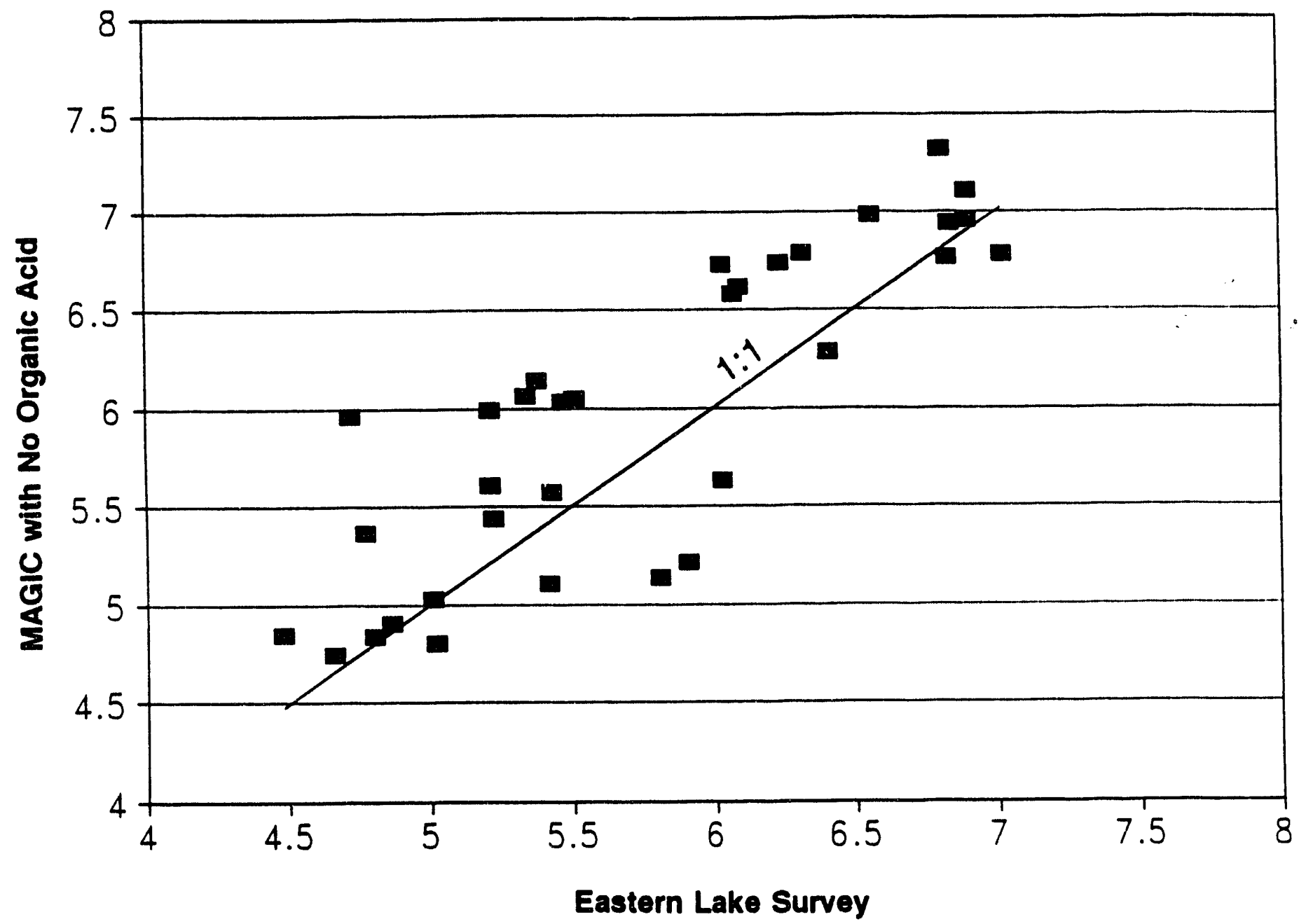

Figure 5. Model estimates of current (1984) lakewater $\mathrm{pH}$ versus $\mathrm{pH}$ values measured by the ELS (Linthurst et al. 1986): A) MAGIC estimates without including organic acids, B) MAGIC estimates with a triprotic organic acid representation, C) diatom estimates. 
B)

1984 pH Comparison

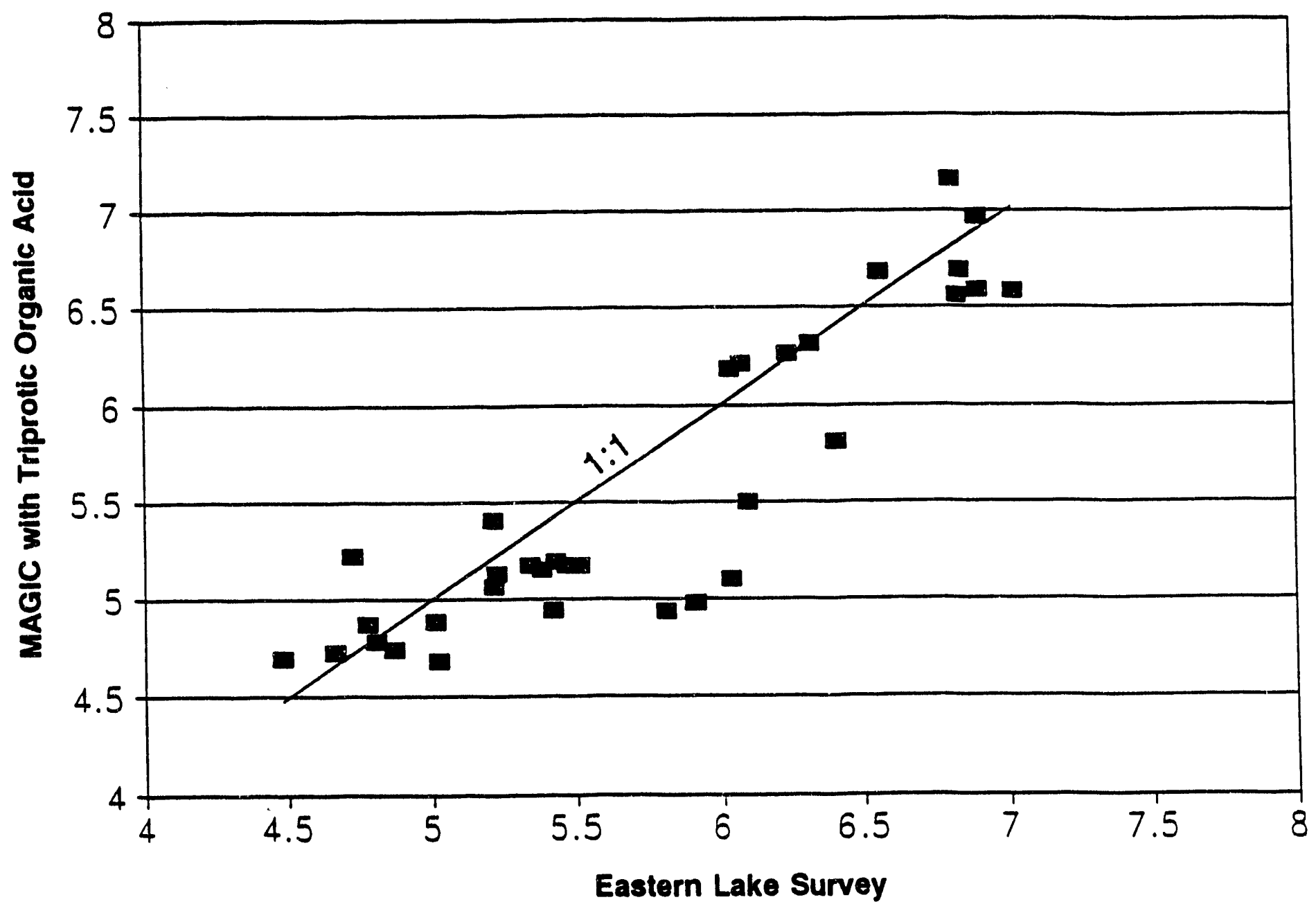

Figure 5. Continued 
C)

\section{$1984 \mathrm{pH}$ Comparison}

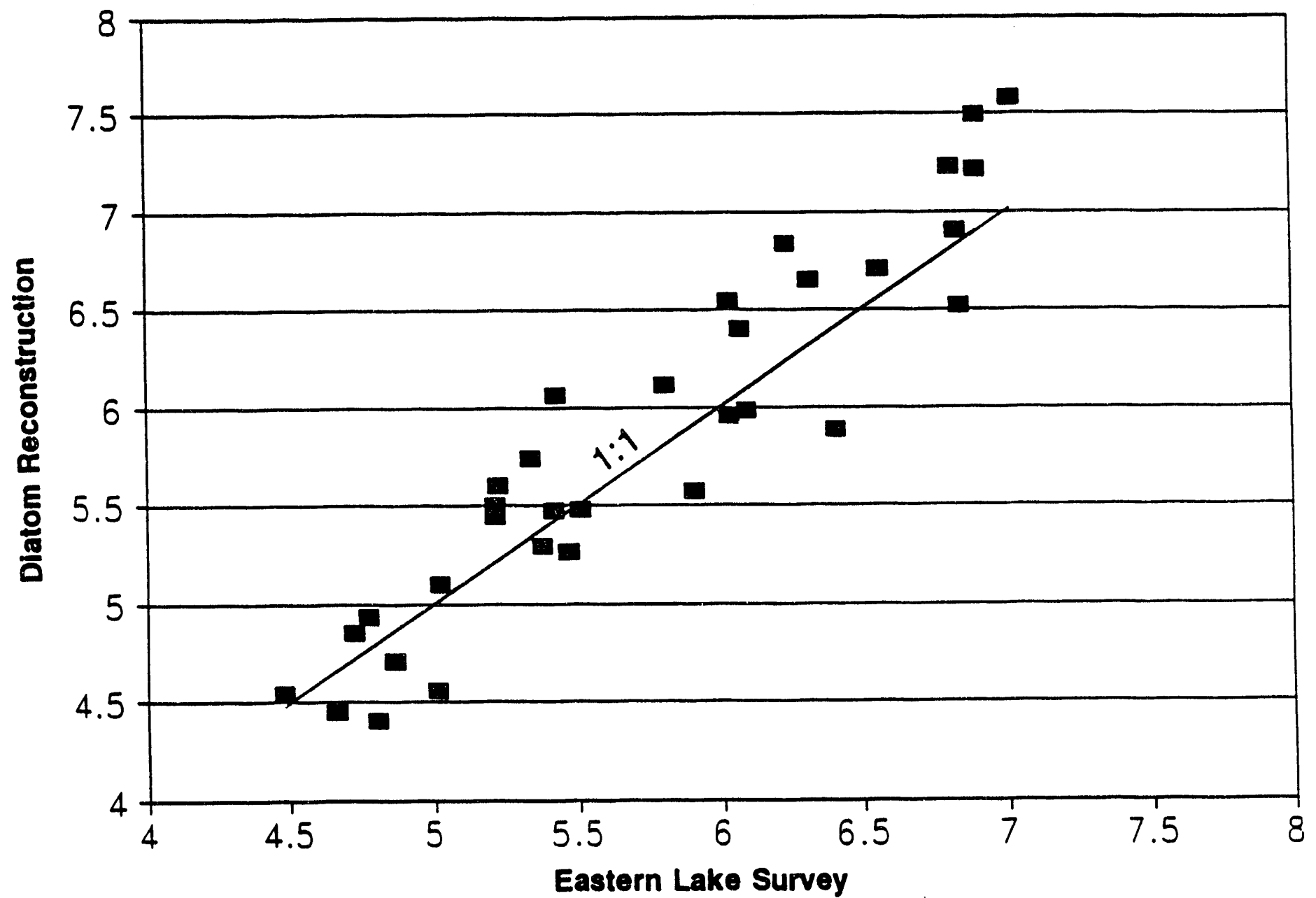

Figure 5. Continued 
approximately of the same order as the mean difference between the diatom-reconstructed and measured pH's (0.1 to $0.2 \mathrm{pH}$ units; see Figure 5c).

Comparisons based on alternative formulations for the organic acid analog model yielded similar results. Although the triprotic acid was judged (by Driscoll et al. 1990) to provide the best empirical fit to the ALSC data, use of the ALSC-fitted monoprotic, diprotic, and Oliver models produced the same regional patterns as the triprotic model when compared to diatom reconstructed historical pH's (Figure 6). Results of the various pairwise comparizons for simulated pre-industrial pH are summarized in Table 12. Comparisons of simulated pH are presented for five different cases. These are inclusion of monoprotic, diprotic, triprotic, and Oliver (Oliver et al. 1983) organic acid analog models in MAGIC and also MAGIC with no organic acid representation.

Table 12. Differences between MAGIC and diatom model estimates of pre-industrial (1844) and current (1984) $\mathrm{pH}$ estimates for the 33 lake Adirondack data set, based on five different MAGIC model applications.

\begin{tabular}{lcccc}
\hline $\begin{array}{c}\text { Organic Acid } \\
\text { Formulation in MAGIC } \\
\text { Model Application }\end{array}$ & \multicolumn{1}{c}{$1844 \mathrm{pH}$ Estimates } & & \multicolumn{1}{c}{$1984 \mathrm{pH}$ Estimates } \\
\cline { 5 - 6 } & Mean & $\begin{array}{c}\text { RMS of } \\
\text { Difference }\end{array}$ & $\begin{array}{c}\text { Mean } \\
\text { Difference }\end{array}$ & $\begin{array}{c}\text { RMS of } \\
\text { Difference }\end{array}$ \\
\hline Monoprotic & 0.17 & 0.48 & -0.35 & 0.58 \\
Diprotic & 0.22 & 0.46 & -0.31 & 0.54 \\
Triprotic & 0.21 & 0.46 & -0.29 & 0.52 \\
Oliver & 0.25 & 0.47 & -0.27 & 0.51 \\
No organic acid & 0.62 & 0.77 & 0.12 & 0.52 \\
\hline \hline
\end{tabular}


A)

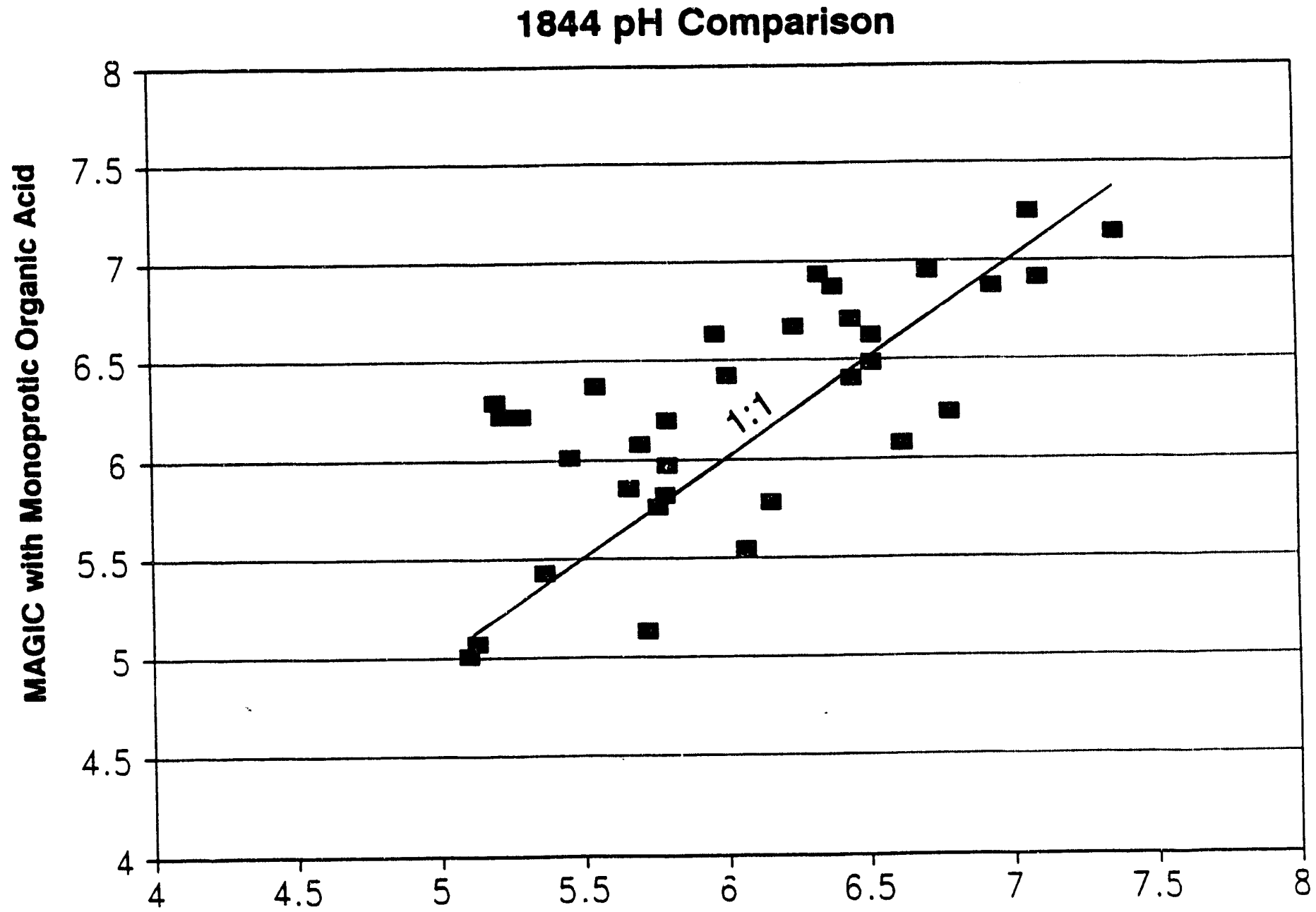

Diatom Reconstruction

Figure 6. MAGIC model hindcast estimates of pre-industrial pH versus diatom-inferred $\mathrm{pH}$ for 33 statistically-selected Adirondack lakes, using A) monoprotic, B) diprotic, and C) Oliver et al. (1983) organic acid analog models. Parameter values for pK's and site density are those of Driscoll et al. (in review). 
B)

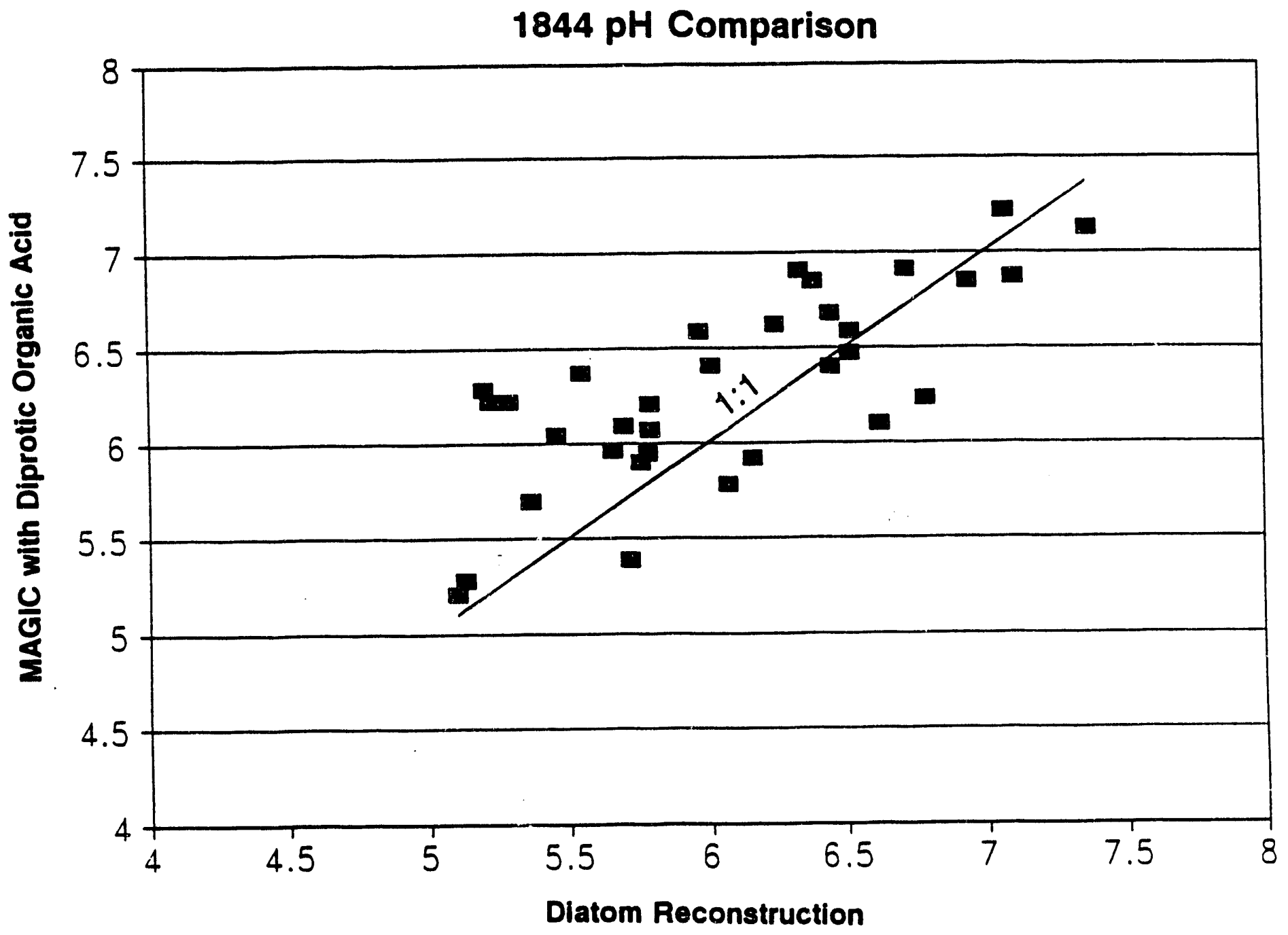

Figure 6. Continued. 
C)

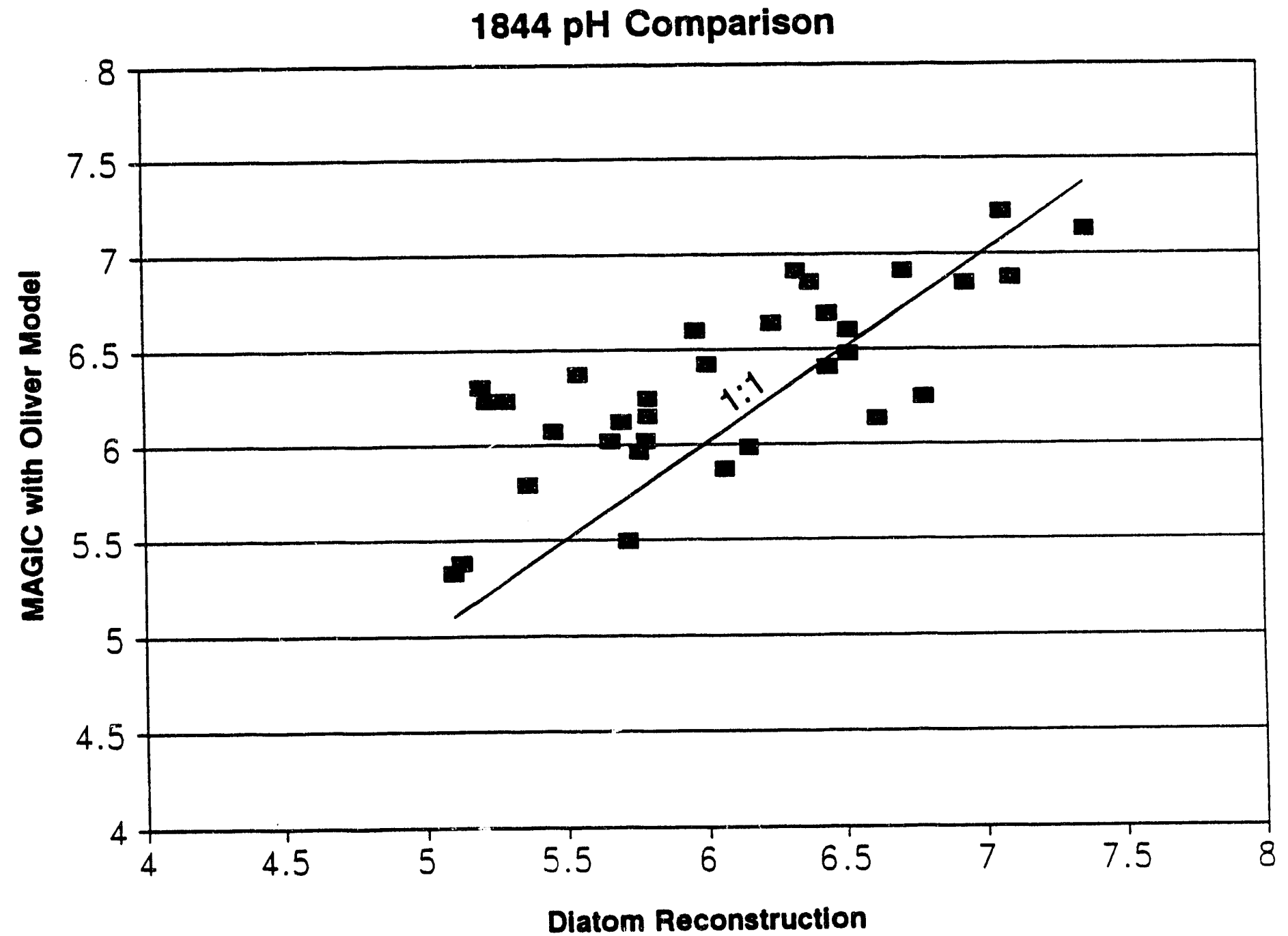

Figure 6. Continued. 
For the year 1844 (pre-industrial reconstructions) only comparisons between the MAGIC and diatom models are available. For the year 1984, however, measured ELS chemical data are also available, in addition to model estimates of current chemistry. Results of the comparisons with measured ELS-I data are summarized in Table 13. For the diatom model, the $1984 \mathrm{pH}$ estimates represent calibrated values using the transfer functions described by Cumming et al. (1992). The mean difference between diatom reconstructed and observed current $\mathrm{pH}$ values is $0.11 \mathrm{pH}$ units (RMS difference $=0.34$ ). For the MAGIC model the $1984 \mathrm{pH}$ estimates represent values based on the re-calibration to the Adirondack sub-region (as described earlier) with five different assumptions regarding organic acids in the surface waters. The mean differences between observed pH's and those simulated by MAGIC range from -0.25 to 0.22 units (RMS differences range from 0.51 to 0.58$)$.

The results summarized in Tables 12 and 13 present the quantitative differences obtained by MAGIC with the four organic acid analog models and without organic acids. A mean bias (offset) of $0.62 \mathrm{pH}$ units was found between diatom and MAGIC model estimates of pre-industrial pH when no organic acid analog was included. This bias was reduced to mean differences of 0.17 to $0.25 \mathrm{pH}$ units with inclusion of the various organic acid analog models. Choice among the various organic acid analog models investigated did not have a substantial effect on the degree of agreement with diatom estimates. Although inclusion of a "reasonable" organic acid representation in the MAGIC simulations greatly improved agreement with diatom pH estimates, the selection of which of the four organic acid models to use was not particularly important for the regional analysis.

The extent to which the inclusion of an crganic acid representation in MAGIC alters our estimates of historic acidification for the population of low ANC (DDRP) Adirondack lakes is illustrated in Figure 7. All three methods of estimating pre-industrial pH that are shown in the figure (diatoms, MAGIC without organics, and MAGIC with triprotic organic acid) result in cumulative frequency distributions of $\mathrm{pH}$ that are higher than current measured (ELS-I) $\mathrm{pH}$. The 
Table 13. Comparisons between the various MAGIC model estimates of current (1984) $\mathrm{pH}$ and $\mathrm{pH}$ values measured by the ELS-I.

\begin{tabular}{|c|c|c|c|c|}
\hline \multirow{2}{*}{$\begin{array}{c}\text { Organic acid } \\
\text { formulation in MAGIC } \\
\text { model application }\end{array}$} & \multicolumn{2}{|c|}{$\begin{array}{c}\text { ELS-I minus MAGIC } \\
\text { pH estimates }\end{array}$} & \multicolumn{2}{|c|}{$\begin{array}{c}\text { ELS-I measured minus } \\
\text { ELS-I predicted' }\end{array}$} \\
\hline & Mean & RMS & Mean & RMS \\
\hline Monoprotic & 0.24 & 0.58 & 0.30 & 0.44 \\
\hline Diprotic & 0.19 & 0.54 & 0.24 & 0.37 \\
\hline Triprotic & 0.18 & 0.52 & 0.22 & 0.35 \\
\hline Oliver & 0.16 & 0.51 & 0.20 & 0.34 \\
\hline No organic acid & -0.23 & 0.52 & -0.21 & 0.39 \\
\hline
\end{tabular}

' ELS-1 predicted $\mathrm{pH}$ was calculated using the MAGIC algorithm and input variables from ELS-I and the respective organic acid analog model. The $P_{C O}$ input variable was calculated from measured $\mathrm{pH}$ and DIC, using PK's of inorganic carbon reactions from the literature.

diatom estimates suggest the least amount of acidification, and MAGIC without organic acids suggests the greatest amount of acidification. MAGIC estimates with a triprotic organic acid are intermediate, but are closer to diatom estimates than to the MAGIC estimates without organics. The differences between the methods are most pronounced at the lowest end of the $\mathrm{pH}$ distribution. MAGIC without organics exhibited a pre-industrial pH distribution with a minimum $\mathrm{pH}$ that was a full $\mathrm{pH}$ unit higher than did MAGIC with the triprotic acid.

\subsection{Acid Neutrallzing Capacity (ANC)}

Diatom inference equations have been developed and applied for estimating acid neutralizing capacity (ANC) of lakewater (e.g. Sullivan et al. 1990, Cumming et al. 1992). ANC has been considered in some cases to be, a better indicator of a water's acid-base status than $\mathrm{pH}$. The definition of "acidic" is often based on water having Gran titration ANC less than zero (e.g., NAPAP 1991). The principal advantage of ANC over pH for quantifying acidity, or the extent of 


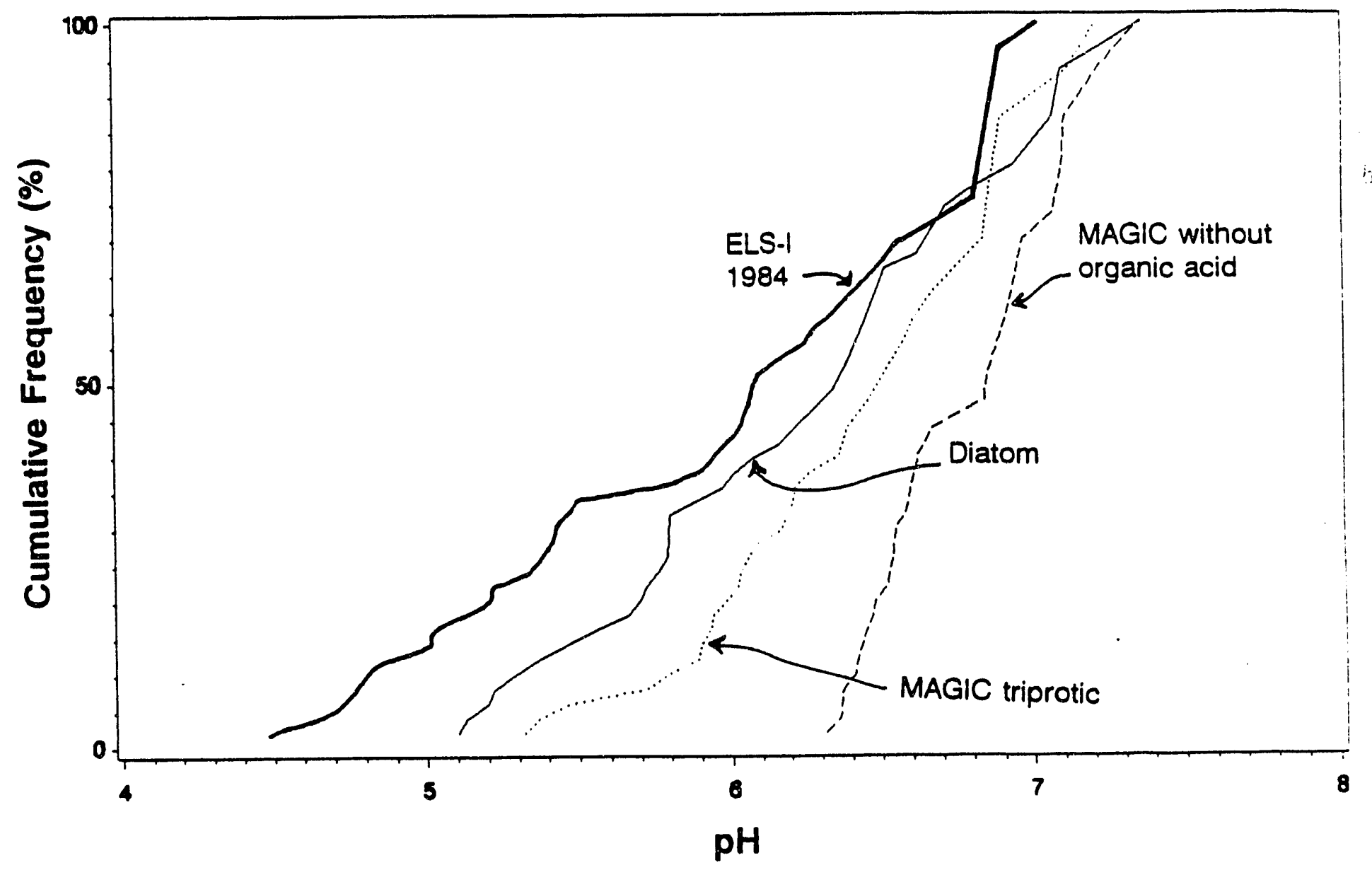

Figure 7. Cumulative frequency distributions of current measured pH from ELS-I and estimates of pre-industrial pH using three different approaches (diatoms, MAGIC with the triprotic organic acid, and MAGIC without an organic acid representation).

Distributions were derived using population weighting factors developed for the DDRP (Church et al. 1989), and were based on the subset of 33 lakes. 
change in acid-base status, is that ANC is more stable than $\mathrm{pH}$. For example, $\mathrm{pH}$ varies with changes in dissolved $\mathrm{CO}_{2}$ in response to in-lake biological activity (photosynthesis and respiration). The influence of $\mathrm{P}_{\mathrm{CO}_{2}}$ on lakewater $\mathrm{pH}$ varies diurnally and seasonally, especially in systems having $\mathrm{pH}$ greater than about 5.5 and in systems that are highly productive but not well buffered.

No single chemical parameter, however, is sufficient for characterizing surface water acidbase status. Indeed, Hemond (in press) suggested that at least three of the following four parameters must be known:

1. $\mathrm{pH}$

2. $P_{\mathrm{CO}_{2}}$ or total carbonate content $\left(C_{T}\right)$

3. $C_{B} \cdot C_{A}$ (sum of base cations minus mineral acid anions)

4. Organic acid concentration

In some cases, aluminum concentration is also important.

There are two potentially-important problems associated with an assessment of historical acidification of lakewaters based on diatom inference of ANC. First, there are uncertainties and differences in the way ANC is defined. Diatom reconstructions and lakewater measurements are generally based on Gran titration ANC. Models, including MAGIC, calculate ANC as $C_{B}-C_{A}$. Measures of ANC based on those two definitions usually differ, largely because of the partially counteracting influences of $\mathrm{Al}$ and organic scids on the titration results (Sullivan et al. 1989, Figure 8). The Al influence causes a shift to higher Gran ANC for acidic lakes, and the organic acid influence causes a shift to lower Gran ANC, especially for higher ANC lakes. Sullivan et al. (1991) corrected for this problem in the earlier MAGIC/diatom comparison for Adirondack lakes by calibrating the diatoms to ANC defined in a way equivalent to that used in MAGIC. .

The second potential problem witti the use of diatom-inferred ANC concerns the strong correlation between $\mathrm{pH}$ and $\mathrm{ANC}$ in natural waters. Diatoms are very sensitive to $\mathrm{pH}$ (Patrick et al. 1968 , Gensemer and Kilham 1984, Smith 1990), which is an important controlling variable for 


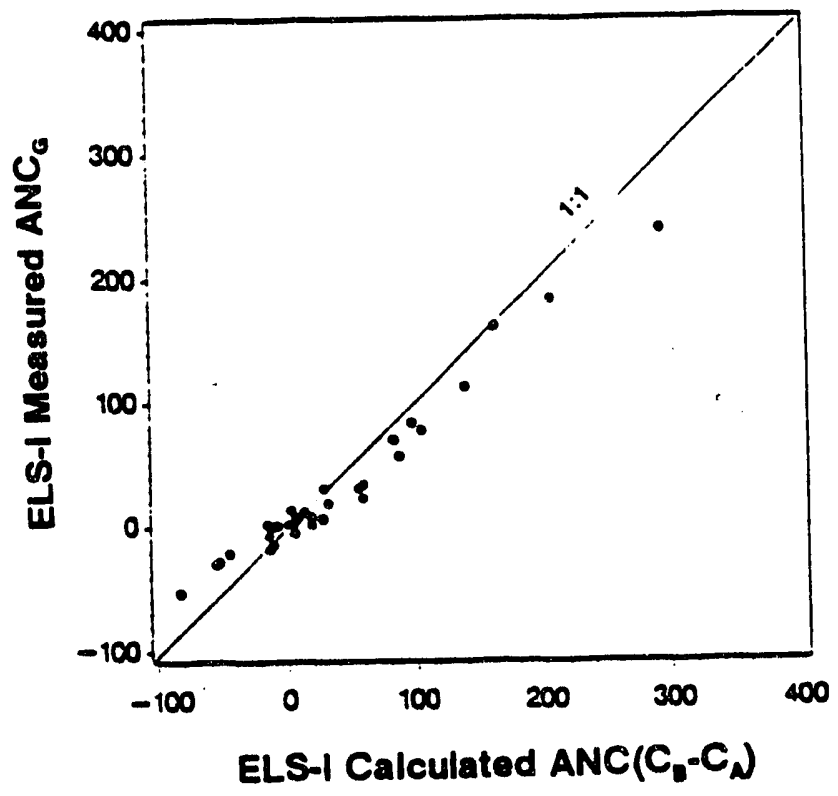

Figure 8. Comparison of calculated $\left(C_{B}-C_{N}\right)$ versus Gran titrated $A N C$ for the study lakes using data from the ELS-I. $\mathrm{C}_{B}$ is the sum of $\mathrm{Ca}^{2+}, \mathrm{Mg}^{2+}, \mathrm{Na}^{+}, \mathrm{K}^{+}$, and $\mathrm{NH}_{4}^{+} ; \mathrm{C}_{A}$ is the sum of $\mathrm{SO}_{4}^{2 \cdot}, \mathrm{NO}_{3}$, and $\mathrm{Cl}^{-}$concentrations. (Source: Sullivan et al. 1991). 
many chemical and physiological reactions. In contrast, ANC is an artificially-constructed parameter with no known relationship to physiological response of aquatic organisms. Gran ANC is operationally defined; ANC defined as $C_{B}-C_{A}$ is specified on the basis of charge balance considerations and is subject to cumulative measurement errors. A major concern is that the biota may be responding principally to $\mathrm{pH}$ and secondarily to such factors as dissolved metals, organic acids, and salinity, whereas the observed robustness of the diatom inferences of current ANC may be largely controlled by the strong correlation between $\mathrm{pH}$ and ANC. If the lakes have changed historically in their $\mathrm{pH} / \mathrm{ANC}$ relationships, then diatomi-inferences of historic ANC might be biased. Furthermore, it is not unreasonable to assume that the $\mathrm{pH} / \mathrm{ANC}$ relationship in Adirondack lakewaters may have changed since pre-industrial times, in view of the presumed increases in lakewater $\mathrm{SO}_{4}{ }^{2 \cdot}, \mathrm{Al}$, and $\mathrm{C}_{\mathrm{B}}$ concentrations. The quantitative importance of such a change for historic ANC reconstructions is not known.

In view of the potential complicating factors described above, we judged that historic comparisons of water chemistry conducted in this project should focus primarily on $\mathrm{pH}$, rather than ANC. In addition, to provide some comparison of diatom and MAGIC estimates of ANC, while attempting to correct for the latter problem, paleolimnological estimates of ANC were recalculated from diatom-inferred $\mathrm{pH}$. This was accomplished using the algorithms in MAGIC for calculating ANC, given $\mathrm{pH}, \mathrm{P}_{\mathrm{CO}_{2}}, \mathrm{~K}_{\mathrm{N}}, \mathrm{DOC}$, and the $\mathrm{pK}$, values and site density of organic acids specified in the various organic acid analog models.

Results of the pairwise comparisons between MAGIC and diatom estimates of pre-industrial and current ANC are summarized in Table 14, based on MAGIC simulations and diatom reconstructions corrected with the four organic acid analog models and without organics. A mean bias (offset) of $-48 \mu \mathrm{eq} L^{-1}$ of ANC was found between diatom and MAGIC estimates of preindustrial ANC when no organic acid analog was included. This bias was reduced to mean differences of -8 to $-11 \mu \mathrm{eq} L^{-1}$ with inclusion of the various organic acid analog models. 
Table 14. Differences between MAGIC and diatom model estimates of pre-industrial (1844) and current (1984) ANC estimates for the 33 lake Adirondack data set, based on five different MAGIC model applications.

\begin{tabular}{lccccc}
\hline $\begin{array}{c}\text { Organic Acid } \\
\begin{array}{c}\text { Formulation in MAGIC } \\
\text { Model Application }\end{array}\end{array}$ & $\begin{array}{c}\text { Mean } \\
\text { Difference }\end{array}$ & $\begin{array}{c}\text { RMS of } \\
\text { Difference }\end{array}$ & & $\begin{array}{c}\text { Mean } \\
\text { Difference }\end{array}$ & $\begin{array}{c}\text { RMS of } \\
\text { Difference }\end{array}$ \\
\hline Monoprotic & 8 & 46 & -32 & 126 \\
Diprotic & 9 & 47 & -30 & 128 \\
Triprotic & 9 & 47 & -30 & 128 \\
Oliver & 1 & 48 & -28 & 129 \\
No organic acid & 48 & 69 & 6 & 119 \\
\hline \hline
\end{tabular}

Graphical comparison of pre-industrial and current estimated ANC values (Figure 9) illustrates that much of the bias (mean difference) between MAGIC and the diatoms may be due to those lakes inferred by the diatom approach to be very low $\left(<-50 \mu e q L^{-1}\right)$ or very high $\left(>300 \mu e q L^{-1}\right)$ in ANC. This is attributable to the difficulty of calculating ANC from $\mathrm{pH}$, using the method employed here, for lakes having $\mathrm{pH}$ less than about 5.0 or greater than about 7.0 .

The difficulty can be understood by consideration of a typical pH-ANC titration curve. At very high or very low values of ANC, the titration curve is relatively flat; large changes in ANC result in only small changes in $\mathrm{pH}$. The problem of estimating ANC from $\mathrm{pH}$ is, therefore, subject to the inverse sensitivity; small errors (or natural variation) in pH results in large errors (or noise) in estimated ANC. As seen in Figure 9, these effects do appear to limit the ANC range over which these corrections can be applied to provide unbiased diatom estimates of ANC. In general, however, when the very high and very low values are ignored, the agreement between ANC estimates from MAGIC and the diatoms appears to be reasonably good both historically and for the present day. 
A)

1844 ANC Comparison

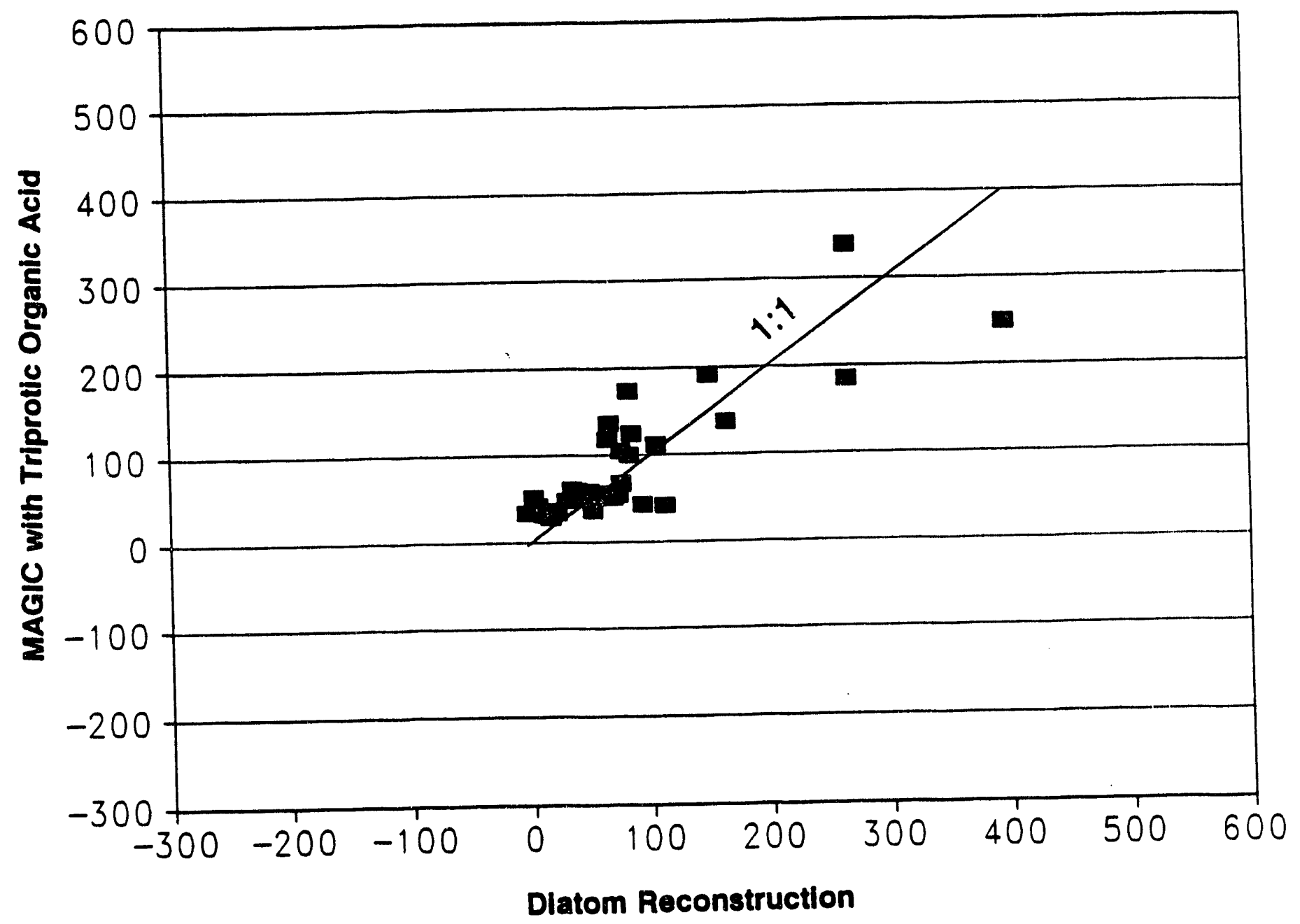

Figure 9. MAGIC model estimates of ANC versus diatom-inferred ANC (calculated as described in text from diatom-inferred $\mathrm{pH}$ ) for 33 statistically selected Adirondack lakes: A) preindustrial estimates; B) current estimates. 
B)

1984 ANC Comparison

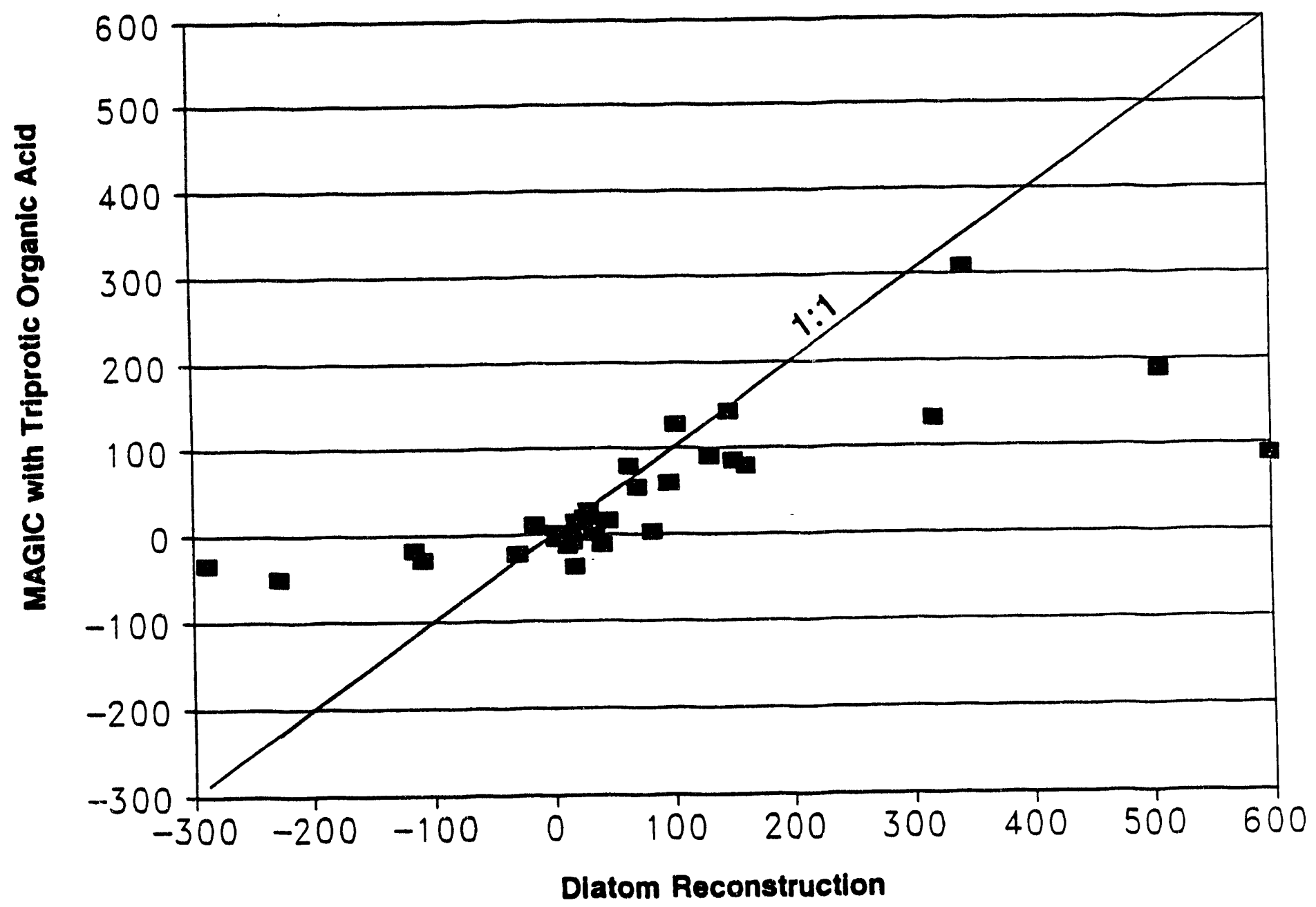

Figure 9. Continued. 


\subsection{DISCUSSION}

\subsection{Comparisons Botween MAGIC and Diatom Estimates of Acld-Base Status}

\subsection{1. $\mathrm{pH}$}

Results of the hindcast comparisons between paleolimnological inferences of pre-industrial lakewater $\mathrm{pH}$ and MAGIC simulations, with and without the inclusion of organic acids, illustrate three important points:

1. There is a systematic departure with decreasing $\mathrm{pH}$ between diatom and MAGIC model hindcasts of pre-industrial pH when organic acids are not included in the MAGIC simulations.

2. Inclusion of a reasonable formulation for organic acidity in the MAGIC simulations of preindustrial pH greatly improves their agreement with diatom reconstructions.

3. The choice among organic acid analog models (e.g., mono-, di-, triprotic, or Oliver model) does not alter the degree of agreement with diatom reconstructions to an appreciable degree for a regional analysis.

The inclusion of organic acids in the MAGIC model simulations of pre-industrial pH did not alter the agreement between diatom and MAGIC model hindcasts for lakes with $\mathrm{pH}$ values greater than about 6.5. Previous hindcast comparisons (Sullivan et al. 1991) that did not include an organic acid representation had obtained good agreement for these high-pH lakes. For low-pH lakes, however, the lack of organic acid representation resulted in an increasing level of divergence between diatom and MAGIC model hindcasts of pre-industrial $\mathrm{pH}$ for the lower-pH lakes. Thus, the lakes of most relevance with respect to potential biological effects of acidification, especially those having pH less than 5.5, exhibited increasingly larger discrepancies with decreasing $\mathrm{pH}$ between diatom and MAGIC model estimates of pre-industrial pH when organic acids were omitted from the analysis. The inclusion of an organic acid representation in the MAGIC simulations conducted in this study resulted in a great improvement in the agreement between these two modeling approaches. Coupling of Driscoll's triprotic organic acid analog model to MAGIC resulted in pre-industrial pH estimates that were, on average, $0.4 \mathrm{pH}$ units closer to diatom estimates than were the MAGIC hindcasts that excluded organics. For lakes having $\mathrm{pH}$ less than 6.0, the improvement was even more pronounced; inclusion of the triprotic organic acid 
analog model reduced the discrepancy between diatom and MAGIC pH hindcasts for these lakes by 0.6 of a pH unit, from a mean difference of 0.8 to a mean difference of 0.2 . For some individual lakes, the improvement was a full pH unit.

\subsubsection{Acid Noutralizing Capacity}

Inclusion of organic acids in the modeling approach also improved the agreement between diatom and MAGIC model estimates of pre-industrial ANC. This comparison is more problematic than the pH comparison, however, and should be interpreted with some caution. Results of the ANC hindcast estimates for the diatom approach presented in this report were not based directly on diatom transfer functions for ANC, as was done by Sullivan ot al. (1991). Instead, diatominferred pre-industrial pH was used as a predictor of diatom-derived pre-industrial ANC, using a

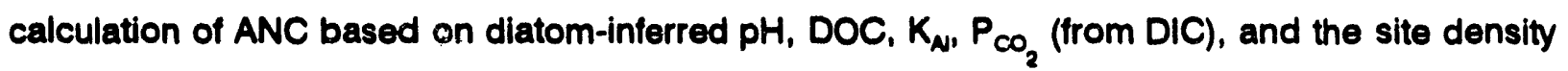
and $\mathrm{pK}$, values of organic acids. For this calculation, DIC, DOC, pK,'s and site density were assumed to be constant over time. Direct diatom estimates of pre-industrial ANC, via transfer functions, were not used because of the following concerns:

1. Diatom-inferred ANC is probably not independent of the $\mathrm{pH}$ reconstructions. In other words, the biota may respond principally to $\mathrm{pH}$, which in turn is highly correlated with ANC.

2. The currently observed statistical relationship between $\mathrm{pH}$ and ANC for the group of lakes is unlikely to be identical to the historic relationship. This is primarily because the ANC of many of the lakes has changed, leading to a change in the shape of the ANC/pH relationship, even if DOC concentrations have not changed (e.g., Hemond 1990).

3. If 1 and 2 are true, then pre-industrial estimates of ANC, based on diatom inference equations derived for current ANC, will be biased.

The alternative approach was used of calculating diatom-inferred ANC from diatom-inferred pH. Nevertheless, the ANC comparisons presented in Figure 9 are not without problems. Although the ANC estimates derived for lakes in the range of ANC values between about -50 and 300 req $L^{-1}$ show good agreement between MAGIC-triprotic and diatom inferences for both current and pre-industrial chemistry (Figure 9a,b), considerable divergence was observed for lakes at the 
extremes of the ANC distribution (Figure 9b). This is attributable to the substantial problem of estimating ANC from pH at the extremes of the titration curve. See discussion of this issue in Section 5.2 .

The approach used here for estimating diatom-inferred ANC from diatom-inferred pH differs from direct diatom inferences of ANC as shown in Figure 10. There are possible problems with both methods, and it is not entirely clear which is most appropriate. The ANC inferences that are derived from pH are generally in closer agreement with the MAGIC estimates of ANC, however, than are the direct diatom inferences.

Thus, we emphasize that the $\mathrm{pH}$ comparisons are more robust than the ANC comparisons, and the latter should be interpreted with caution. The $\mathrm{pH}$ reconstructions are also more important because of the biological relevance of $\mathrm{pH}$. Effects of acidic deposition on fish and other aquatic biota are caused mainly by changes in $\mathrm{pH}, \mathrm{Al}^{\mathrm{n}+}$, and $\mathrm{Ca}^{2+}$ (Baker et al. 1990). There is no known physiological basis for direct effects from ANC on diatoms, fish, or any other aquatic biota, although ANC is often correlated with physiologically important parameters.

\subsubsection{Carbon Dioxide and Seasonal Effects}

A portion of the remaining observed discrepancy between diatom and MAGIC estimates of $\mathrm{pH}$, in both 1984 and 1844, may be attributable to the effects of dissolved $\mathrm{CO}_{2}$ on $\mathrm{pH}$ measurements. The algorithm used in the MAGIC modeling exercise to calculate $\mathrm{pH}$ is based on a number of equilibrium expressions, including the dissociation of carbonic acid, which is formed when $\mathrm{CO}_{2}$ combines with water. In contrast, the diatom inference equations that were derived in the PIRLA-II project, and used in this study, were calibrated to air-equilibrated pH values. Thus, the influence of dissolved $\mathrm{CO}_{2}$, which depresses $\mathrm{pH}$ values, is not reflected in the diatom-inferred $\mathrm{pH}$ values for the study lakes. The use of air-equilibrated $\mathrm{pH}$ in the diatom calibrations potentially has a greater effect on lakes having $\mathrm{pH}$ greater than about 5.5. Air-equilibrated pH 


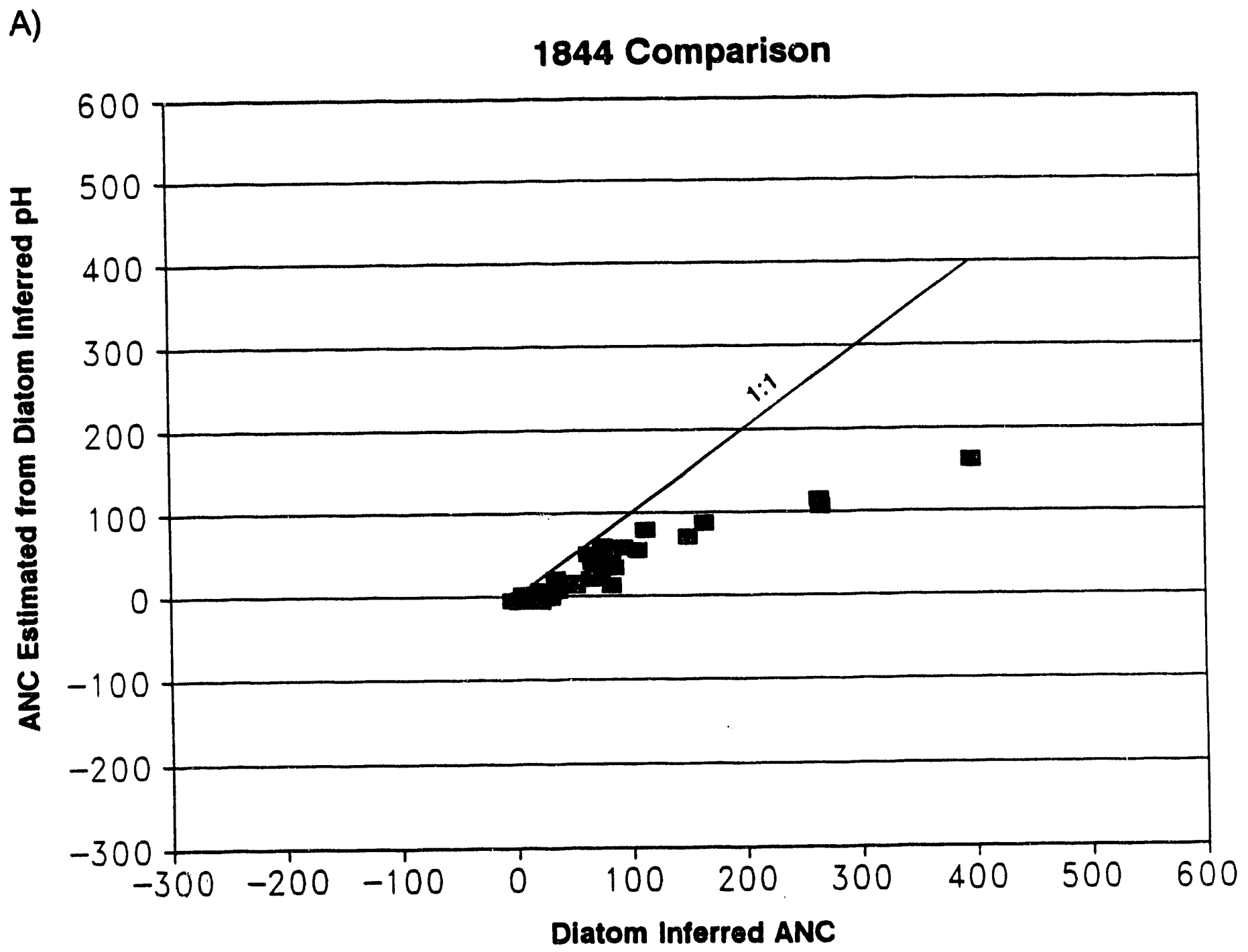

Figure 10. ANC estimated from diatom-inferred $\mathrm{pH}$, using the MAGIC algorithm that includes DOC, $K_{N}, P_{C O}$, and the site density and $p K_{2}$ values of organic acids, versus direct diatom inferences of ANC. Comparisons are presented for A) 1844 and B) 1984. 
B)

1984 Comparison

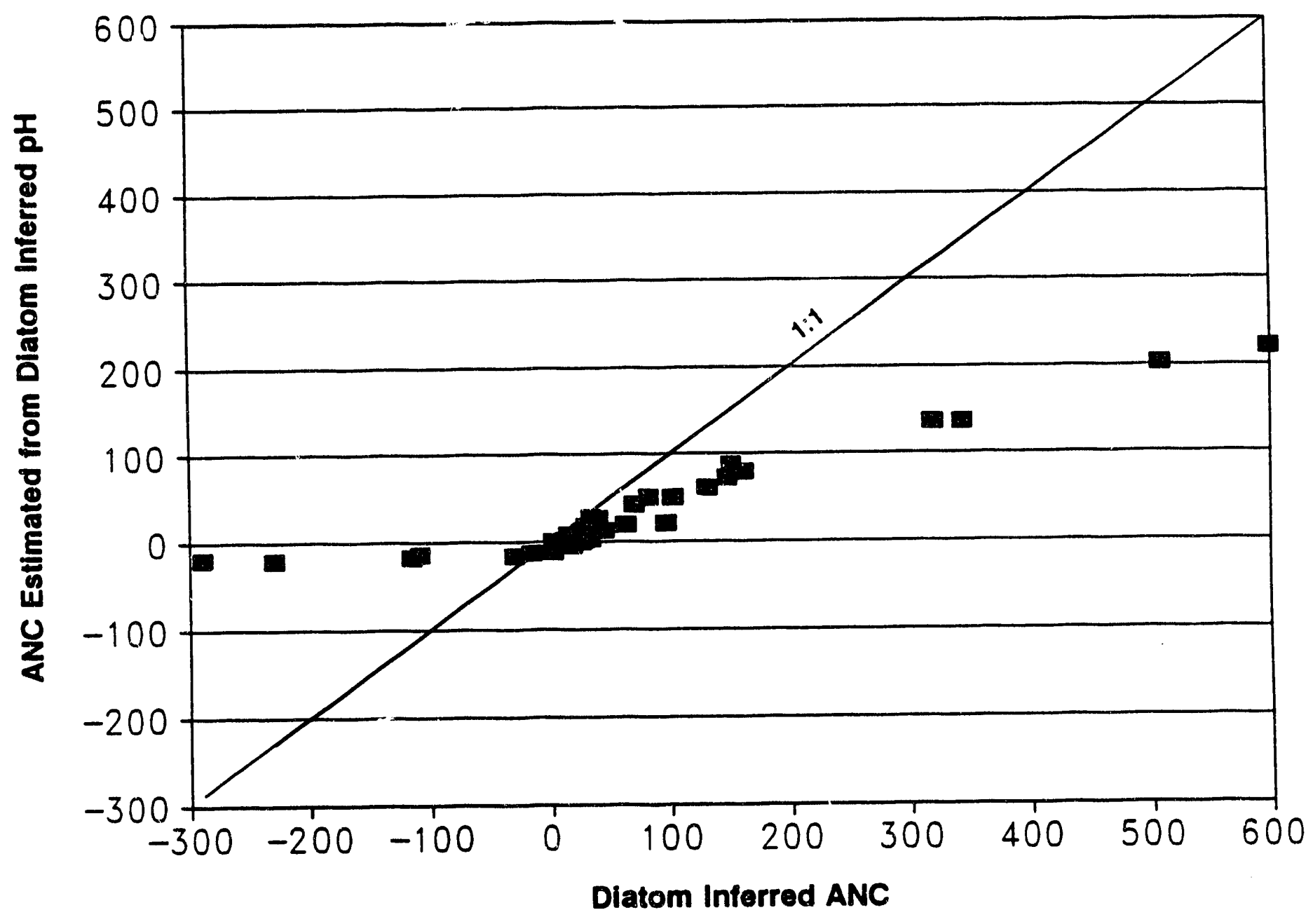

Figure 10. Continued. 
values are generally higher than non-equilibrated values, and the discrepancy increases with increasing $\mathrm{pH}$ for the ELS-1 lakes in the Adirondack Mountains.

In addition to differential $\mathrm{CO}_{2}$ effects on the diatom-inferred $\mathrm{pH}$ values versus the $\mathrm{pH}$ values calculated by MAGIC, this comparison could also be biased by any potential differences in chemical methods employed by the two studies to which the models were initially calibrated (PIRLA-II and ELS-I). Furthermore, ELS-I was conducted during the fall season, whereas PIRLA $\mathrm{pH}$ values were collected during summer. Differences in sampling methods, seasonal effects, and $\mathrm{CO}_{2}$ saturation might account for at least part of the remaining discrepancies between MAGIC and diatom model estimates of $\mathrm{pH}$ (see additional details in Appendix B).

\subsection{Relative Magnitude of the Dlscrepancies Between Models}

Although inclusion of an organic acid representation clearly improved the agreement between MAGIC and diatom estimates of pre-industrial $\mathrm{pH}$, it is useful to put the extent of agreement into perspective. It is unclear how closely one should expect the hindcast results to agree, given two fundamentally different modeling approaches. Also, in addition to the fundamental differences in approach, the tools may not always be estimating the same thing; paleolimnological techniques reconstruct changes in chemistry from all causes, whereas the MAGIC model estimates changes in response to sulfur deposition only. We can obtain some indication, however, of the extent of agreement that might be reasonable by examining simulated versus observed values for current chemistry. A plot of predicted $1984 \mathrm{pH}$, using MAGIC with the triprotic organic acid representation, versus the measured pH values obtained in 1984 by the ELS-I is depicted in Figure 5. The mean difference of $0.22 \mathrm{pH}$ units and root mean squared difference $(0.33 \mathrm{pH}$ units) for the triprotic model were generally similar to the differences obtained between the diatom and triprotic model estimates for both 1984 and 1844 simulations $(0.29$ and $0.21 \mathrm{pH}$ units, respectively; Table 12). In other words, the MAGIC triprotic model matched diatom estimates about as well as it matched measured values. Similar results were also found for the Oliver 
model, with progressively poorer agreement between measured and simulated pH using the diprotic acid and monoprotic acid models, respectively (Table 12).

Alternatively, a measure of the reasonableness of agreement between diatom and MAGIC estimates can be evaluated by examining the differences in measured $\mathrm{pH}$ values obtained in fall, 1984 by the ELS-I and those obtained in Fall, 1986 by the ELS-II (Figure 11), using the same methods. The mean difference between 1984 and 1986 measurements was $0.1 \mathrm{pH}$ units. Thus, annual variability could account for a portion of the differences.

Based upon the differences between calculated and measured $\mathrm{pH}$ and upon the differences between $\mathrm{pH}$ measured in 1984 and 1986, some perspective can be gained regarding the extent of bias and scatter that should be expected in a comparison between MAGIC and diatom estimates of $\mathrm{pH}$. A comparison between MAGIC simulated $\mathrm{pH}$ and $\mathrm{pH}$ estimated via any independent modeling approach would not be expected to exhibit a mean difference less than about 0.2 or a root mean squared difference less than about $0.3 \mathrm{pH}$ units. Thus, the diatom estimates and MAGIC triprotic estimates of pre-industrial pH agreed nearly as closely as one could expect, given the uncertainties inherent in the model formulations.

One could also ask the question as to whether the MAGIC and diatom estimates of preindustrial $\mathrm{pH}$ should agree. Diatom estimates of $\mathrm{pH}$ have been compared with measured $\mathrm{pH}$ values at numerous lake sites where changes in acid-base status have occurred. Such validations of the diatom approach have been performed for lakes that have been acidified and lakes that have recovered from acidification or have been limed in Canada (e.g., Dixit et al. 1987, 1991, 1992), Sweden (e.g., Renberg and Hultberg 1992), and Scotland (e.g., Allot et al. 1992). Diatom-inferred pH histories generally agree reasonably well with the timing, trend, and magnitude of known acidification and deacidification periods. In several cases, however, the sedimentary reconstructions were slightly damped in comparison with measured values. That is, the diatom reconstructions did not fully reflect the magnitude of either the water $\mathrm{pH}$ decline or subsequent recovery. 


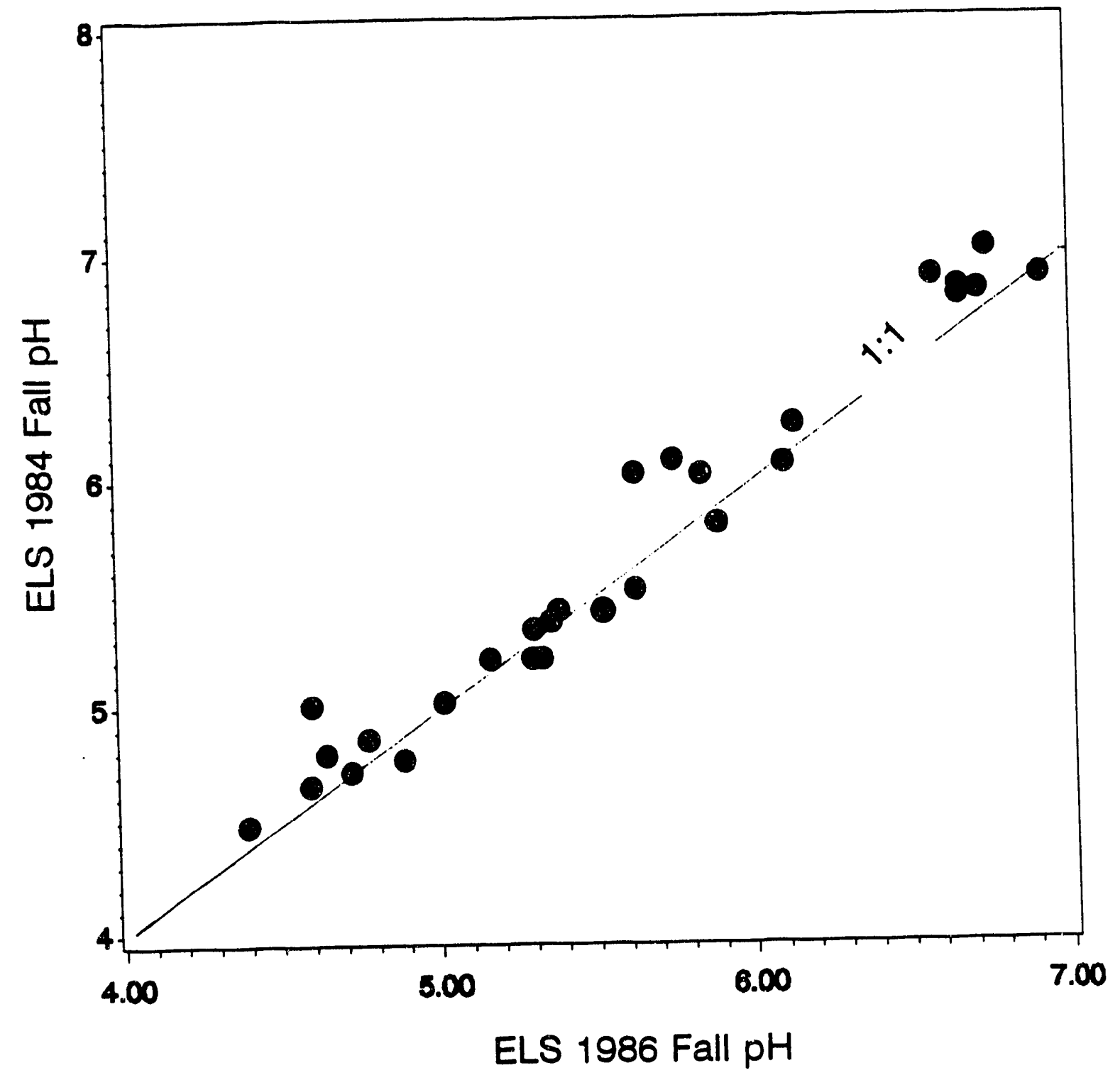

Figure 11. Measured pH (non-equilibrated) values obtained in 1984 by the ELS-I versus measured values obtained in 1986 by the ELS-II for the 33 study lakes. Both surveys collected measurements during the fall season using the same methods. 
Renberg and Hultberg (1992) compared diatom-inferred pH reconstructions with the known $\mathrm{pH}$ history for several decades at Lake Lysevatten in southwestern Sweden. The diatom-inferred $\mathrm{pH}$ history agreed well with both the acidification period of the 1960 s and early 1970 s and also the liming that occurred in 1974 . The magnitude of $\mathrm{pH}$ change inferred from sedimentary reconstructions was slightly smalier, however, than the measured changes in $\mathrm{pH}$ for both acidification and deacidification.

Allot et al. (1992) found diatom reconstructions of pH recovery in the deacidifying Round Loch of Glenhead, Scotland to be somewhat smaller than the measured pH recovery since the late 1970s. The authors attributed this difference to attenuation of the reconstructed $\mathrm{pH}$ record due to sediment mixing processes.

Dixit et al. (1992) analyzed sedimentary diatoms and chrysophytes from Baby Lake (Sudbury, Ontario) to assess trends in lakewater chemistry associated with the operation, and closure in 1972, of the Coniston Smelter. Extremely high sulfur emissions caused the lake to acidity from $\mathrm{pH} \approx 6.5$ in 1940 to a low of 4.2 in 1975 . Following closure of the smelter, lakewater pH recovered to pre-industrial levels. The diatom-inferred acidification and subsequent recovery of the lake corresponded with the pattern of measured 'alues. However, the diatom-inferred pH response was more compressed and did not fully express the amplitude of the $\mathrm{pH}$ decline or the extent of subsequent recovery.

Comparisons of lakewater chemistry between pre-industrial and modern times also may be sensitive to a number of factors that are not represented in process models of acidification. Changes in acid base chemistry may have occurred in response to climatic differences, anthropogenic activities (e.g., logging, road building), forest growth, or beaver abundance, for example. These changies are expected to be reflected in diatom reconstructions, but not process model simulations. The influence of such factors on historic changes in lakewater chemistry is poorly known.

It is not known why diatom-inferences of $\mathrm{pH}$ change are often slightly attenuated relative to measured acidification or deacidification. Possible explanations include the preference of many 
diatom taxa for benthic habitats where $\mathrm{pH}$ changes may be buffered by chemical and biological processes. Alternatively, such an attenuation could be an artifact of the averaging techniques used to infer past water chemistry. It is thus not surprising that the MAGIC simulations that included organic acid representations estimated pre-industrial pH values slightly higher than diatom-inferred values. It is not possible to determine which method provides estimates closer to reality. It is reassuring, however, that they provide results that are generally in close agreement.

These results demonstrate that 1) organic acids should be considered in modeling the response of lakewaters in the Adirondack Mountains to acidic deposition, and 2) once organic acids are included in the modeling effort, reasonable agreement is obtained in hindcast comparisons with diatom-inferred pH. It should be emphasized, however, that the test presented here included only two points in time, and essentially only $\mathrm{pH}$. MAGIC, and other process models, require further testing and validation. Many important geochemical processes are not well represented in the model or the input data, and it is not clear how this might affect model results. In particular, there remain problems in simulating hydrological flow paths, aluminum dynamics, and nitrogen processing.

\subsection{Importance of Findings}

The results of this intercomparison are important for acidic deposition assessment activities in two respects. First, this study is the first to show quantitative agreement between changes in $\mathrm{pH}$ of natural aquatic systems subjected to acidic deposition, as estimated by two independent and conceptually different approaches over a large geographic region and over a long temporal span. Previous model verification and validation studies have been of relatively short duration (e.g. Norton et al. 1992), site specific (e.g. Renberg and Hultberg 1992), or comparisons among two or more models that share many fundamental assumptions (e.g., Cook et al. 1992). Second, and perhaps more importantly, this demonstrated agreement between MAGIC and paleolimnological model hindcast estimates of lakewater $\mathrm{pH}$ is dependent upon inclusion of organic acids in the 
process model. The latter result was obtained despite the relatively low levels of DOC in the study lakes (mean value $=313 \mu \mathrm{M}$ ). The importance of organic acids in achieving reliable model results probably increases with increasing lakewater DOC. Such a contention is supported by preliminary results emerging from the Humic Lake Acidification Experiment (HUMEX) in which half of a wetland-dominated catchment, and the respective half of the lake it drains into, are being artificially acidified with sulfuric and nitric acids (Gjessing 1992).

Thus, we have shown here that long-term projections of the effects of acidic deposition on surface water $\mathrm{pH}$ are sensitive to the dynamics of organic acids for lakes having only moderate concentrations of DOC. Future assessment activities, such as those conducted previously by NAPAP (1991) and those on-going in Europe in conjunction with the critical loads debates and mapping activities (e.g., Bull 1992, Forsius et al. 1992), should consider organic acid effects in the process models used in conducting assessments. Failure to include consideration of organic acids may introduce substantial bias into the assessment results regarding $\mathrm{pH}$ and associated biological effects.

\subsection{CONCLUSIONS}

Research in recent years has clearly demonstrated that organic acids are important contributers to the acidity of fresh waters. Although naturally-occurring organic acids are complex and variable in their acid-base characteristics, they have considerable strong acid character and can substantially lower the $\mathrm{pH}$ of natural waters. Furthermore, organic acids increase the buffer capacity of surface waters, thereby making them less susceptible to acidification in response to atmospheric inputs of mineral acids.

Despite the weil-documented importance of organic acids in regulating or modifying both the acid-base character of fresh waters and the acidification response, recent model projections of future changes in the chemistry of lakes and streams in the eastern United States to changes in acidic deposition have not considered these important processes in the model formulations (e.g., Church et al. 1989, NAPAP 1991). Also, a recent comparison between diatom-inferred pre- 
industrial $\mathrm{pH}$ and model hindcasts of pre-industrial $\mathrm{pH}$, using the MAGIC model, for a statisticallyselected set of 33 Adirondack lakes showed poor agreement when organic acids were not included in the MAGIC model formulations (Sullivan et al. 1991). Preliminary analyses conducted by Sullivan et al. (1991) further suggested that inclusion of a reasonable organic acid representation into MAGIC would improve the agreement between MAGIC and diatom estimates of pre-industrial $\mathrm{pH}$.

The research described herein is a continuation of the research conducted by Sullivan et al. (1991). A triprotic organic acid analog model was developed, based on data collected by the Adirondack Lakes Survey Corporation (ALSC) from 1400 lakes located in the Adirondack Mountains of New York (Driscoll et al. 1990, in review). A good fit was obtained between measured and modeled lakewater pH using calibrated values of the organic acid site density of $0.055 \mathrm{~mol}$ sites per mol $\mathrm{C}$ and calibrated pK values of $2.62,5.66$, and 5.94 . This triprotic organic acid analog model was combined with the MAGIC model and the revised MAGIC simulations of current and pre-industrial pH were compared with the diatom-inferred $\mathrm{pH}$ values. MAGIC projections of pre-industrial pH were in much closer agreement with the diatom estimates when the organic acid model was included, even without further calibration of the parameters of the organic acid model. MAGIC estimates of pre-industrial pH were, on average, $0.6 \mathrm{pH}$ units higher than diatom estimates when organic acids were not included in the model simulations, but only $0.2 \mathrm{pH}$ units higher when organic acids were included. This difference was even more pronounced for lakes having pH less than 6.0 (i.e., those of greatest biological relevance with respect to acidification effects). For those lakes, the average $\mathrm{pH}$ difference improved from $0.8 \mathrm{pH}$ units to $0.2 \mathrm{pH}$ units, upon inclusion of the triprotic organic acid analog model.

A series of sensitivity analyses were conducted to evaluate the influence of several potential confounding factors and uncertainties on the comparison results. It was found that the results of the regional comparison were relatively insensitive to the exact nature of the organic acid analog model. Alternative monoprotic and diprotic models and also the Oliver et al. (1983) model gave 
results that were generally similar to those of the triprotic model. Furthermore, the nature of the aluminum formulations in the model (based on extractable Al or total Al) and the manner in which $\mathrm{P}_{\mathrm{CO}_{2}}$ and $\mathrm{K}_{\mathrm{N}}$ were derived (site specific or regional average values) had only minor influences on the regional comparison results.

The inclusion of the triprotic organic acid analog model with MAGIC removed most of the substantial blas that had been observed between MAGIC and diatom estimates of pre-industrial $\mathrm{pH}$ (Figures 3 and 4). Furthermore, the differences between MAGIC and diatom estimates of preindustrial pH based on the MAGIC/triprotic model were well within the range of expected differences due to annual and seasonal variability, uncertainties in the algorithm used to calculate $\mathrm{pH}$ from measured ion chemistry, and the influence of dissolved $\mathrm{CO}_{2}$ on the measured airequilibrated $\mathrm{pH}$ values that were used to calibrate the diatom model. Although further model testing is needed. the inclusion of organic acids in MAGIC is a necessary and important component of modeling the effects of acid deposition on surface water chemistry using this model.

This research demonstrates that naturally-occurring organic acids can have a substantial effect on model projections of past surface water chemistry. Even for lakes having relatively low levels of DOC, the failure to include a reasonable organic acid representation in the model formulation can introduce considerable bias into model estimates of past $\mathrm{pH}$. Although the extent to which model projections of future chemistry might also be biased by a failure to include organic acids in the model simulations is not known, this research suggests that organic acids play an important role in model simulations and should be included in any model assessment of past or future acidification.

Future research needs have been identified that are important for making further improvements in both the diatom and MAGIC models. In particular, further testing against measured data is required. The various factors that influence the acid-base chemistry of surface water, other than acidic deposition, also warrant further research. Additional uncertainties involve 
hydrological flowpaths, effects of strong acid additions on DOC structure, and organo-metal interactions. 


\subsection{LITERATURE CITED}

Alken, R.R., D.M. McKnight, R.L. Wershaw, and P. MacCarthy, eds. 1985. Humic Substances in Soll, Sediment, and Water. Wiley, New York.

Allot, T.E.H., R. Harriman, and R.W. Battarbee. 1992. Reversibility of lake acidification at the Round Loch of Glenhead, Galloway, Scotland. Environ. Pollut. 77:219-225.

Almer, B., W. Dickson, C. Ekstrфm, E. Hфrnstrфm, and U. Miller. 1974. Effects of acidification on Swedish lakes. Ambio 3:30-36.

ALSC. 1990. Adirondack Lake Survey: An Interpretive Analysis of Fish Communities and Water Chemistry, 1984-87. J.P. Baker and S.A. Gherini (coordinators), Adirondack Lakes Survey Corporation Interpretive Report, Ray Brook, NY.

Anderson, D.S., R.B. Davis, and F. Berge. 1986. Relationships between Diatom Assemblages in Lake Surface Sediments and Limnological Characteristics in Southern Norway. P. 97. In J.P. Smol, R.W. Battarbee, R.B. Davis, and J. Meriläinen, eds. Diatoms and Lake Acidity, eds. Dr. W. Junk, Dordrecht, The Netherlands.

Arzet, K., D. Krause-Dellin, and C. Steinberg. 1986. Acidification of four lakes in the Federal Republic of Germany as reflected by diatom assemblages, cladoceran remains, and sediment chemistry, pp. 227-250. In Smol, J.P., R.W. Battarbee, R.B. Davis, and J. Meriläinen, eds. Diatoms and Lake Acidity. Dr. W. Junk, Dordrecht, The Netherlands.

Baker, J.P. and C.L. Schofield. 1982. Aluminum toxicity to fish in acidic waters. Water Air Soil Pollut. 18:289-309.

Baker, J.P., D.P. Bernard, S.W. Christensen, and M.J. Sale. 1990. Biological Effects of Changes in Surface Water Acid-Base Chemistry. State of Science/Technology Report 13. National Acid Precipitation Assessment Program. Washington, DC.

Baker, L.A., A.T. Herlihy, P.R. Kaufmann, and J.M. Eilers. 1991. A.cidic lakes and streams in the United States: the role of acidic deposition. Science. 252:1151-1154.

Bard, Y. 1974. Nonlinear Parameter Estimation. Academic Press, N.Y. 341 pp.

Battarbee, R.W. 1984. Diatom analysis and the acidification of lakes. Phil. Trans. R. Soc. Lond. $B, 305: 451-477$.

Beven, K.J. and M.J. Kirkby. 1979. A physically based, variable contributing area model of basin hydrology. Hydro. Sci. Bull. 24:43-69.

Birks, H.J.B., S. Juggins, and J.M. Line. 1990a. Lake surface-water chemistry reconstructions from paleolimnological data, pp. 301-313. In B.J. Mason, ed. The Surface Waters Acidification Programme. Cambridge Univ. Press, Cambridge.

Birks, H.J.B., J.M. Line, S. Juggins, A.C. Stevenson, and C.J.F. ter Braak. 1990b. Diatoms and pH reconstruction. Phil. Trans. R. Soc. Lond. B 327:263-278. 
Bishop, K. 1991. Episodic increases in stream acidity, catchment flow pathways, and hydrograph separation. Ph.D. Thesis, Jesus College, Cambridge.

Brakke, D. F., A. Henriksen, and S. A. Norton. 1987. The relative importance of acidity sources for humic lakes in Norway. Nature 329:432-434.

Brezonik, P.L., J.G. Eaton, T.M. Frost, P.J. Garrison, T.K. Kratz, C.E. Mach, J.H. McCormick, J.A. Perry, W.A. Rose, C.J. Sampson, B.C.L. Shelley, W.A. Swenson, and K.E. Webster. In Review. Experimental acidification of Little Rock Lake, Wisconsin: Chemical and biological changes over the $\mathrm{pH}$ range 6.1 to 4.7 .

Brezonik, P.L., L.A. Baker, and T.E. Perry. 1987. Mechanisms of alkalinity generation in acidsensitive softwater lakes, pp. 229-262. In R. Hites and S.J. Eisenreich, eds. Sources and fates of aquatic pollutants (Adv. Chem. Ser. 216). Amer. Chem. Soc., Washington, DC.

Brezonik, P.L., E.P. Weir, and R.A. Hoisve. In Review. Chemical Responses of a Seepage Lake to Experimental Acidification: Results for Little Rock Lake at pH 5.6 and 5.1. Submitted to Can J. Fish. Aquat. Sci.

Bull, K.R. 1992. An introduction to critical loads. Environ. Pollut. 77:173-176.

Campbell, P.G.C., H.J. Hansen, B. Dubreuil, and W.O. Nelson. 1992. Geochemistry of Quebec North Shore salmon rivers during snowmelt: Organic acid pulse and aluminum mobilization. Can. J. Fish. Aquat. Sci. 49:1938-1952.

Charles, D.F. 1984. Recent PH history of Big Moose Lake (Adirondack Mountains, New York, USA) inferred from sediment diatom assemblages. Verh. Internat. Verein. Limnol. 22:E-9-566.

Charles, D.F. 1985. Relationships between surface sediment diatom assemblages and lakewater characteristics in Adirondack lakes. Ecology 66:994-1011.

Charles, D.F. 1987. Diatom counts of Adirondack lake surface sediment samples. PIRLA Unpublished Report Series, Report number 12, Department of Biology, Indiana University, Bloomington, IN. 393 pp.

Charles, D.F., and S.A. Norton. 1986. Paleolimnological evidence for trends in atmospheric deposition of acids and metals, pp. 335-435. In Acid deposition: Long-term Trends. Committee on monitoring and assessment of trends in acid deposition. National Academy Press, Washington, D.C.

Charles, D.F., and J.P. Smol. 1988. New methods for using diatoms and chrysophytes to infer past pH of low-alkalinity lakes. Limnol. Oceanogr. 33:1451-1462.

Charles, D.F. and J.P. Smol. 1990. The PIRLA II project: regional assessment of lake acidification trends. Verh. Internat. Verein. Limnol. 24:474-480.

Charles, D.F., and D.R. Whitehead. 1986a. Paleoecological Investigation of Recent Lake Acidification (PIRLA); Methods and Project Description. Electric Power Research Institute, Palo Alto, CA. 228 pp.

Charles, D.F., and D.R. Whitehead. 1986b. The PIRLA project: Paleoecological investigation of recent lake acidification. Hydrobiologia 143:13-20. 
Charles, D.F., R.W. Battarbee, I. Renberg, H. van Dam, and J.P. Smol. 1989. Paleoecological analysis of lake acidification trends in North America and Europe using diatoms and chrysophytes, pp. 207-276. In S.A. Norton, S.E. Linberg, and A.L. Pages, eds. Acid Precipitation. Vol. 4 Soils, Aquatic Processes and Lake Acidification. Springer-Verlag, New York.

Charles, D.F., M.W. Binford, E.T. Furlong, R.A. Hites, M.J. Mitchell, S.A. Norton, F. Oldfleld, M.J. Paterson, J.P. Smol, A.J. Uutala, J.R. White, D.R. Whitehead, and R.J. Wise. 1990. Paleoecological investigation of recent lake acidification in the Adirondack Mountains, N.Y. J. Paleolimnol. 3:195-241.

Charles, D.F., D.R. Whitehead, D.R. Engstrom, B.D. Fry, R.A. Hites, S.A. Norton, J.S. Owen, L.A. Roll, S.C. Schindler, J.P. Smol, A.J. Uutala, J.R. White, and R.J. Wise. 1987. Paleolimnological evidence for recent acidification of Big Moose Lake, Adirondack Mountains, N.Y. (USA). Biogeochemistry 3:267-296.

Charles, D.F., D. R. Whitehead, D.S. Anderson, R. Bienert, K.E. Camburn, R.B. Cook, T.L. Crisman, R.B. Davis, B.D. Fry, R.A. Hites, J.S. Kahl, J.C. Kingston, R.G. Kreis, Jr., M.J. Whiting, and R.J. Wise. 1986. The PIRLA project (Paleoecological Investigation of Recent Lake Acidification): preliminary results for the Adirondacks, New England, N. Great Lake States, and N. Florida. Water Air Soll Pollut. 30:355-365.

Christophersen, M., H.M. Seip, and R.F. Wright. 1982. A model for streamwater chemistry at Birkenes, Norway. Water Resour. Res. 18:977-997.

Church, M.R., K.W. Thornton, P.W. Shaffer, D.L. Stevens, B.P. Rochelle, R.G. Holdren, M.G. Johnson, J.J. Lee, R.S. Turner, D.L. Cassell, D.A. Lammers, W.G. Campbell, C.I. Liff, C.C. Brandt, L.H. Liegel, G.D. Bishop, D.C. Mortenson, S.M. Pierson, and D.D. Schmoyer. 1989. Direct/ Delayed Response Project. Future Effects of Long-Term Sulfur Deposition on Surface Water Chemistry in the Northeast and Southern Blue Ridge Province. U.S. Environmental Protection Agency, EPA $600 / 3-89 / 061 a-d$, Washington, DC. 887 pp.

Church, M.R., P.W. Shaffer, K.W. Thornton, D.L. Cassell, C.I. Liff, M.G. Johnson, D.A. Lammers, J.J. Lee, G.R. Holdren, J.S. Kern, L.H. Liegel, S.M. Pierson, D.L. Stevens, B.P. Rochelle, and R.S. Turner. 1992. Direct/Delayed Response Project: Future Effects of Long-Term Sulfur Deposition on Stream Chemistry in the Mid-Appalachian Region of the Eastern United States. U.S. Environmental Agency, EPA600/R-92/186, Washington, DC. 384 pp.

Cook, R.B., K.A. Rose, A.L. Brenkert, and P.F. Ryan. 1992. Systematic comparison of ILWAS, MAGIC, and ETD watershed acidification models: 3. Mass balance budgets for acid neutralizing capacity. Environ. Pollut. 77:235-242.

Cosby, B.J., G.M. Hornberger, and R.F. Wright. 1989a. A regional model of surface water acidification in southern Nonway: calibration and validation using survey data. In J. Kamari, ed. Proceedings of the IIASA-IMGW Task Force Meeting on Environmental Impact Models to Assess Regional Acidification. Reidel Publishing.

Cosby, B.J., G.M. Hornberger, P.F. Ryan, and D.M. Wolock. 1989b. MAGIC/DDRP Final Report. Vol. 1: Model, calibration, results, uncertainty analysis, QAVC. Internal Report. U.S. EPA Environmental Research Laboratory-Corvallis, Corvallis, OR. 
Cosby, B.J., G.M. Hornberger, D.M. Woloch, and P.F. Ryan. 1987. Calibration and coupling of conceptual rainfall-runoff and chemical flux models for long-term simulation of catchment response to acidic deposition, pp. 151-160. In M.B. Beck, ed. Systems Analysis in Water Quality Management. Pergamon Press.

Cosby, B.J., G.M. Hornberger, J.N. Galloway, and R.F. Wright. 1985a. Modelling the effects of acid deposition: assessment of a lumped-parameter model of soil water and streamwater chemistry. Water Resour. Res. 18:51-63.

Cosby, B.J., R.F. Wright, G.M. Hornberger, and J.N. Galloway. 1985b. Modelling the effects of acid deposition: estimation of long-term water quality responses in a small forested catchment. Water Resour. Res. 21:1591-1601.

Cosby, B.J., G.M. Hornberger, J.N. Galloway, and R.F. Wright. 1985c. Time scales of catchment acidification: a quantitative model for estimating freshwater acidification. Environ. Sci. Technol. 19:1144-1149.

Cronan, C.S., and G.R. Aiken. 1985. Chemistry and Transport of Soluble Humic Substances in Forested Watersheds of the Adirondack Park, New York. Geochem. Cosmochim. Acta 49:1697. 1705.

Cumming, B.F., J.P. Smol, J.C. Kingston, D.F. Charles, H.J.B. Birks, K.E. Camburn, S.S. Dixit, A.J. Uutala, and A.R. Selle. 1992. How much acidification has occurred in Adirondack region (New York, USA) lakes since pre-industrial times? Can. J. Fish. Aquat. Sci. 49:128-141.

Davidson, G.A. 1984. Paleolimnological reconstruction of the acidification history of an experimentally acidified lake. Master's Thesis, University of Manitoba. 186 pp.

Davis, R.B., and D.S. Anderson. 1985. Methods of pH calibration of sedimentary diatom remains for reconstructing history of pH in lakes. Hydrobiologia 120:69-87.

Davis, R.B., and F. Berge. 1980. Atmospheric deposition in Norway during the last 300 years as recorded in SNSF lake sediments II. Diatom stratigraphy and inferred pH, pp. 270-271. In D. Drabløs and A. Tollan, eds. Ecological impact of acid precipitation. Proceedings of an International Conference, Sandefjord, Nonway, SNSF Project, Oslo, Norway.

Davis, R.B., D.S. Anderson, and F. Berge. 1985. Loss of organic matter, a fundamental process in lake acidification: paleolimnological evidence. Nature 316:436-438.

Davis, R.B., D.S. Anderson, M.C. Whiting, J.P. Smol, and S.S. Dixit. 1990. Alkalinity and pH of three lakes in northern New England, U.S.A., over the past 300 years. Phil. Trans. R. Soc. Lond. B 327:413-421.

Davis, R.B., S.A. Norton, C.T. Hess, and D.F. Brakke. 1983. Paleolimnological reconstruction of the effects of atmospheric deposition of acids and heavy metals on the chemistry and biology of lakes in New England and Norway. Hydrobiologia 103:113-123.

Del Prete, A., and C. Schofield. 1981. The utility of diatom analysis of lake sediments for evaluating acid precipitation effects on dilute lakes. Archiv. Hydrobiol. 91:332-340. 
DeNicola, D.M. 1986. The representation of living diatom communities in deep-water sedimentary diatom assemblages in two Maine (U.S.A.) lakes, pp. 73-85. In J.P. Smol et al., eds. Diatoms and Lake Acidity. Dr W. Junk Publishers, Dordrecht, The Netherlands.

Dickson, W.T. 1978. Some Effects of the Acidification of Swedish Lakes. Verh. Intern. Verein. Limnol. 20:851-856.

Dixit, S.S. 1983. The uallity of sedimentary diatoms as a measure of historical lake pH. Master's Thesis, Brock University, Ontario.

Dixit, A.S., S.S. Dixit, and J.P. Smol. 1992. Long-term trends in lake water pH and metal concentrations inferred from diatoms and chrysophytes in three lakes near Sudbury, Ontario. Can. J. Fish. Aquat. Sci. 49:1-8.

Dixit, S.S., A S. Dixit, and R.D. Evans. 1987. Paleolimnology evidence of recent acidification in two Sudbiry (Canada) lakes. Sci. Total Environ. 67:53-67.

Dixit, S.S., A.S. Dixit, and J.P. Smol. 1989a. Lake acidification recovery can be monitored using chrysophycean microfossils. Can. J. Fish. Aquat. Sci. 46:1309-1312.

Dixit, S.S., A.S. Dixit, and J.P. Smol. 1989b. Relationship between chrysophyte assemblages and environmental variables in seventy-two Sudbury lakes as examined by canonical correspondence analysis (CCA). Can. J. Fish. Aquat. Sci. 46:1667-1676.

Dixit, S.S., A.S. Dixit, and J.P. Smol. 1991. Multivariable environmentz: inferences based on diatom assemblages from Sudbury (Canada) lakes. Freshw. Biol. 26:251-266.

Dixit, S.S., B.F. Cumming, J.C. Kingston, J.P. Smol, H.J.B. Birks, A.J. Uutala, D.F. Charles, and K.E. Camburn. In Press. Diatom assemblages from Adirondack lakes (Now York, U.S.A.) and the development of predictive models for retrospective environmental assessment. J. Paleolimnol.

Driscoll, C.T., M. Lehtinen, R. Munson, and S.A. Gherini. 1990. The contribution of strong inorganic acids and organic acids in regulating $\mathrm{H}^{+}$and $\mathrm{Al}$ in Adirondack, NY (USA) lakes. Presented at the International Conference on Acidic Deposition. Its Nature and Impacts. Glasgow, Scotland, September 16-21.

Driscoll, C.T., M.D. Lehtinen, and T.J. Sullivan. In review. Modeling the acid-base chemistry of organic solutes in Adirondack, NY, lakes.

Efron 3. 1983. Estimating the error rate of a prediction rule: improvement on cross-validation. J. Amer. Stat. Assoc. 78:316-331.

Flower, R.J., and R.W. Battarbee. 1983. Diatom evidence for recent acidification of two Scottish Lochs. Nature 305:130-133.

Flower, R.L., R.W. Battarbee, and P.G. Appleby. 1987. The recent paleolimnology of acid lakes in Galloway, south-west Scotland: diatom analysis. $\mathrm{pH}$ trends, and the role of afforestation. J. Ecol. 75:797-824.

Forsius, M., J. Kämäri, and M. Posch. 1992. Critical loads for Finnish lakes: comparison of three steady-state modeis. Environ. Poilut. 77:165-193. 
Gensemer, R.W. and S.S. Kilham. 1984. Growth rates of five freshwater algae in well-buffered acidic media. Can. J. Fish. Aquat. Sci. 41:1240-1243.

Gjessing, E. 1992. The HUMEX Project: Experimental acidification of a catchment and its humic lake. Environ. Internat. 18:535-543.

Glover, M. and A.H. Webb. 1979. Weak and strong acids in surface waters of the Tovdal region in S. Norway. Water Res. 13:781-784.

Gorham, E., J. Ford, M. Santelman, and S. Eisenreich, 1985. Chemistry of bog waters. In: W. Stumm (Ed.), Chemistry of Lakes, Springer-Verlag.

Hedin, L.O., G.E. Likens, K.M. Postek, and C.T. Driscoll. 1990. A Field Experiment to Test Whether Organic Acids Buffer Acid Deposition. Nature 345:798-800.

Hemond, H.F. 1980. Biogeochemistry of Thoreau's Bog, Concord, Massachusetts. Ecological Monographs 50:507-526.

Hemond, H.F. 1990. Acid neutralizing capability alkalinity, and acid-base status of natural waters containing organic acids. Environ. Sci. Technol. 24:1486-1489.

Hemond, H.F. In Review. Role of organic acids in acidification of fresh waters. Dahlem Conferenzen.

Henriksen, A. and H.M. Seip. 1980. Strong and weak acids in surface waters of southern Norway and southwest Scotland. Water Res. 14:809-813.

Henriksen, A., D.F. Brakke, and S.A. Norton. 1988. Total organic carbon concentrations in acidic lakes in southern Norway. Environ. Sci. Technol. 22:1103-1105.

Hornberger, G.M., K.J. Beven, B.J. Sosby, and D.E. Sappington. 1985. Shenandoah watershed study: Calibration of a topography-based, variable contributing area hydrological model of a small forested catchment. Water Resour. Res. 21:1841-1850.

Husar, R.B., T.J. Sullivan, and D.F. Charles. 1991. Historical trends in atmospheric sulfur deposition and methods for assessing long-term tret rds in surface water chemistry. pp. 65-82, In: Charles, D.F. (ed.). Acidic Deposition and Aquatic Ecosystems. Regional Case Studies. Springer-Verlag, New York..

Huttunen, P., K. Kentämies, A. Liehu, M. Liukkonen, T. Nustio, O. Sandman, and J. Turkia. 1990. Paleoecological evaluation of the recent acidification of susceptible lakes in Finland, pp. 10711090. In Kauppi et al., eds. Acidification in Finland. Springer-Verlag, Berlin.

Jenne, E.A., L.E. Eary, L.W. Vail, D.C. Girvin, A.M. Liebetrau, L.F. Hibler, T.B. Miley, and M.J. Monsour. 1989. An evaluation and analysis of three d'ynamic watershed acidification models (MAGIC, ETD, and ILWAS). PNL-6687, Pacific Northwest Laboratory, Richland, WA.

Jones, V.J., and R.J. Flower. 1986. Spatial and temporal variability in periphytic diatom communities: Faleoecological significance in an acidified lake, pp. 87-94. In: J.P. Smol et al., eds. Diatoms and Lake Asidity. Dr. W. Junk Publishers, Dordrecht, The Netherlands. 
Kämäri, J., M. Forsius, P. Kortelainen, J. Mannio, and M. Verta. 1991. Finnish Lake survey: Present status of acidification. Ambio 20:23-27.

Kerekes, J., S. Beauchamp, T. Tordon, and T. Pollock. 1986. Sources of sulphate and acidity in wetlands and lakes in Nova Scotia. Water Air Soil Pollut. 31:207-314.

Kingston, J.C., and H.J.B. Birks. 1990. Dissolved Organic Carbon Reconstruction from Diatom Assembiages in PIRLA Project Lakes, North America. Phil. Trans. R. Soc. Lond. B. 327:279-288.

Kingston, J.C., H.J.B. Birks, A.J. Uutala, B.F. Cumming, and J.P. Smol. 1992. Assessing trends in fishery resources and lake water aluminum from paleolimnological analyses of siliceous algae. Can. J. Fish. Aquat. Sci. 49:116-127.

Kingston, J.C., R.B. Cook, R.G. Kreis, Jr., K.E. Camburn, S.A. Norton, P.R. Sweets, M.W. Binford, J.J. Mitchell, S.C. Schindler, L.C.K. Shane, and G. King. 1990. Paleoecological investigation of recent lake acidification in the northern Great Lakes states. J. Paleolimnol. 4:153-201.

Kortelainen, P. and J. Mannio. 1988. Natural and anthropogenic acidity sources for Finnish lakes. Water Air Soil Pollut. 42:3341-352.

Kramer, J.R., P. Brassard, P. Collins, T.A. Clair, and P. Takats. 1990. Variability of organic acids in watersheds. In Perdue, E.M. and E.T. Gjessing (Eds.) Organic Acids in Aquatic Ecosystems. Dahlem Konferenzen, Life Sciences Research Report 48, Chichester, Wiley.

Kramer, J.R., C.S. Cronan, J.P. DePinto, H.F. Hemond, E.M. Perdue, and S. Visser. 1989. Organic Acids and Acidification of Surface Waters. Report to Acid Deposition Committee, Utility Air Regulatory Group.

Kramer, J.R., and S.S. Davies. 1988. Estimation of non-carbonate protolytes for selected lakes in the Eastern Lake Survey. Environ. Sci. Technol. 22:182-185.

Krug, E.C. 1991. Review of acid-deposition-catchment interaction and comments on future research needs. J. Hydrol. 128:1-27.

Krug, E.C., and C.R. Frink. 1983. Acid rain on acid soil: a new perspective. Science 221:520-525.

Krug, E.C., P.J. Isaacson, and C.R. Frink. 1985. Appraisal of some current hypotheses describing acidification of watersheds. J. Air Pollut. Control Assoc. 35:109-114.

Lam, D.C.L., A.G. Bobba, R.A. Bourbonniere, G.D. Howell, and M.E. Thompson. 1989. Modeling organic and inorganic acidity in two Nova Scotia rivers. Water Air Soil Pollut. 46:277-287.

Lammers, D.A., D.L. Cassell, J.J. Lee, D.L. Stevens, R.S. Turner, W.G. Campbell, and M.G. Jchnson. 1987. Field operations and quality assurance/quality control for Direct/Delayed Response Project soil mapping activities in the Southern Blue Ridge region. EPA/600/3-88/016. NTIS PB88 195 722/AS. U.S. Environmental Protection Agency, Corvallis, OR. 122 pp.

Lee, J.J., D.A. Lammers, M.G. Johnson, M.R. Church, D.L. Stevens, D.S. Coffey, R.S. Turner, L.J. Blume, L.H. Liegel, and G.R. Holdren. 1989. Watershed surveys to support an assessment of the regional effect of acidic deposition on surface water chemistry. Environ. Mgmt. 13:95-108. 
Lind, C.J., and J.D. Hem. 1975. Effects of organic solutes on chemical reactions of aluminum. U.S. Geological Survey Water Supply Paper 1827-G.

Linthurst, R.A., D.H. Landers, J.M. Eilers, D.F. Brakke, W.S. Overton, E.P Meier, and R.E. Crowe. 1986. Characteristics of Lakes in the Eastern United States. Volume I. Population Descriptions and Physico-Chemical Relationships. EPA/600/4-86/007a, U.S. Environmental Protection Agency, Washington, DC. 275 pp.

Marmorek, D.R., D.P. Bernard, M.L. Jones, L.P. Rattie, and T.J. Sullivan. 1988. The Effects of Mineral Acid Deposition on Concentrations of Dissolved Organic Acids in Surface Waters. ERLCOR-500 AP. U.S. Environmental Protection Agency, Environmental Research Laboratory, Corvallis, Oregon.

NAPAP Aquatic Effects Working Group 1991. National Acid Precipitation Assessment Program 1990 Integrated Assessment Report. National Acid Precipitation Assessment Program, Washington, DC. 520 pp.

Norton, S.A., R.F. Wright, J.S. Kahl, and J.P. Schofield. 1992. The MAGIC simulation of surface water acidification at, and first year results from, the Bear Brook Watershed Manipulation, Maine, USA. Environ. Pollut. 77:279-286.

Oliver, B.G., E.M. Thurman, and R.L. Malcolm. 1983. The contribution of humic substances to the acidity of colored natural waters. Geochim. Cosmochim. Acta 47:2031-2035.

Overrein, L.N., H.M. Seip, and A. Tollan. 1980. Acid Precipitation - Effects on Forest and Fish. Final Report, SNSF Project, Oslo, Norway.

Patrick, R., N.A. Roberts, and B. Davis. 1968. The effect of changes in pH on the structure of diatom communities. Notulae Naturae 416:1-16.

Perdue, E.M. 1985. Acidic Functional Groups of Humic Substances, pp. 493-526. . In G.R. Aiken, D.M. McKnight, R.L. Wershaw, and P. MacCarthy, eds. Humic Substances in Soil, Sediment, and Water. Wiley-Interscience, NY.

Perdue, E.M., 1990. Modeling the acid-base chemistry of organic acids in laboratory experimental and freshwaters. In E.M. Perdue and E.T. Gjessing, eds. Organic Acids in Aquatic Ecosystems, Dahlem Konferenzen, Life Sciences Research Report 48, Chichester, Wiley.

Perdue, E.M., J.H. Reuter, and R.S. Parrish. 1984. A statistical model of proton binding by humus. Geochim. Cosmochim. Acta 48:1257-1263.

Peters, N.E. and C.T. Driscoll. 1987. Hydrogeologic controls of surface-water chemistry in the Adirondack region of New York State. Biogeochemistry 3:163-180.

Pollman, C.D., and D.E. Canfield. 1991. Florida: A case study of hydrologic and biogeochemical controls on seepage lake chemistry. In D.F. Charles ed. Acid Deposition and Aquatic Ecosystems, Springer-Verlag, N.Y.

Rawls, W.J., D.L. Bakensiek, and K.E. Saxton. 1982. Estimation of soil water properties. Trans. ASAE 25:1317-1320, 1328. 
Renberg, I., and J.E. Wallin. 1985. The history of the acidification of Lake Gärdsjon as deduced from diatoms and Sphagnum leaves in the sediment, pp. 47-52. In F. Andersson and B. Olsson, eds. Lake Gärdsjøn: An Acid Forest and Its Catchment. Ecological Bulletin No. 37.

Renberg, I., and T. Hultberg. 1982. The pH history of lakes in southwestern Sweden, as calculated from the subfossil diatom flora of the sediments. Ambio 11:30-33.

Renberg, I. and $\mathrm{H}$. Hultberg. 1992. A paleolimnological assessment of acidification and liming effects on diatom assemblages in a Swedish lake. Can. J. Fish. Aquat. Sci. 49:65-72.

Rosenbrock, H.H. 1960. An automatic method for finding the greatest or least value of a function. Comput. J. 3:175-184.

Rustad, S., N. Christophersen, H.M. Seip, and P.J. Dillon. 1986. Model for streamwater chemistry of a tributary to Harp Lake, Ontario. Can. J. Fish. Aquat. Sci. 43:625-633.

Schindler, D.W. and M.A. Turner. 1982. Biological, Chemical, and Physical Responses of Lakes to Experimental Acidification. Water Air Soil Pollut. 18:259-271.

Smith, M.A. 1990. The ecophysiology of epilithic diatom communities of acid lakes in Galloway, southwest Scotland. Phil. Trans. R. Soc. Lond. B 327:251-256.

Smol, J.P., D.F. Charles, and D.R. Whitehead. 1984. Mallomonadacean (Chrysophyceae) assemblages and their relationships with limnological characteristics in 38 Adirondack (New York) lakes. Can. J. Bot. 62:911-923.

Smol, J.P., R.W. Battarbee, R.B. Davis, and J. Meriläinen, eds. 1986. Diatoms and Lake Acidity. Dr. W. Junk. Dordrecht, The Netherlands.

Sullivan, T.J., R.S. Turner, D.F. Charles, B.F. Cumming, J.P. Smol, C.L. Schofield, C.T. Driscoll, B.J. Cosby, H.J.B. Birks, A.J. Uutala, J.C. Kingston, S.S. Dixit, J.A. Bernert, P.F. Ryan, and D.R. Marmorek. 1992. Use of historical assessment for evaluation of process-based model projections of future environmental change: Lake acidification in the Adirondack Mountains, New York, U.S.A. Environ. Pollut. 77:253-262.

Sullivan, T.J., J. A. Bernert, E. A. Jenne, J. M. Eilers, B. J. Cosby, D. F. Charles, and A. R. Selle. 1991. Comparison of MAGIC and diatom paleolimnological model hindcasts of lakewater acidification in the Adirondack region of New York. Prepared for the U.S. Department of Energy under Contract DE-AC06-76RLO 1830. Pacific Northwest Laboratory, Richland, WA.

Sullivan, T.J., D.F. Charles, J.P. Smol, B.F. Cumming, A.R. Selle, D.R. Thomas, J.A. Bernert, and S.S. Dixit. 1990a. Quantification of changes in lakewater chemistry in response to acidic deposition. Nature 345:54-58.

Sullivan, T.J., D.L. Kugler, M.J. Small, C.B. Johnson, D.H. Landers, B.J. Rosenbaum, W.S. Overton, W.A. Kretser, and J. Gallagher. 1990b. Yariation in Adirondack, New York, lakewater chemistry as a function of surface area. Water Resour. Bull. 26:167-176.

Sullivan, T.J., C.T. Driscoll, S.A. Gherini, R.K. Munson, R.B. Cook, D.F. Charles, and C.P. Yatsko. 1989. The influence of organic acid anions and aqueous aluminum on measurements of acid neutralizing capacity in suriace waters. Nature 338:408-410. 
Sweets, P.R., R.W. Binert, T.L. Cusimono, and M.W. Binford. 1990. Paleoecological investigations of recent lake acidification in northern Florida. J. Paleolimnol. 4:103-137.

Taylor, M.C., H.C. Duthie, and S.M. Smith. 1988. Errors Associated with Diatom-inferred Indices for Predicting PH in Canadian Shield Lakes, p. 273. In F. Round,ed. Proceedings of the 9th International Diatom Symposium, Bristol, U.K.

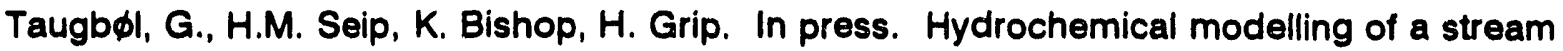
dominated by organic acids and organically bound aluminum. Water Air Soil Pollut.

ter Braak, C.J.F. 1985. Correspondence analysis of incidence and abundance data: properties in terms of a unimodal response model. Biometrics 41:859-873.

ter Braak, C.J.F. 1986. Canonical correspondence analysis: a new eigenvector technique for multivariate direct gradient analysis. Ecology 67:1167-1179.

ter Braak, C.J.F. 1987. The analysis of vegetation-environment relationships by canonical correspondence analysis. Vegetatio 69:79-87.

ter Braak, C.J.F. 1988. Partial canonical correspondence analysis, pp. 551-558. In H.H. Bock, ed. Classification and Related Methods of Data Analysis. North-Holland:Amsterdam.

ter Braak, C.J.F., and L.G. Barendregt. 1986. Weighted averaging of species indicator values: its efficiency in environmental calibration. Mathemat. Biosci. 78:57-72.

ter Braak, C.J.F., and N.J.M. Gremmen. 1987. Ecological amplitudes of plant species and the internal consistency of Ellenberg's indicator values for moisture. Vegetatio 69:79-87.

ter Braak, C.J.F., and C.W.N. Looman. 1986. Weighted averaging, logistic regression and the Gaussian response model. Vegetatio 65:3-11.

ter Braak, C.J.F., and I.C. Prentice. 1988. The theory of gradient analysis. Advan. Ecolog. Res. 18:271-317.

Thornton, K., D. Marmorek, and P. Ryan. 1990. Methods for Projecting Future Changes in Surface Water Acid-Base Chemistry. State of the Science, SOS/T 14, National Acid Precipitation Assessment Program.

Thurman, E.M. 1985. Organic Geochemistry of Natural Waters. Martinus Nijhoff. Dr. W. Junk, Dordrecht, The Netherlands.

Tipping, E., C.A. Backes, and M.A. Hurley. 1988. The complexation of protons, aluminum and calcium by aquatic humic substances: $A$ model incorporating binding-site heterogeneity and macroionic effects. Wat. Res. 22:597-611.

Tolonen, K., and T. Jaakkola. 1983. History of lake acidification and air pollution studied on sediments in South Finland. Annales Botanici Fennici 20:57-78.

van Dam, H. 1988. Acidification of three moorland pools in the Netherlands by acid precipitation and extreme drought periods over seven decades. Freshw. Biol. 20:157-176. 
Webster, K.E., A.D. Newell, L.A. Baker, and P.L. Brezonik. 1990. Climatically induced rapid acidification of a softwater seepage lake. Nature 347:374-376.

Wright, R.F. 1989. RAIN Project: Role of organic acids in moderating $\mathrm{pH}$ change following reduction in acid deposition. Water Air Soil Pollut. 46:251-259.

Wright, R.F., E. Lotse, and A. Semb. 1988. Reversibility of acidification shown by wholecatchment experiments. Nature 334:670-675. 


\section{APPENDICES}

A. Manuscripts Prepared for Peer-Reviewed Literature

B. Sensitivity Analyses

C. Recalibration 
APPENDIX A

MANUSCRIPTS PREPARED FOR PEER-REVIEWED LITERATURE

1. Hemoid, $H$. Role of organic acids in acidification of fresh waters.

2. Sullivan, T.J., B.J. Cosby, C.T. Driscoll, D.F. Charles, and H.F. Hemoid. Long-term environmental change: intercomparisons among paleolimnological and process-based model hindcasts of lake acidification

3. Driscoll, C.T., M.D. Lehtinen, and T.J. Sullivan. Modeling the acid-base chemistry of organic solutes in Adirondack, NY, lakes.

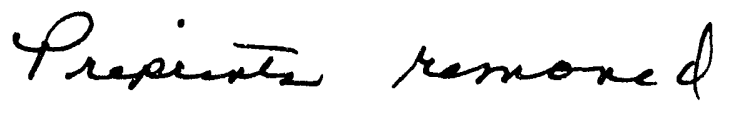




\section{APPENDIX B}

\section{SENSITIVITY ANALYSES}

A series of sensitivity analyses were conducted to evaluate the potential importance of several issues to regional modeling output. The following issues were considered:

1. Use of average $P_{\infty}$ and $K_{N}$ values for the Adirondack region versus individual watershed-specific Estimates;

2. Use of measured values of total aluminum versus extractable Al;

3. Potential magnitude of the effects of sampling differences (seasonality and airequilibration prior to $\mathrm{pH}$ measurement) between the ELS-I and PIRLA-II studies.

4. Assumption that DOC concentrations have changed over time; and

The results of varying the input parameters as described in items 1,2 , and 3 on the model output for each of the organic acid analog models were evaluated, and are described in this section.

The sensitivity of the modeling results to potential changes in lakewater DOC concentration was evaluated within the context of model recalibration efforts. These analyses are described in Appendix $\mathbf{C}$.

Aluminum and $\mathrm{P}_{\mathrm{CO}_{2}}$ model input parameters were investigated for the 33 Adirondack lakes. Both pH and ANC model output were examined. Comparisons were made for a variety of 1984 ' estimates and 1844 hindcasts. These analyses employed the five different organic acid formulations: mono-, di-, and triprotic, Oliver, and no organic acid (Tables 9-11 in the report). As illustrated below, this involved a total of 5,280 evaluations. The regional analysis was somewhat smaller, yielding 160 test results (i.e., $5280 \div 33$ lakes).

Results of the principal recomparisons between the MAGIC and diatom models are presented as a series of histograms in Figures B1 and B2 and scatter plots in Figures B3 and B4. 


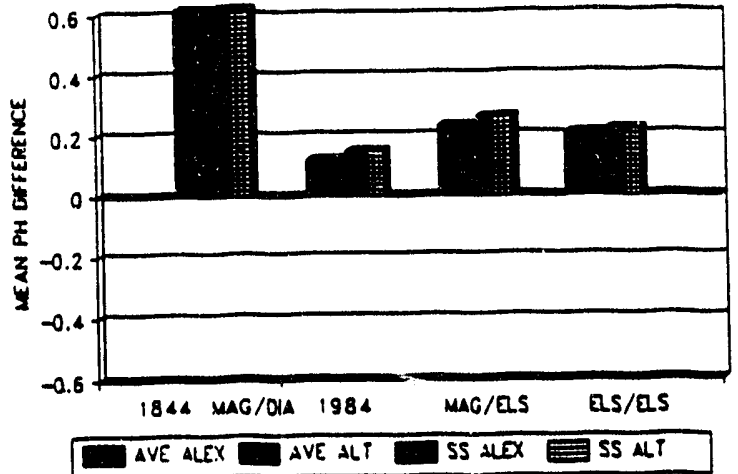

B)

MONOPROTIC ACID USING ALSC MODEL PARAMETERS

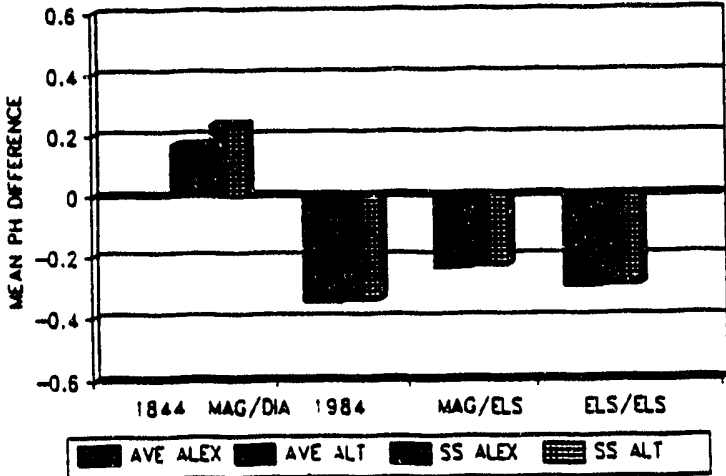

D)

TRIPROTIC ACID USING ALSC MODEL PARAMETERS

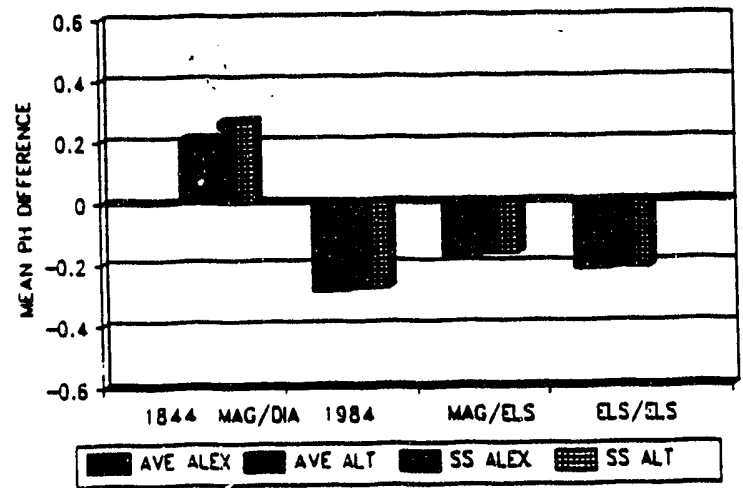

C) DIPROTIC ACID USING ALSC MODEL PARAMETERS
E) OLIVER ACID USING ALSC MODEL PARAMETERS

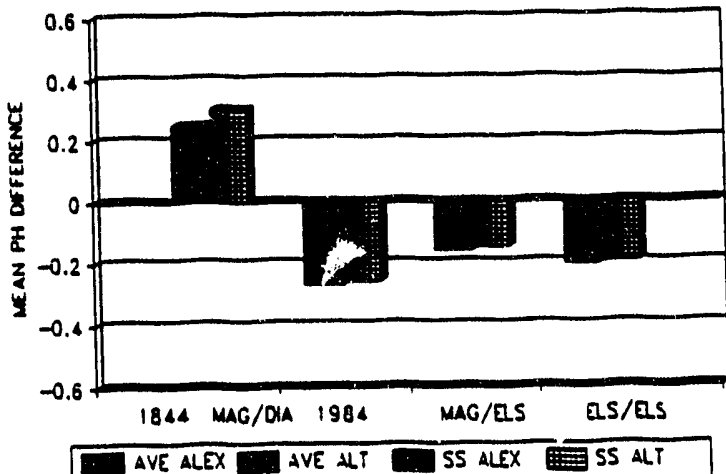

Figure B1. Histograms showing the mean value of the differences between various simulations or measurements of $\mathrm{pH}$ for 33 Adirondack lakes. Fach of the four bars in a group represents one of the four conditions regarding choice of aluminum input variable and site-specific (SS) or regional average $P_{C O}$ and $K_{N}$ (see text). Each group of bars represents a different pairwise comparison, and includes (from left to right): 1844 hindcasts of MAGIC versus diatoms, 1984 reconstructions of MAGIC versus diatoms, 1984 reconstructions of MAGIC versus ELS measured valies, and 1984 ELS measured values versus predicted values from the equilibrium equations. The five sets of histograms were based on $A)$ no organic acid representation and $B$ through $E$. mono-, di-, triprotic, and Oliver, respectively. 
A) NO ACID

USINC ALSE MODEL PARAMETERS

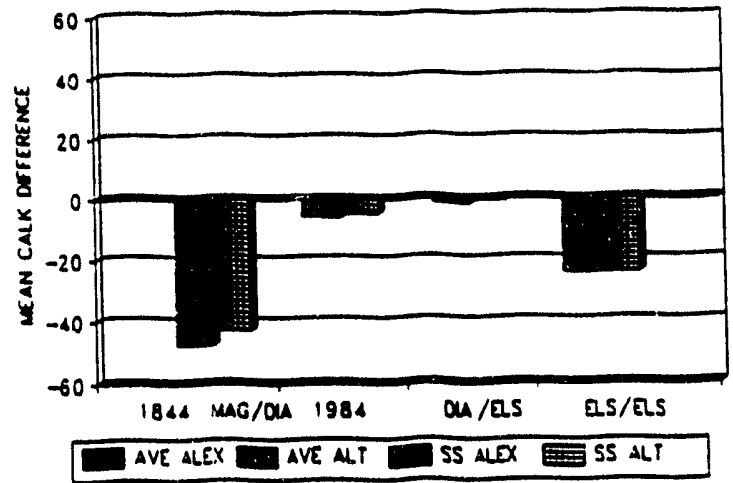

B) MONOPROTIC ACID USING ALSC MODEL PARAMETERS

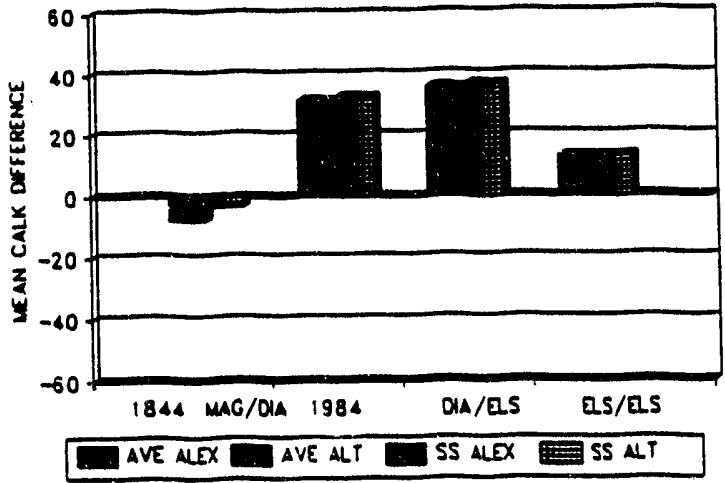

D) TRIPROTIC ACID USING ALSC MOOEL PARAMETERS

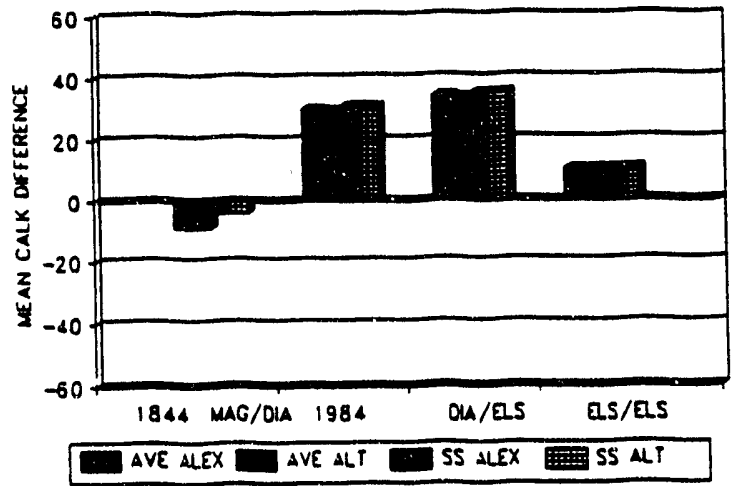

C) DIPROTIC ACID

USING ALSC MODEL PARAMETERS

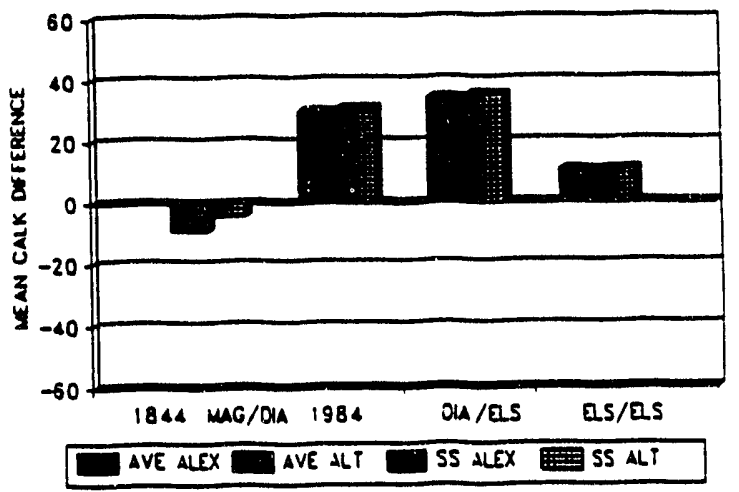

E) OLIVER ACID

USING ALSC MODEL PARAMETERS

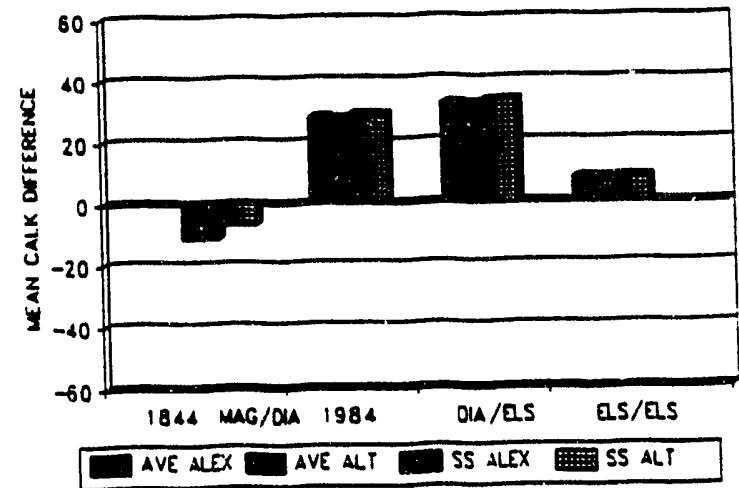

Figure B2. Histograms for calculated alkalinity (CALK) comparisons, as describsd for pH in Figure B1. 
M)

$1844 \mathrm{PH}$

AVE PCO2. KAL (ALEX) ALSC PARAMETERS

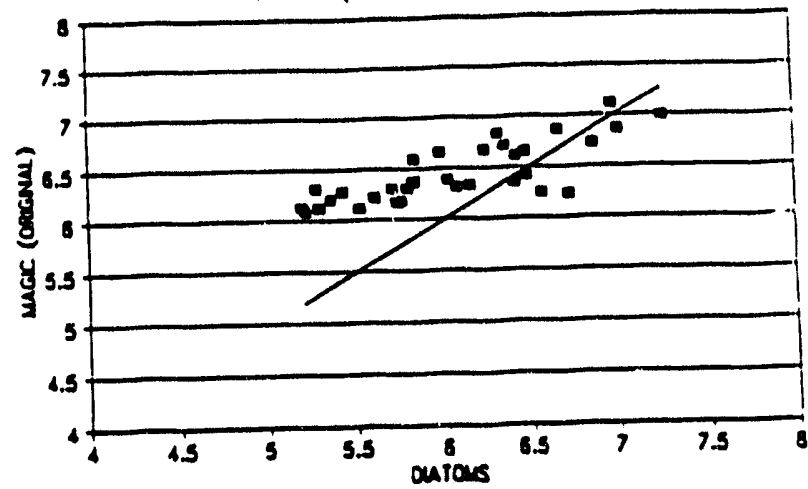

B)

$1844 \mathrm{PH}$

AVE PCO2. KAL (ALEX) ALSC PARAMETERS

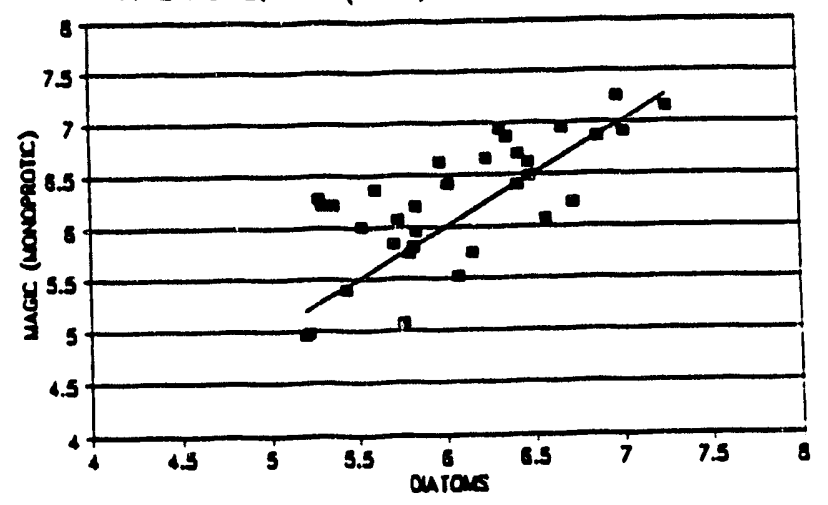

D)

$1844 \mathrm{PH}$

AVE PCO2. KAL (ALEX) ALSC PARAMETERS

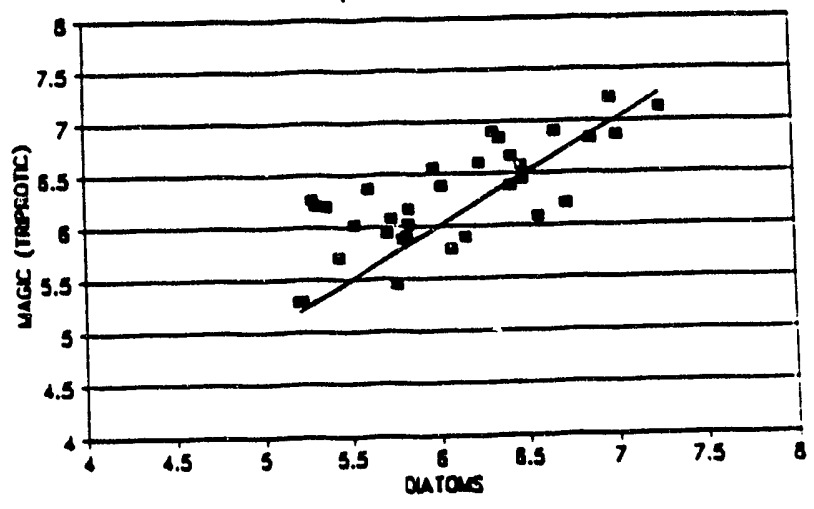

C)

$1844 \mathrm{PH}$

ave PCO2. Kal (ALEX) alsC parameters

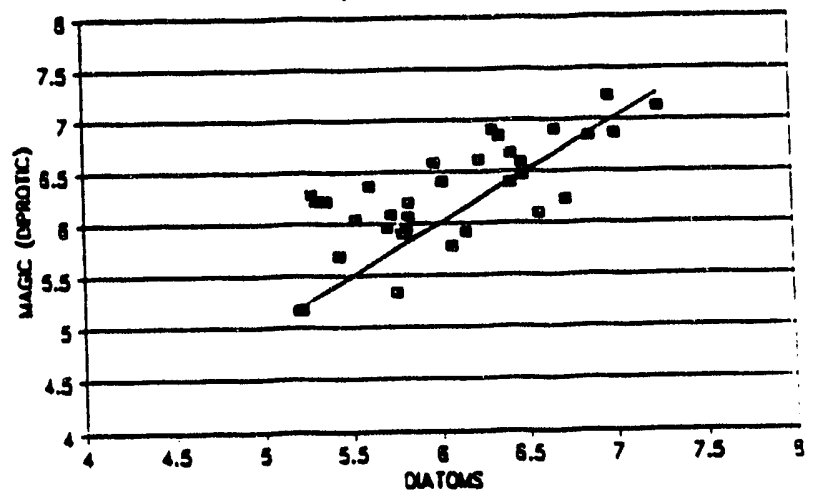

E) AVE PCO2, KAL (ALEX) PH

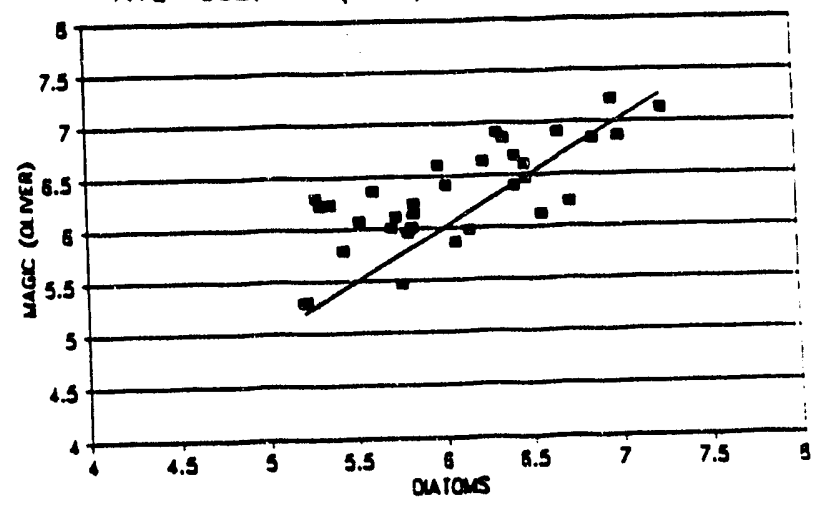

Figure B3. MAGIC estimates of $1844 \mathrm{pH}$ versus diatom-inferred $1844 \mathrm{pH}$ for 33 Adirondack lakes. MAGIC estimates included A) no organic acid, and $B$ through $E$ monoprotic acid through the Oliver models. All model estimates were based on extractable aluminum and regional average values for $\mathrm{P}_{\mathrm{CO}_{2}}$ and $\mathrm{K}_{\mathrm{Al}}$. 
A) $1984 \mathrm{PH}$

AVE PCO2. KAL (ALEX) ALSC PARAMETERS

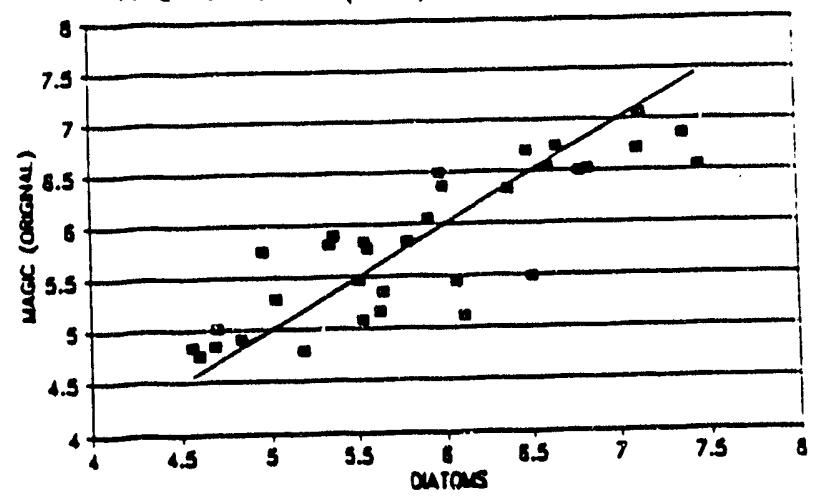

B)

$1984 \mathrm{PH}$

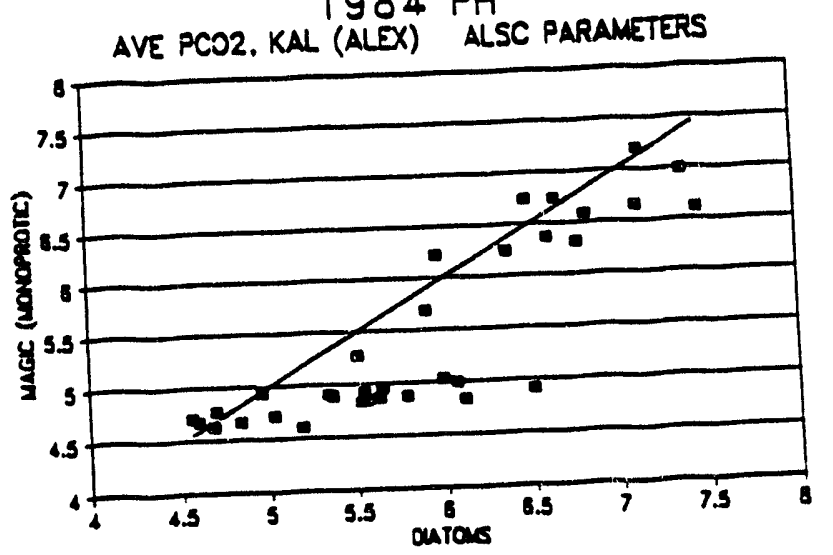

D)

\section{$1984 \mathrm{PH}$}

AVE PCO2. KAL (ALEX) ALSC PARAMETERS

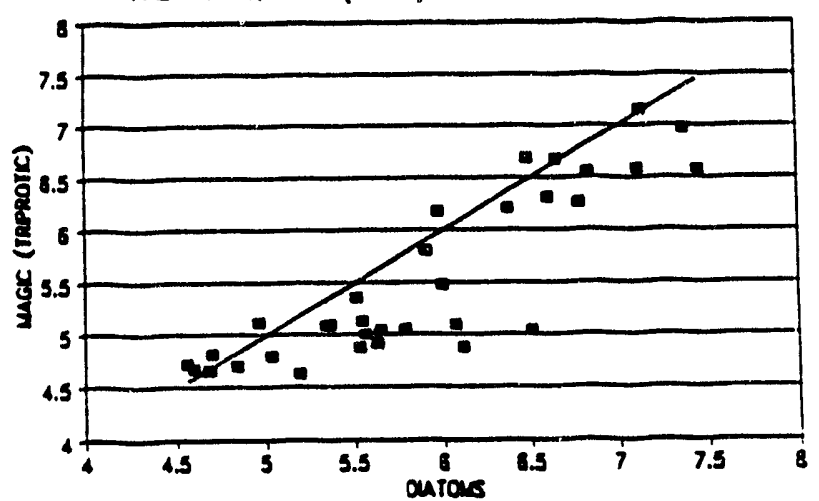

C)

$1984 \mathrm{PH}$

aVE PCO2. KaL (ALEX) alsc PARAMETERs

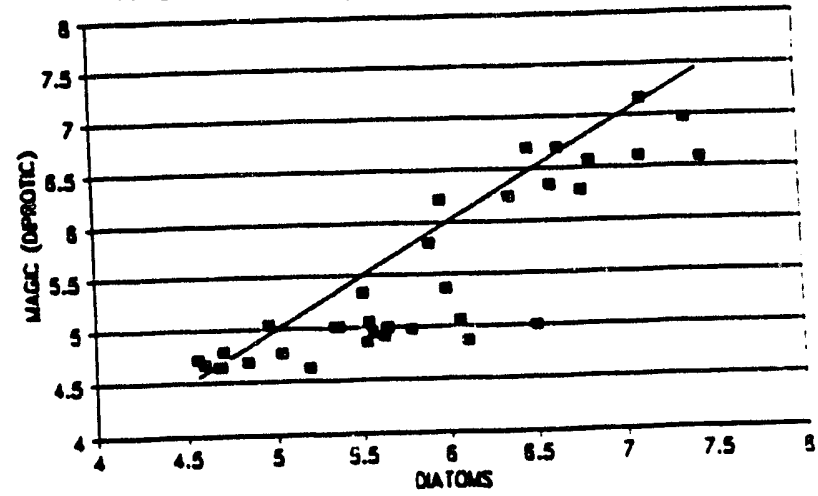

E) $1984 \mathrm{PH}$ AVE PCO2. KAL (ALEX) aLSC PARAMETERS

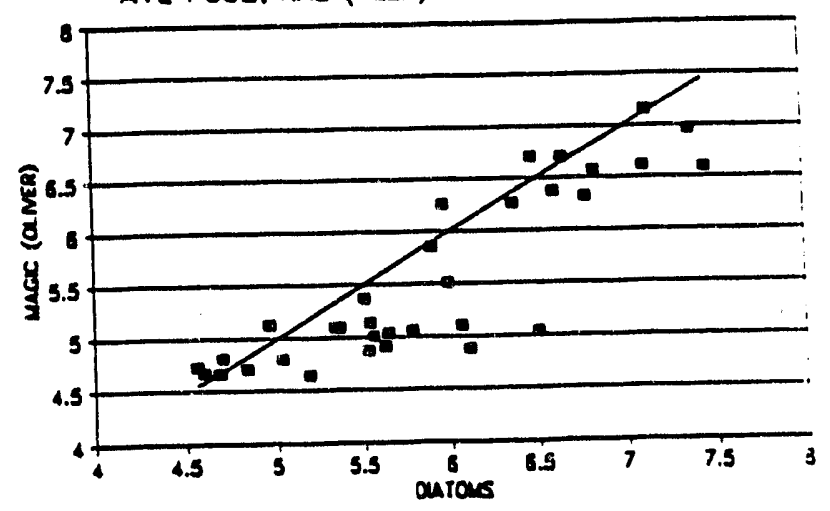

Figure B4. MAGIC estimates of $1984 \mathrm{pH}$ versus diatom-inferred $1984 \mathrm{pH}$ for 33 Adirondack lakes. MAGIC estimates included A) no organic acid, and $B$ through $E$ monoprotic acid through the Oliver models. All model estimates were based on extractable aluminum and regional average values for $\mathrm{F}_{\mathrm{CO}_{2}}$ and $\mathrm{K}_{\mathrm{Al}}$. 
Analysis Design

\begin{tabular}{|c|c|c|c|c|}
\hline $\begin{array}{l}\text { Monoprotic } \\
\text { Diprotic } \\
\text { Triprotic } \\
\text { Oliver } \\
\text { Model }\end{array}$ & $\begin{array}{l}\text { Ave } P_{\mathrm{CO}_{2}}, K_{\mathrm{N}} \text { (ALT) } \\
\text { SS } P_{\mathrm{CO}_{2}}, K_{N} \text { (ALT) } \\
\text { Ave } P_{\mathrm{CO}_{2}}, K_{N} \\
(\text { ALEX) } \\
\text { SS P } \mathrm{COO}_{2}, K_{N} \\
(\text { ALEX) }\end{array}$ & $\begin{array}{l}1844 \mathrm{Mag} / \mathrm{Dia} \\
1984 \mathrm{Mag} / \mathrm{Dia} \\
1984 \mathrm{Mag} / \mathrm{ELS} \\
1984 \mathrm{ELS} / \mathrm{ELS}\end{array}$ & $\begin{array}{l}\text { pH diff } \\
\text { CALK diff }\end{array}$ & $\begin{array}{l}1 A 1-012 \\
1 A 1-012 \\
1 A 1-014 \\
\ldots \\
\ldots(n=33)\end{array}$ \\
\hline (5 models) & ( 4 conditions) $x$ & (4 measures) & $\begin{array}{r}(2 \text { criteria) } \times \\
=5,280\end{array}$ & $\begin{array}{l}\text { (33 lakes) } \\
\text { luations }\end{array}$ \\
\hline
\end{tabular}

The mean difference in $\mathrm{pH}$ model output between the MAGIC and diatom models is presented in. Figure B1. Histograms a through e in the figure depict results for no organic acid, and each of the four organic acid models, respectively. Each of the four bars in each group represents a different pairwise comparison based on extractable (ALEX) or total (ALT) aluminum, and site-specific (SS) or regional average (AVE) values for $P_{\mathrm{CO}_{2}}$ and $K_{\mathrm{N}}$. The four groups of bars represent the four major kinds of pairwise comparisons:

1. 1844 hindcasts for the MAGIC and diatom models

2. 1984 current estimates for the MAGIC and diatom models

3. 1984 estimates for MAGIC and measured ELS values

4. 1984 predicted ELS pH (calculated from measured alkalinity as Gran ANC) and measured ELS pH

Figure $\mathrm{B1a}$ shows that there is a large difference in $\mathrm{pH}$ between the MAGIC and diatom models for 1844 hindcasts of pH when no organic acid is used (as per Sullivan et al. 1991). The mean $\mathrm{pH}$ difference without considering organic acids was approximately $0.6 \mathrm{pH}$ units (Figure B1a). Once organic acids were included in the analysis, the mean pH difference was substantially lower $(0.2$ to $0.3 \mathrm{pH}$ units, Figure $B 1 b, c, d, e)$. The mean $\mathrm{pH}$ difference was not greatly affected by the choice of organic acid representation; all four organic acid models yielded generally similar results. The mean $\mathrm{pH}$ difference was also not greatly affected by the choice of aluminum measurement (ALEX versus ALT) or site-specific versus regional average values for $P_{\mathrm{CO}_{2}}$ and $K_{\mathrm{N}}$. The only dramatic effect on the 1844 hindcasi results was obtained by including any reasonable 
organic acid representation. It should also be noted that inclusion of the various organic acid models increased the mean $\mathrm{pH}$ difference between the MAGIC and diatom estimate- of $1984 \mathrm{pH}$. In other words, inclusion of organics lessened the agreement between the models for current $\mathrm{pH}$. This is due, at least in part, to the fact that the MAGIC model was not recalibrated to the new data. The calculations are based on model calibrations that did not include organics. The degree to which the current chemistry estimates might be improved by further calibration is discussed in Appendix C.

The histograms depicted in Figure B2 show results for calculated alkalinity (CALK) in a similar fashion to the $\mathrm{pH}$ presentation in the previous figure. Again, the results indicate that the MAGIC and diatom models give very different 1844 hindcast results (average CALK difference of about 50 $\mu e q L^{-1}$ ) when no organic acid model is used, and much closer agreement (average CALK difference of about 10 to $20 \mu \mathrm{eq} L^{-1}$ ) when any of the four organic models is included. Agreement between models is again lessened for current chemistry estimates, in the absence of further calibration.

Individual $\mathrm{pH}$ reconstructions for the 33 . Adirondack lakes are compared for pre-industrial and current conditions in Figures B3 and B4, respectively. For these analyses, regional average values were used for $P_{\mathrm{CO}_{2}}$ and $K_{N}$, and ALEX was used as the aluminum input data. The major biases observed between the MAGIC and diatom pre-industrial $\mathrm{pH}$ reconstructions were removed by inclusion of any of the four organic acid models (Figure B3), although the current chemistry estimates for $\mathrm{pH}$ showed poorer agreement after inclusion of organics, in the absence of further calibration (Figure B4).

To evaluate the extent to which $\mathrm{CO}_{2}$ effects could potentially influence the comparison results, and also take into consideration any possible seasonal or methodological differences between the ELS-I and PIRLA studies, diatom-inferred pH values for 1984 were "adjusted" in the sensitivity analysis depicted in Figures B5 and B6. These adjusted diatom-inferred pH values were obtained by correcting the inferred $\mathrm{pH}$ values for each lake by an amount equivalent to the difference between pH used in the PIRLA study (air-equilibrated summer measurement) and the 
pH obtained by ELS-I (non-equilibrated fall measurement) (Figure B5). Such an adjustment is not totally appropriate, however, particularly for the pre-industrial $\mathrm{pH}$ values, largely because the magnitude of $\mathrm{CO}_{2}$ effects increases with increasing $\mathrm{pH}$. This adjustment gives an approximation, however, of the direction and perhaps the magnitude of these influences on the comparison results.

Figure B6 shows the results of the comparison between diatom-inferred and MAGIC simulations of current $\mathrm{pH}$, after "adjustment" of the diatom-inferred $\mathrm{pH}$ values as described above. Results are presented using the MAGIC/triprotic model. A slight improvement was obtained between the MAGIC/triprotic model and diatom estimates of current $\mathrm{pH}$ after this adjustment, as compared with unadjusted values (Figure 5B), and the mean difference was reduced from -0.29 to $-0.16 \mathrm{pH}$ units. This suggests that differences in sampling methods, seasonality, and/or $\mathrm{CO}_{2}$ effects might account for at least part of the remaining discrepancy, at least for current $\mathrm{pH}$ estimates.

The following conclusions were drawn from the sensitivity analyses reported in this appendix.

1. Results of the regional modeling effort were not very sensitive to the assumptions regarding the use of regional average versus site-specific estimates of $P_{\mathrm{CO}_{2}}$ and $K_{A}$.

2. Results of the regional modeling effort were not very sensitive to the choice of aluminum input variable (total versus extractable Al).

3. The inclusion of any reasonable organic acid representation improved the previouslyobserved discrepancies between MAGIC and diatom estimates of pre-industrial chemistry, and the inclusion of organic acids was more important than assumptions regarding $\mathrm{P}_{\mathrm{CO}_{2}}$ and $\mathrm{Al}$.

4. Remaining discrepancies were not unreasonably large relative to the potential influence of seasonal and methodological differences between the studies used as bases for the diatom and MAGIC modeling efforts. 


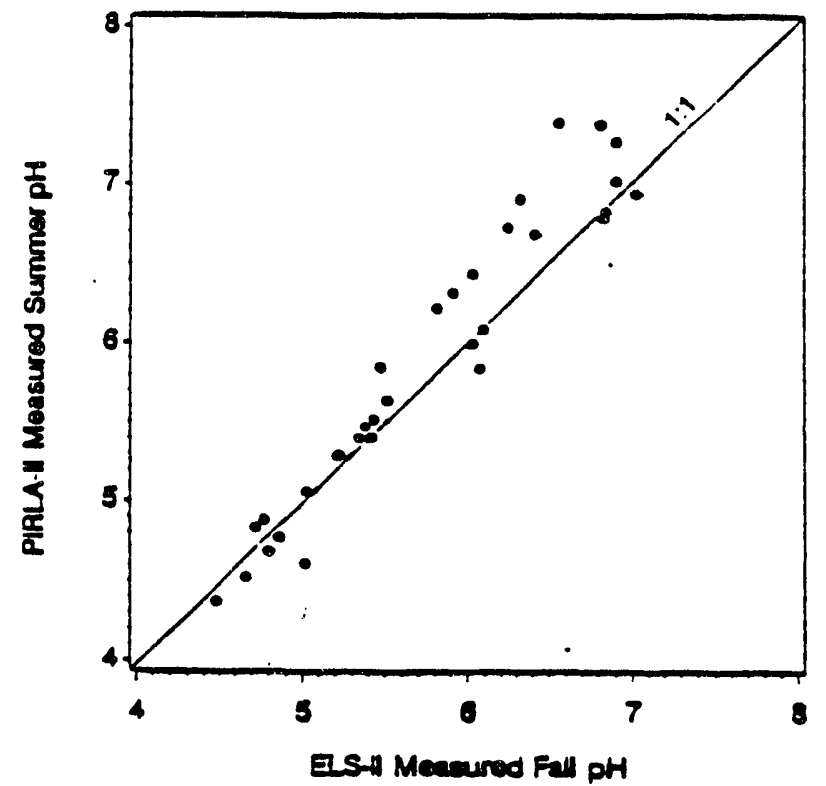

Figure B5. $\quad$ Comparison between air-equilibrated pH measured in PIRLA-II (average of summer samples) and non-equilibrated field pH measured in ELS-II (single fall measurement) for the study lakes (Source: Sullivan et al. 1991). 


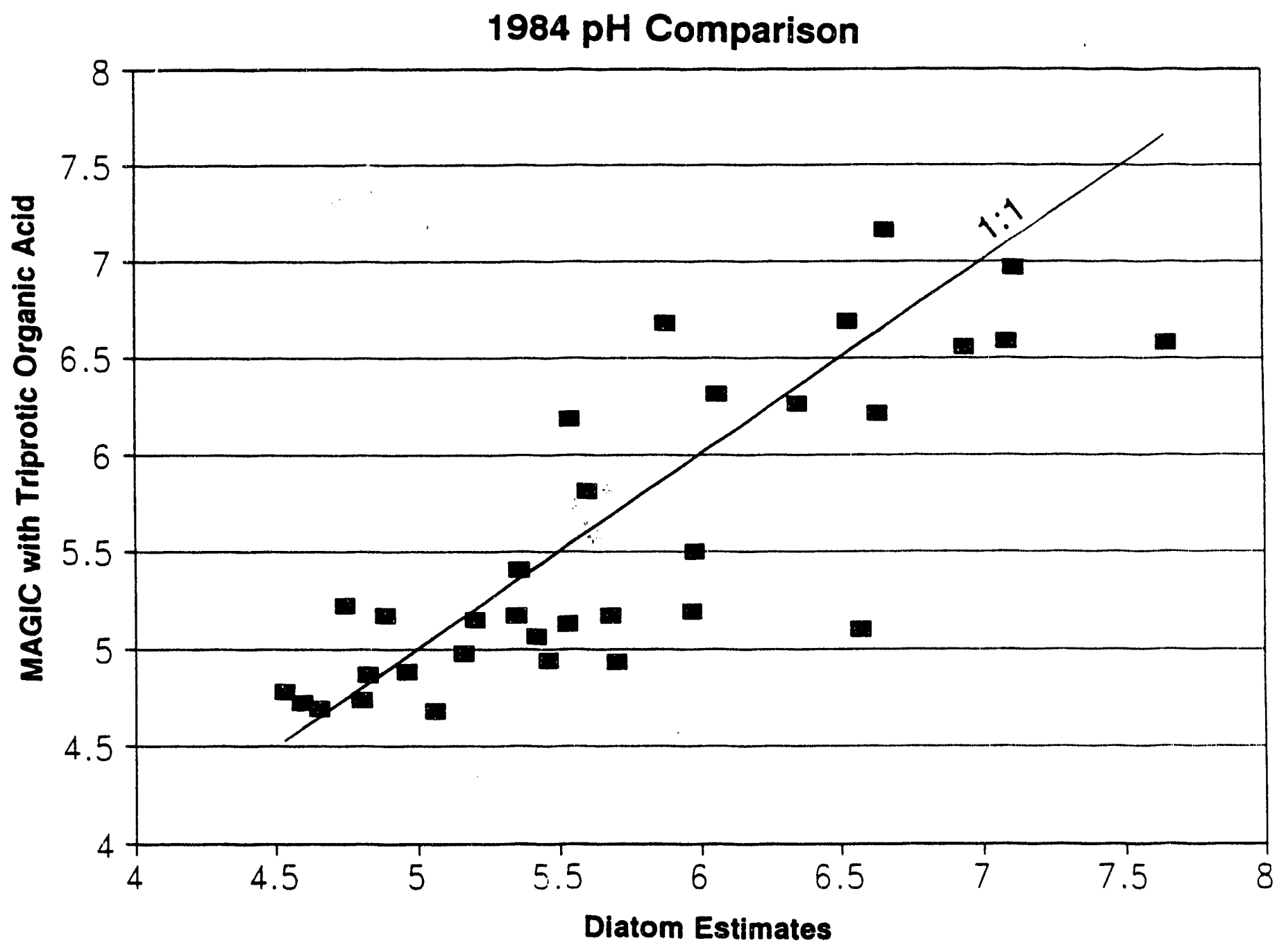

Figure B6. Comparison between diatom-inferred and MAGIC estimates of current $\mathrm{pH}$. MAGIC estimates include the triprotic organic acid analog model. Diatom estimates were "adjusted" by the differences between ELS-I and PIRLA measurements of $\mathrm{pH}$ (see description in text). 
APPENDIX C

RECALIBRATION OF TRIPROTIC ORGANIC ACID SUBMODEL TO THE ADIRONDACK REGION 


\section{APPENDIX C}

\section{RECALIBRATION OF MAGIC AND TRIPROTIC ORGANIC ACID ANALOG MODEL TO CURRENT AND PRE-INDUSTRIAL LAKEWATER CHEMISTRY}

All applications of the organic acid analog models, employed in combination with the MAGIC model and presented in the main body of this report, were based on organic acid parameter values calibrated by Driscoll et al. (in review) to the Adirondack Lakes Survey (Kretser et al. 1989) database. No attempt was made to recalibrate the adjustable parameters in the models (site density and dissociation constant(s)) to the DDRP or ELS-I databases. It is not known to what extent the lakes represented in the ALSC and DDRP databases might differ with respect to acidbase characteristics of dissolved organic solutes. Thus, it is unclear to what extent a recalibration of the various organic acid analog models might improve the agreement between MAGIC and diatom model estimates of current chemistry. In addition, although it has been proposed that lakewater DOC concentrations can decrease in response to strong acid inputs (Almer et al. 1974, Krug and Frink 1983), historic DOC concentrations were assumed equal to current measured values in the model scenarios. Furthermore, acid deposition has increased the flux of metals, especially Al, from watersheds to surface waters. These ionic metals frequently bind to organic acids, thereby decreasing the site density and increasing the apparent pKa's (because pKa's of organo-metal complexes are typically less acidic than the pKa's of the organic ligands themselves). Thus, the influence of possible decreases in DOC concentrations and historic changes in site density and/or apparent pKa's were not considered in the modeling efforts discussed in this report, and could influence the extent of agreement between MAGIC and diatom model estimates of pre-industrial chemistry. To evaluate both of these issues, a model recalibration exercise was conducted using MAGIC and the triprotic organic acid analog.

The recalibration procedure consisted of altering the calibrated organic acid site density value ( $\mathrm{mol}$ sites/mol organic $\mathrm{C}$ ) in an iterative fashion, to yield average differences of zero between modeled and measured current $\mathrm{pH}$. Subsequently, this calibrated site density was 
applied to the pre-industrial chemistry estimates, and DOC was scaled upwards in order to yield average differences of zero between MAGIC and diatom model estimates of pre-industrial pH.

Results of this recalibration are presented in Table $\mathrm{C}-1$ and Figures $\mathrm{C} 1$ and $\mathrm{C2}$. The recalibrated site density that yielded a mean difference of zero between MAGIC/triprotic acid and measured current $\mathrm{pH}$ was 0.0285 , approximately one-half the site density derived by Driscoll et al. (in review) from the ALSC database. Assuming a pre-industrial site density equal to this recalibrated value, historic DOC concentrations would have to have been 2.93 times higher than current measured values in order to achieve completely unbiased agreement between MAGIC/triprotic acid and diatom model estimates of pre-industrial $\mathrm{pH}$ (Table $\mathrm{C} 1$ ). If we assume that the site density derived by Driscoll et al. (in review) from the ALSC database is representative for pre-industrial chemistry, than the DOC scaling factor is only 1.5 (Table C1). In other words, historic DOC would have to have been, on average, 1.5 times higher than current values in order to achieve unbiased agreement between MAGIC and diatom model estimates of pre-industrial $\mathrm{pH}$.

The recalibration exercise did not yield model estimates of either current or pre-industrial pH that were appreciably different than the results obtained in the absence of the recalibration. Thus, the comparisons for current $\mathrm{pH}$ presented in Figures $5 \mathrm{~b}$ and $\mathrm{C}_{1}$ are generally similar, as are the comparisons for pre-industrial pH presented in Figures 4 and $\mathrm{C2}$.

Data with which to quantify changes in DOC concentraticn that would be expected to have occurred in response to acidic deposition in the Adirondacks are generally not available. The limited data that are available on this issue would suggest that a DOC scaling factor of 2.9 (Table C1) is probably too high (e.g., Wright 1989, Kingston and Birks 1990, Hedin et al. 1990, Cumming et al. 1992). An historic change in DOC by a factor of 1.5 , however, (Table C1) may not be unreasonable. Also difficult to quantify is the effect of Al mobilization in response to acidic deposition (Almer et al. 1974) on the site density and apparent pKa's of organic acids. Because Al mobilization, and subsequent alumino-organic binding, has likely decreased site density and increased the apparent pKa's over time, it is reasonable to assume that organic acids were more 


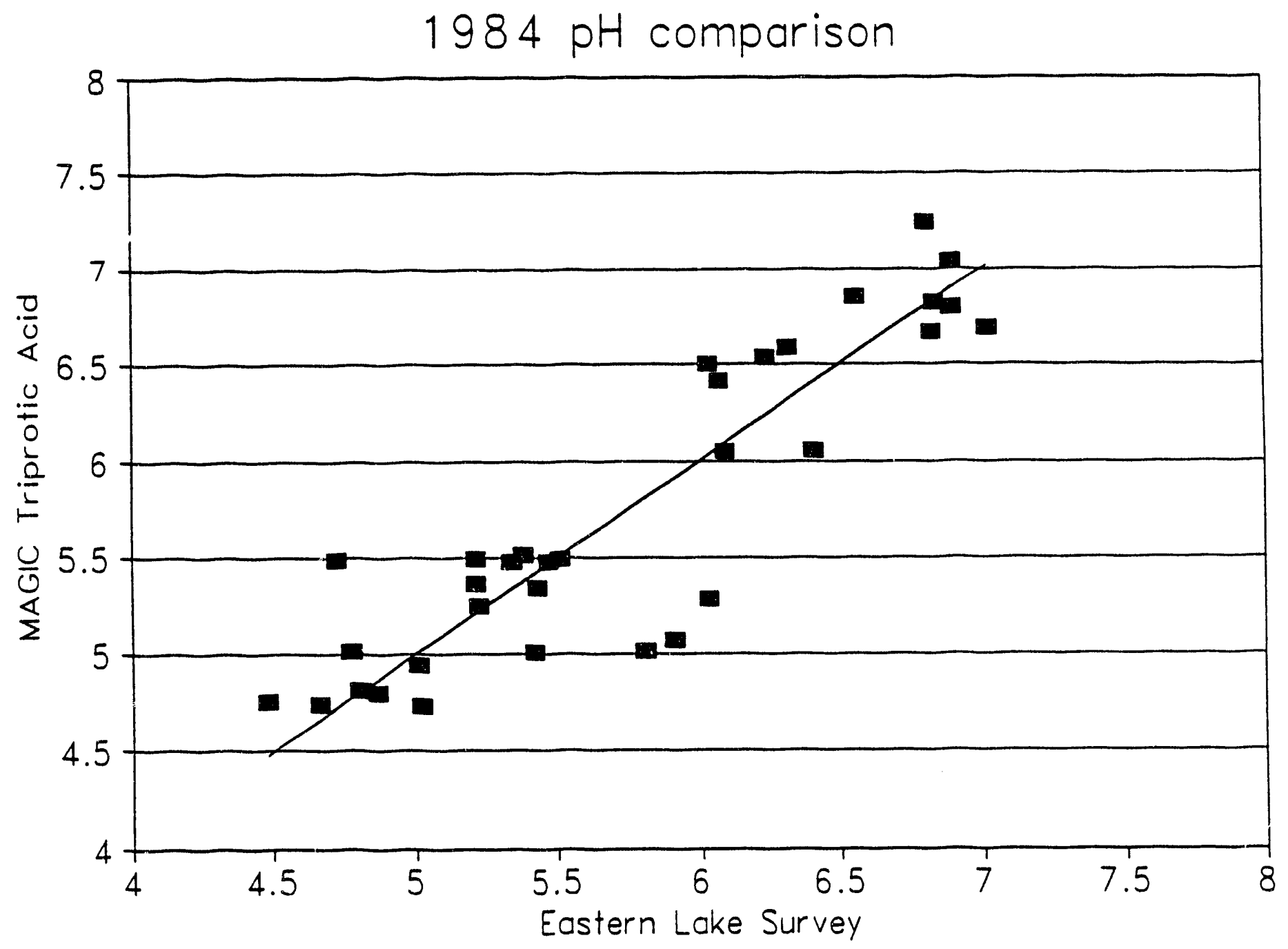

Figure C1. Comparison between the recalibrated MAGIC triprotic acid model estimates of current $\mathrm{pH}$ and measured ELS-I $\mathrm{pH}$. The recalibration procedure involved changing the site density parameter of the model to achieve a mean difference of zero between modeled and measured $\mathrm{pH}$ estimates. 


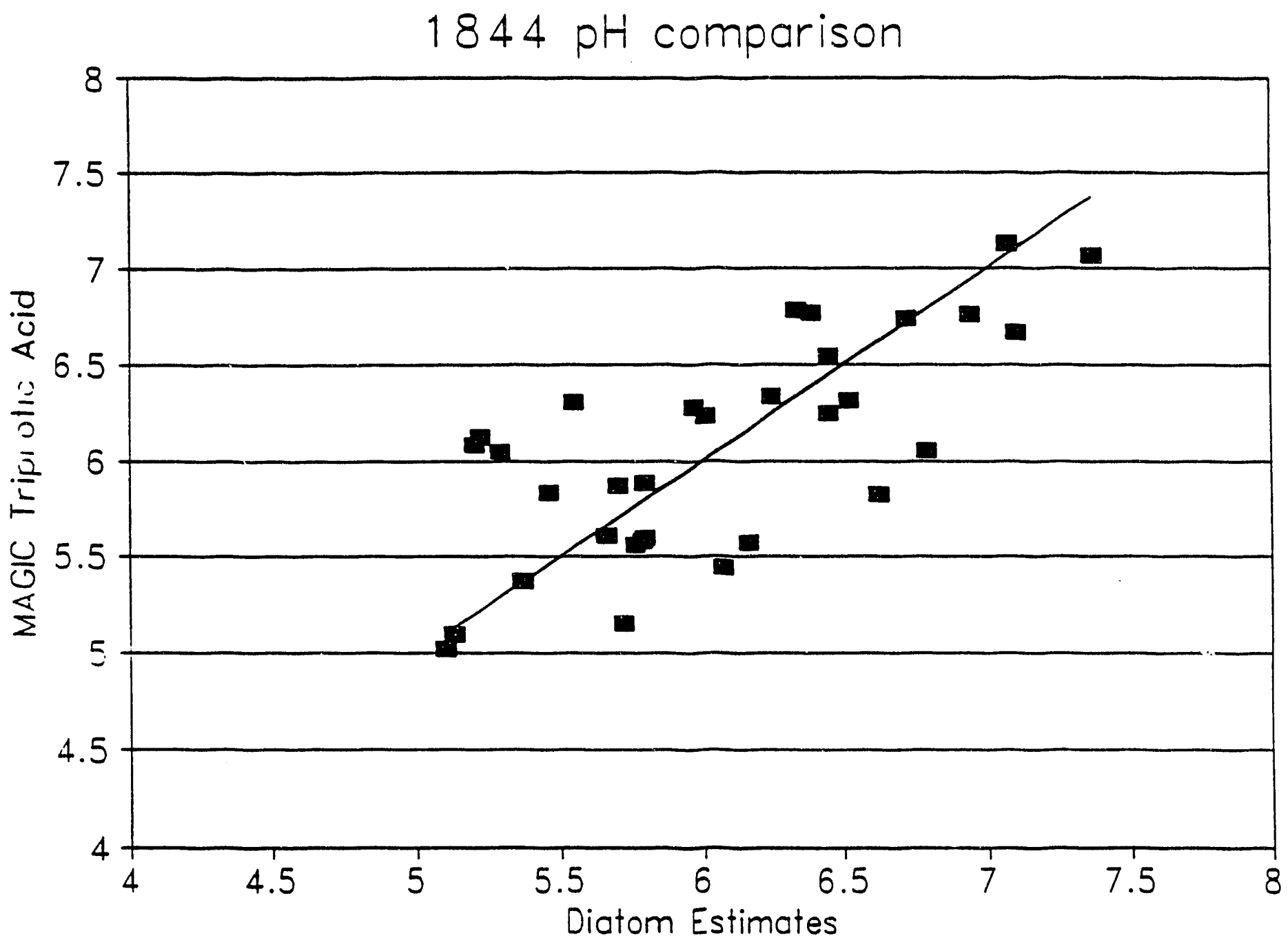

Figure C2. Comparison between the recalibrated MAGIC triprotic acid model estimates of preindustrial $\mathrm{pH}$ and diatom model estimates of pre-industrial $\mathrm{pH}$. The recalibration procedure utilized the calibrated site density estimate used in Figure $\mathrm{C} 1$ and involved scaling pre-industrial DOC upwards to achieve a mean difference of zero between MAGIC triprotic acid and diatom estimates of pre-industrial $\mathrm{pH}$. 
Table C1. Comparison between MAGIC with the triprotic acid analog representation calibrated to the ALSC data (Driscoll et al. in review) and the res:alibrated model.

\begin{tabular}{lll}
\hline \hline Parameter & $\begin{array}{l}\text { Parameter } \\
\text { Estimate }\end{array}$ & Basis for Estimation \\
\hline Site Density & 0.055 & $\begin{array}{l}\text { Calibrated to ALSC } \\
\text { Recalibrated to achieve mean difference between } \\
\text { measured and modeled current pH equal to zero }\end{array}$ \\
DOC scaling factor & 1.0285 & $\begin{array}{l}\text { Based on current measured DOC, and applied to } \\
\text { current chemistry }\end{array}$ \\
& 2.93 & $\begin{array}{l}\text { Recalibrated to achieve mean difference between } \\
\text { MAGIC and diatom modeled pre-industrial pH equal to } \\
\text { zero, assuming recalibrated site density (0.0285). } \\
\text { Recalibrated to achieve mean difference between } \\
\text { MAGIC and diatom modeled pre-industrial pH equal to } \\
\text { zero, assuming ALSC-calibrated site density (0.055). }\end{array}$ \\
\hline \hline
\end{tabular}

effective in acidifying surface waters in the pristine past than they are today. Data are not available with which to evaluate the utility of this recalibration effort and hypothesis of historic change in DOC. Nevertheless, this analysis suggests that possible changes in DOC in response to acidic deposition might explain at least a portion of the discrepancies that remain between MAGIC and diatom estimates of lakewater chemistry. 

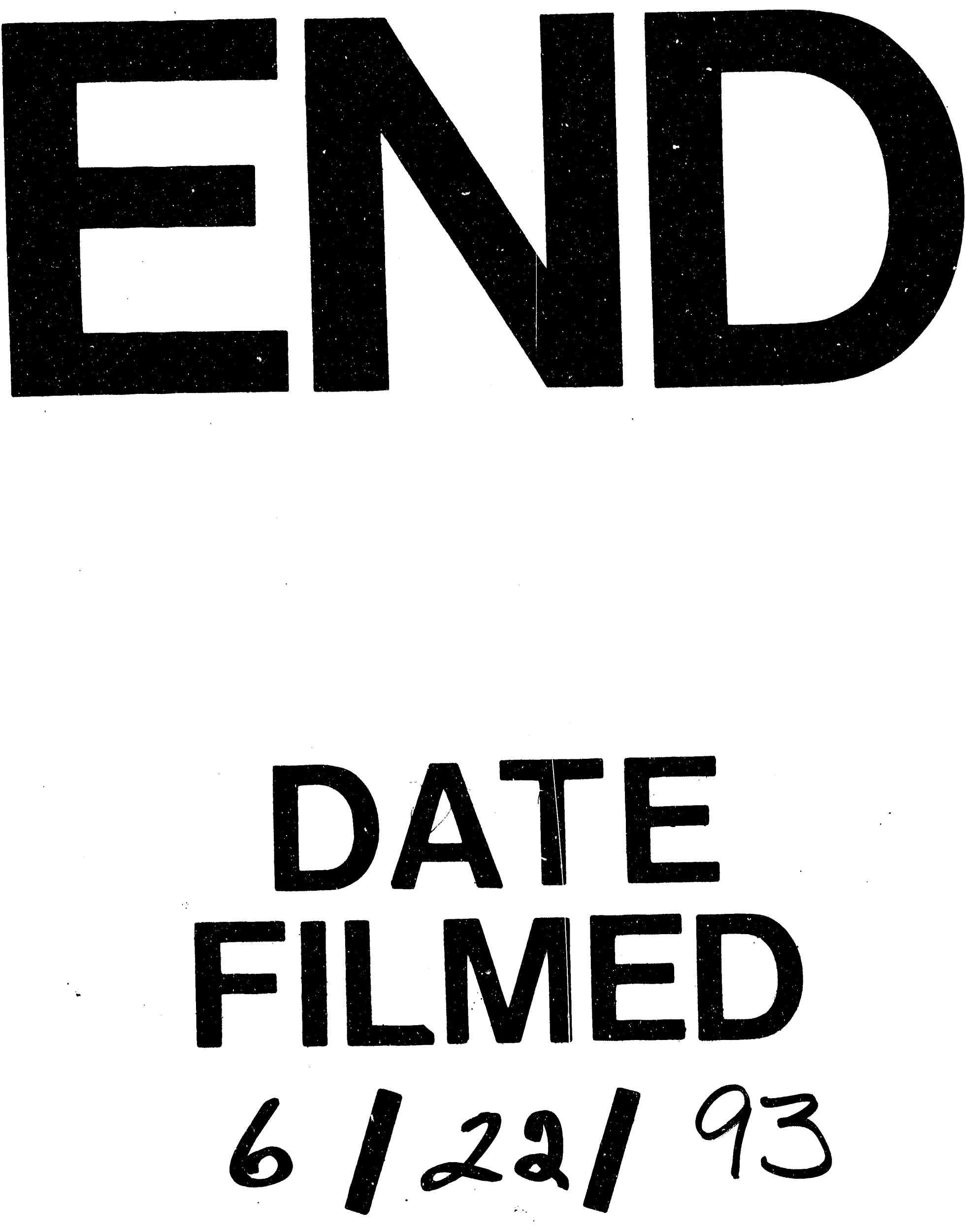

1 